\title{
Monograph
}

urn:1sid:zoobank.org:pub:CA243C98-9461-441A-BBD9-ECBDEC103DD9

\section{A revision of the spider genus Zaitunia (Araneae, Filistatidae)}

\author{
Sergei ZONSTEIN ${ }^{1, *}$ \& Yuri M. MARUSIK ${ }^{2,3,4}$ \\ ${ }^{1}$ Department of Zoology, Steinhardt Museum of Natural History, Tel-Aviv University, \\ 69978 Tel-Aviv, Israel. \\ ${ }^{2}$ Institute for Biological Problems of the North RAS, \\ Portovaya Str. 18, Magadan, Russia. \\ ${ }^{3}$ Department of Zoology \& Entomology, University of the Free State, \\ Bloemfontein 9300, South Africa. \\ ${ }^{4}$ Far Eastern Federal University, Sukhanova, 8, Vladivostok 690950 Russia. \\ *Corresponding author: znn@post.tau.ac.il \\ 2 Email: yurmar@mail.ru \\ ${ }^{1}$ urn:Isid:zoobank.org:author:EADD3607-30FF-49AE-93F5-8410630469BE \\ 2 urn:lsid:zoobank.org:author:616D41E3-0876-4B2B-A788-A970B43E840D
}

\section{Table of contents}

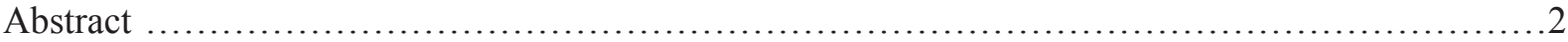

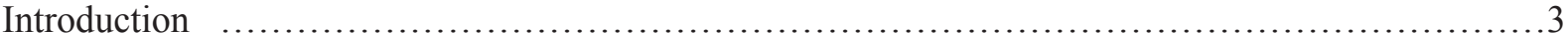

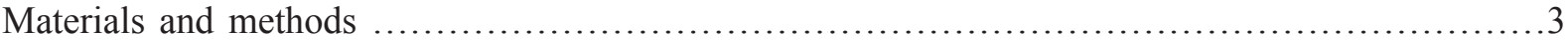

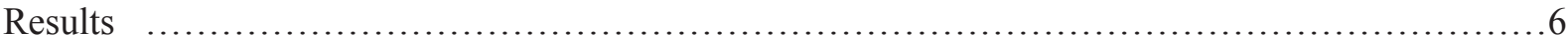

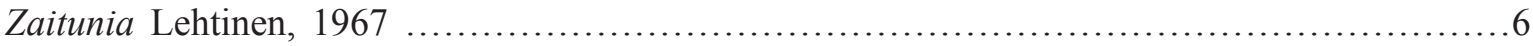

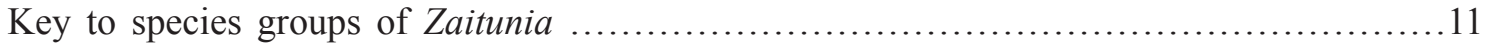

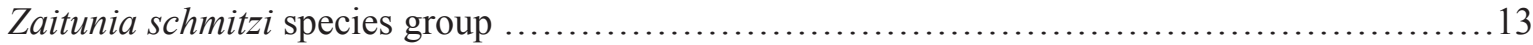

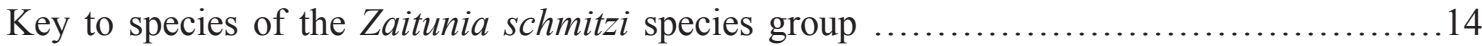

Zaitunia halepensis sp. nov. .................................................... 14

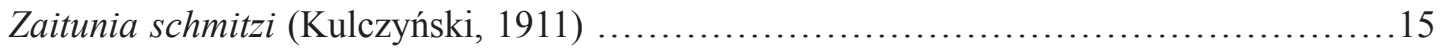

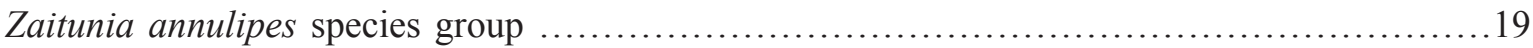

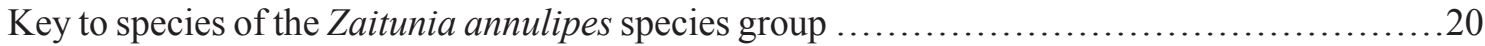

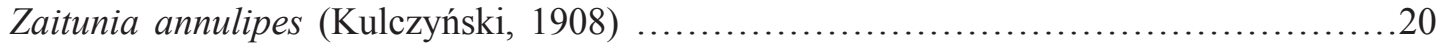

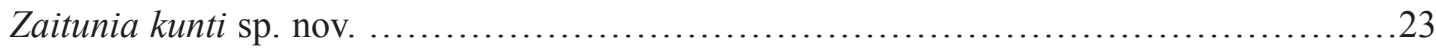

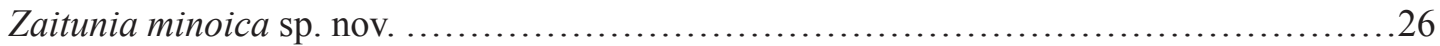

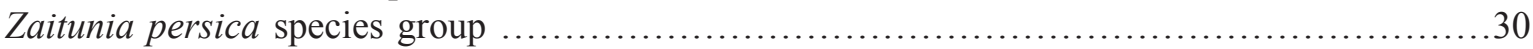

Key to species of the Zaitunia persica species group ..................................... 30

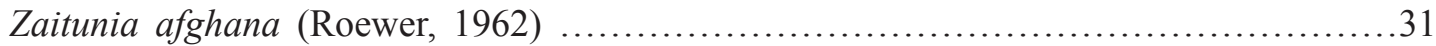

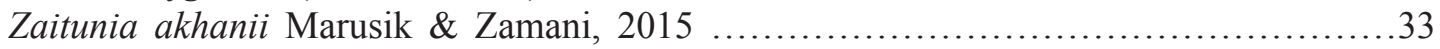

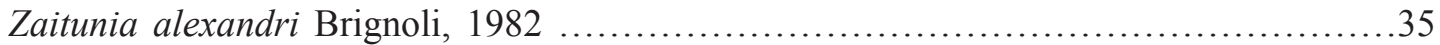

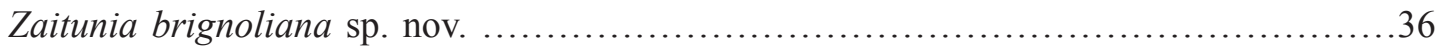

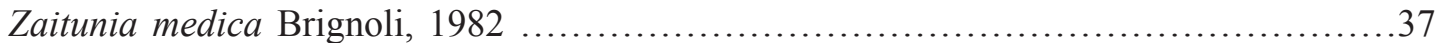

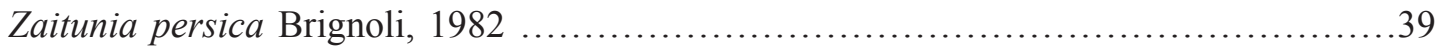




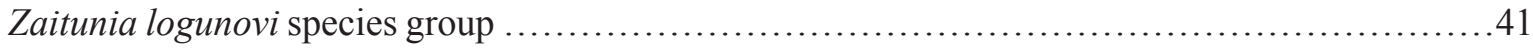

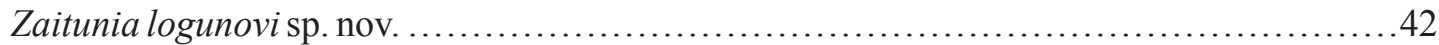

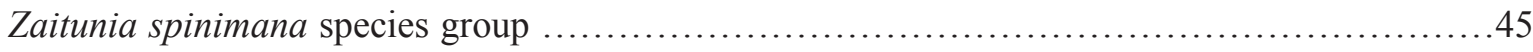

Key to species of the Zaitunia spinimana species group ................................. 46

Zaitunia inderensis Ponomarev, 2005 ............................................. 46

Zaitunia martynovae (Andreeva \& Tyshchenko, 1969) ...............................48

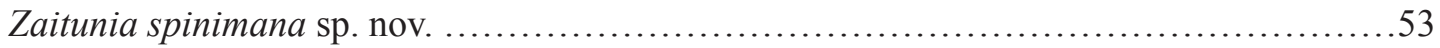

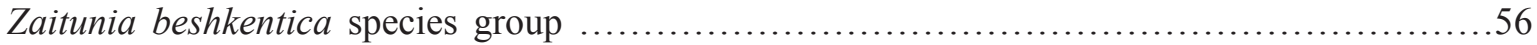

Key to species of the Zaitunia beshkentica species group ................................. 56

Zaitunia beshkentica (Andreeva \& Tyshchenko, 1969) ...............................56

Zaitunia huberi sp. nov. .........................................................6 60

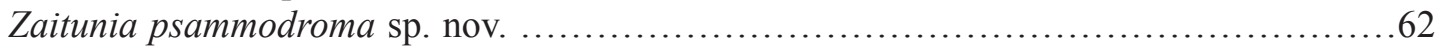

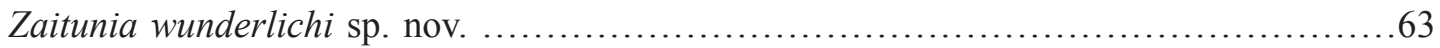

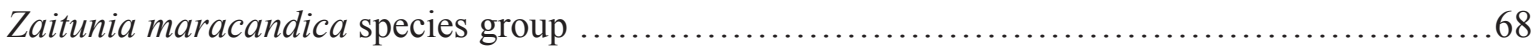

Key to species of the Zaitunia maracandica species group ...............................66

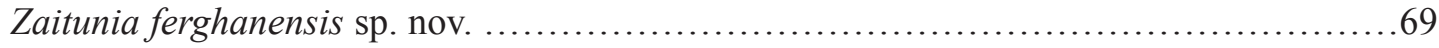

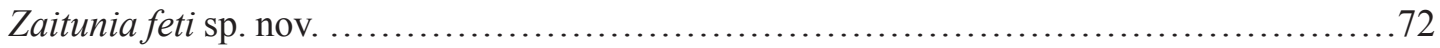

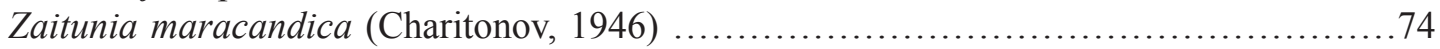

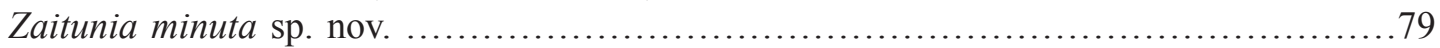

Zaitunia zonsteini Fomichev \& Marusik, 2013 ..................................... 80

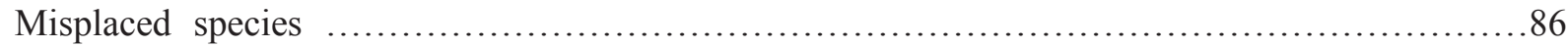

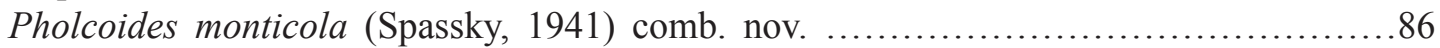

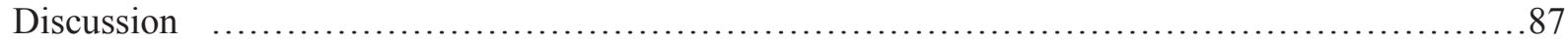

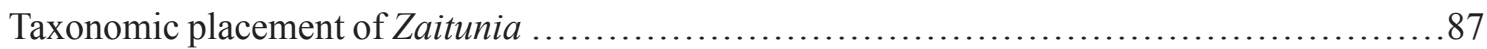

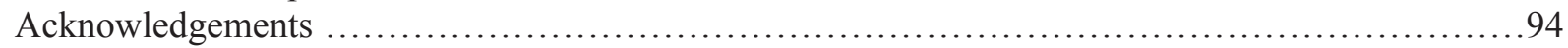

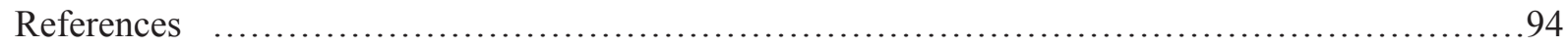

Abstract. The spider genus Zaitunia Lehtinen, 1967 (Araneae, Filistatidae) is revised. It was found to include 24 species distributed in the Eastern Mediterranean, Middle East and Central Asia: q Z. afghana (Roewer, 1962) (Afghanistan),, Z. alexandri Brignoli, 1982 (Iran),, Z. akhanii Marusik

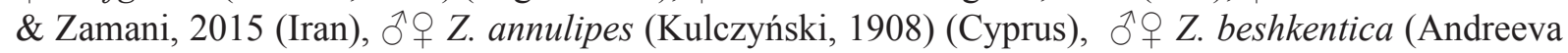
$\&$ Tyshchenko, 1969) (Tajikistan, Uzbekistan), $\bigcirc$ Z. brignoliana sp. nov. (Iran), ふึ? Z. ferghanensis sp. nov. (Kyrgyzstan, Uzbekistan), Z. feti sp. nov. (Turkmenistan), Z. halepensis sp. nov. (Syria),

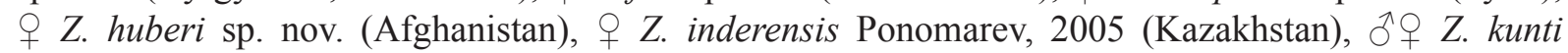

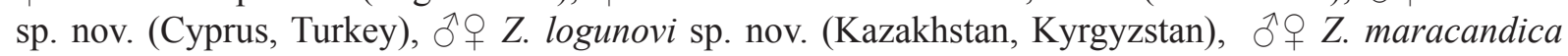
(Charitonov, 1946) (Uzbekistan, Kazakhstan), đิo Z. martynovae (Andreeva \& Tyshchenko, 1969)

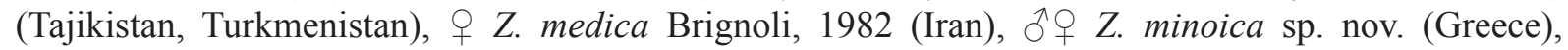
Z. minuta sp. nov. (Uzbekistan), ㅇ Z. persica Brignoli, 1982 (Iran), ठิ Z. psammodroma sp. nov.

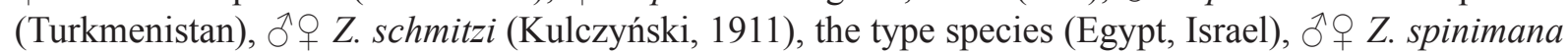
sp. nov. (Kazakhstan, Turkmenistan), $\hat{\jmath} \uparrow$ Z. wunderlichi sp. nov. (Kyrgyzstan) and $\uparrow$ Z. zonsteini Fomichev \& Marusik, 1969 (Kazakhstan). Twelve above-listed species are newly described, and males of $Z$. annulipes, Z. beshkentica, Z. maracandica and Z. martynovae are described for the first time. Two new combinations are established: Z. annulipes (Kulczyński, 1908) comb. nov., ex Filistata, and Pholcoides monticola (Spassky, 1941) comb. nov., ex Zaitunia. New data on distribution of the considered taxa are provided.

Keywords. Araneae, spiders, Filistatidae, Southwest and Central Asia, new species.

Zonstein S. \& Marusik Y.M. 2016. A revision of the spider genus Zaitunia (Araneae, Filistatidae). European Journal of Taxonomy 214: 1-97. http://dx.doi.org/10.5852/ejt.2016.214 


\section{Introduction}

The spider family Filistatidae is a group of cribellate spiders possessing a peculiar combination of both primitive and specialized characters. This is not a species-rich family: by 2015, Filistatidae included 18 genera and only 123 species (World Spider Catalog 2015). Nevertheless, the family has a worldwide distribution, occurring in tropical, subtropical, and warm-temperate areas (Gray 1995; Ramírez \& Grismado 1997). In the Palearctic region, it is mostly confined to the southern part: the Mediterranean, Middle East, Central Asia, and southern China and Japan (Helsdingen 2015; Platnick 2014; WSC 2015).

Until the revision of the cribellate spiders by Lehtinen (1967), all Palearctic filistatids were placed in the type genus Filistata Latreille, 1810 (for the complete list of synonymies, see Platnick 2014). Lehtinen (1967) described several new filistatid genera, including two from the West Palearctic: the widespread Pritha Lehtinen, 1967 and the monotypic Zaitunia Lehtinen, 1967. The genus Pritha was considered to include, among others, some species described by Simon (1868), Kulczyński in Chyzer \& Kulczyński (1897), Strand (1914) and partially by Roewer (1962), whereas the monotypic Zaitunia included only Filistata schmitzi Kulczyński, 1911.

Zaitunia was treated as a monotypic genus until Brignoli (1982) described three new species from Iran; however, the genus diagnosis was not modified. Zonstein (1990) transferred four species described by Spassky (1941), Charitonov (1946) and Andreeva \& Tyshchenko (1969) from Filistata to Zaitunia. Ponomarev (2005), Fomichev \& Marusik (2013) and Marusik \& Zamani (2015) described three more species in Zaitunia, and Zonstein et al. (2013) transferred to this genus one species previously described by Roewer (1962) as a member of Filistata. Thus, the genus currently is thought to have 12 species (World Spider Catalog 2015). However, only the type species is known from both sexes, whereas all other congeneric species are known exclusively from females or juveniles, and only from their original descriptions. Additionally, the genus has never been revised, making its limits with Filistata unclear. Hence, clarifying this problem is one of the objectives of the present study.

Zonstein (2009b) noted that a male of Z. schmitzi (Kulczyński, 1911) differed in many details from males of Central Asian species, and suggested that the latter ones do not belong to Zaitunia but should be placed in a distinct genus. However, in the course of the present study, we recognised an intermediate state of several characters in males from Crete, Cyprus, and Turkey. Thus, all these groups are considered here as belonging to the same genus.

In this study, we examine all available material of this genus (340 specimens), revealing a total of 24 species of Zaitunia, 12 of which are described as new.

In view of the newly obtained data, Zaitunia, with 24 species, becomes the most species-rich genus of the family, vs 21 in Pritha and 19 in Filistata (WSC 2015). The goal of this work is to revise, delimit and re-diagnose Zaitunia, and to study its taxonomy, distribution, and relationships.

\section{Material and methods}

\section{Depositories}

AMNH $=$ American Museum of Natural History, New York, USA
HUJ $=$ Hebrew University, Jerusalem, Israel
IBPS $=$ Institute for Biological Problems of the North, Magadan, Russia
ISEA $=$ Institute for Systematics and Ecology of Animals, Novosibirsk, Russia
IZW $=$ Institute of Zoology, Warsaw, Poland
NMG $=$ Naturhistoriska Museet, Göteborg, Sweden
MNHN $=$ Muséum national d'Histoire naturelle, Paris, France




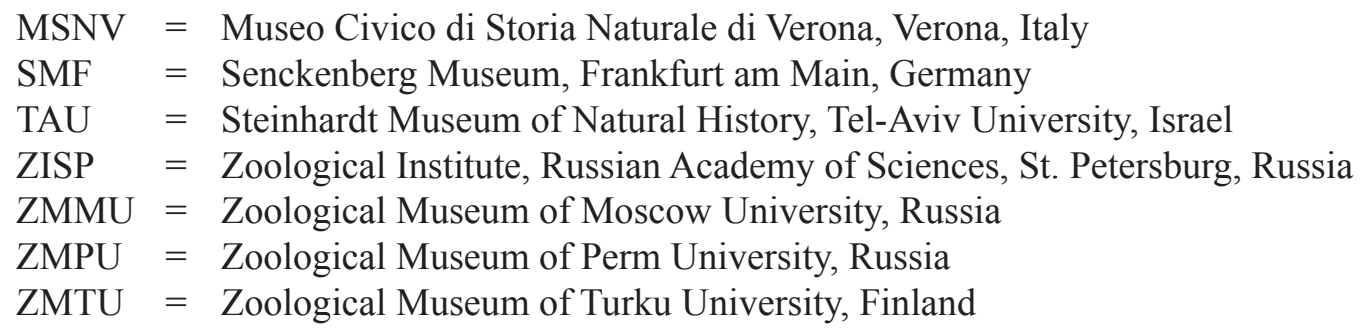

\section{Comparative material examined}

Filistata canariensis Schmidt, 1976: holotype, $q$, from Fuerteventura Isl. (Canary Islands), Spain (SMF 28841).

Filistata gomerensis Wunderlich, 1992: holotype, ð̊ (SMF 37181) and paratype, ๆ (SMF 602199), from La Gomera Isl. (Canary Islands), Spain.

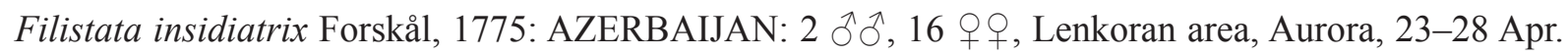
2001, Y.M. Marusik (ZMMU). ISRAEL: 8 $\widehat{\jmath}$, Haifa, Mt Carmel, university campus, 29 Dec. 2010, Y.M. Marusik (ZMMU); 2 $\widehat{\partial}$, Mt Gilboa, 30 Jan. 2011, L. Friedman \& C. Drees (TAU); 8 우, Lake Kinneret, Digit, 14 Sept. 2009, S. Zonstein (TAU); 1 đ, 1 क , Judean Hills, Adullam, 1-30 Apr.

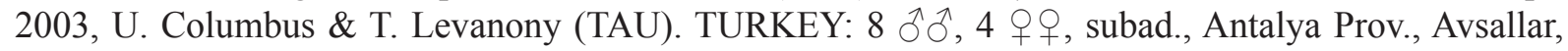
6 Jan. 2013, Y.M. Marusik (ZMMU).

Filistata nigra Simon, 1882 = Sahastata nigra: syntypes, 28 +

Filistata pseudogomerensis Wunderlich, 1992: holotype, $\widehat{\jmath}$ (SMF 37180) and 2 q , , paratypes (SMF 60049, 60277), from Tenerife Isl. (Canary Islands), Spain.

Filistata teideensis Wunderlich, 1992: 1 ð̊, paratype, Tenerife Isl. (Canary Islands), Spain (SMF 60226).

Kukulcania hibernalis (Hentz, 1842): USA: 1 đ̊, 6 ㅇ, Florida, Ocala Hot Springs, 2 Aug. 1994, Yu. M. Marusik (IBPN).

Microfilistata ovchinnikovi Zonstein, 2009: holotype, $\widehat{\jmath}$ and 3 paratypes, + + , Kyzyl-Dzhar, Badhyz Nature Reserve, Turkmenistan (TAU).

Sahastata sinuspersica Marusik, Zamani \& Mirshamsi, 2014: holotype,, , Bandar-e’Abbās, Iran (SMF).

\section{Photographs}

Photographs were taken using a Zeiss Discovery V20 stereo microscope with a Canon PowerShot G9 camera and an Olympus SZX16 stereo microscope with an Olympus E-520 camera, and prepared using the CombineZP software. Scanning electron micrographs were made using the SEM JEOL JSM5200 scanning microscope at the Zoological Museum, University of Turku, Finland. Illustrations of the endogyne, abdomen and spinnerets were made after maceration in a $20 \%$ potassium hydroxide aqueous solution and exposure for a few minutes in an alcohol/water solution of Chlorazol Black. It is worth noting that the receptacles in all Zaitunia species are very small and weakly sclerotized and therefore can easily be overlooked. Differential staining with Chlorazol Black is essential both for observing and photographing receptacles. In most cases, to make photographs of the endogyne and sometimes the palps more clear and to show more details, we placed a dark background in the case of transmission microscopy, or pieces of black plastic (or black paper), or minutia pins near specimens to be photographed. 
Photographs of the somatic characters and some of the palps were taken in dishes with paraffin on the bottom to hold the specimens in the right position. Endogynes were photographed on slides either under an Olympus SZX16 or an Olympus BH-2. Small pieces of cotton were used to fix the specimens in the correct position. Background maps were taken from the website http://www.maps-for-free.com.

\section{Measurements}

Measurements were made to an accuracy of $0.01 \mathrm{~mm}$. Lengths of leg and palp segments were measured on the dorsal side, from the midpoint of the anterior margin to the midpoint of the posterior margin. All measurements are given in millimetres.

\section{Spination}

Since leg spination in most species appears to be almost invariable and thus has no significant taxonomic value, a generalised survey is provided in the description of the genus and particular variants are given only when they noticeably differ from the prevalent case.

\section{Abbreviations}

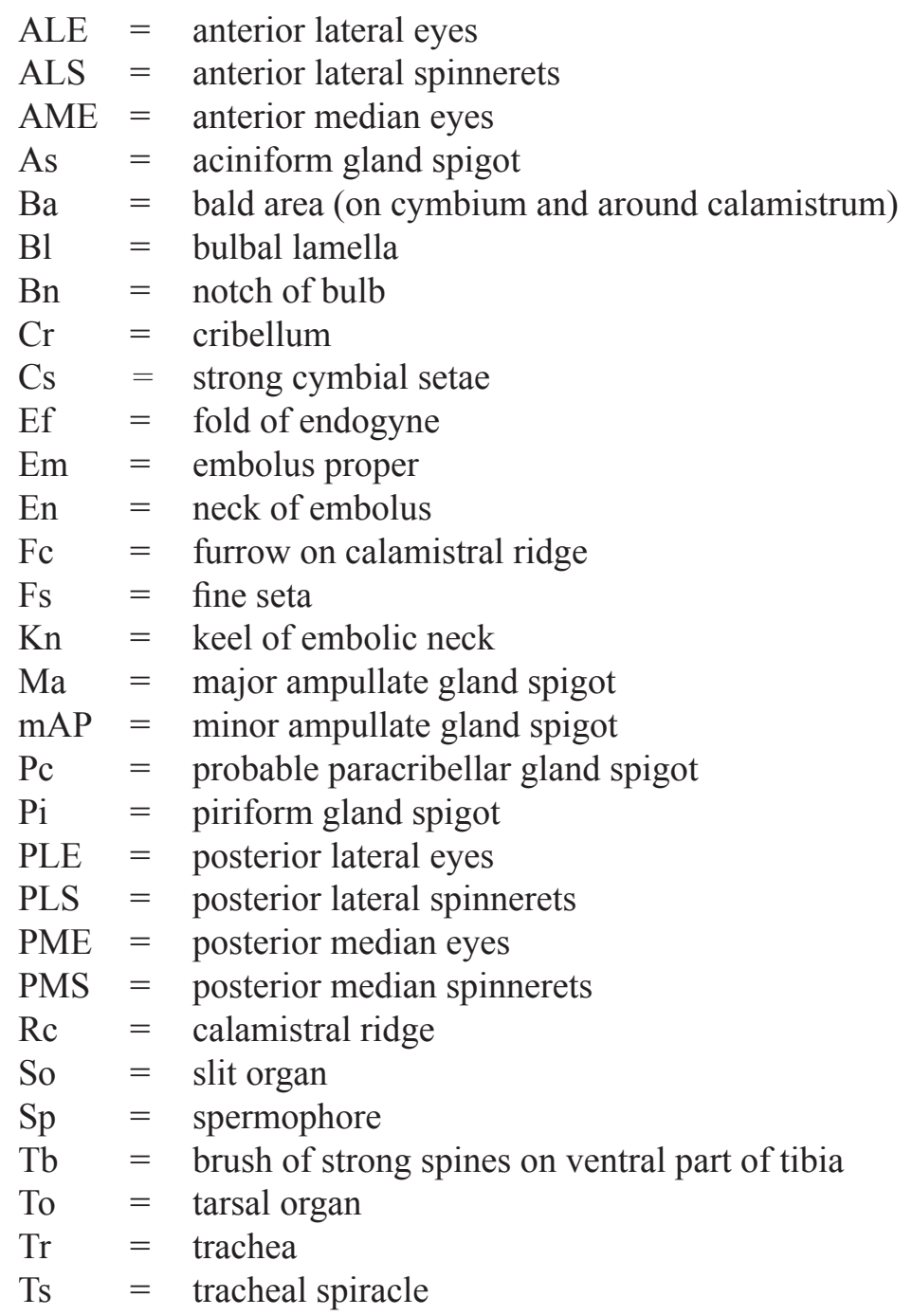




\section{Results}

Class Arachnida Cuvier, 1812

Order Araneae Clerck, 1757

Family Filistatidae Ausserer, 1867

Genus Zaitunia Lehtinen, 1967

Zaitunia Lehtinen, 1967: 275.

Zaitunia - Zonstein 2009b: 126. — Fomichev \& Marusik 2013: 85. — Zonstein et al. 2013: 69. Marusik \& Zamani 2015: 129.

\section{Type species}

Filistata schmitzi Kulczyński, 1911, by monotypy.

\section{Diagnosis}

Zaitunia differs from other filistatine genera by a distinctly domed carapace lacking thoracic fovea, with a broadly rounded subvertical clypeus and by a shortened labium that is wider than long (in Filistata and Kukulcania Lehtinen, 1967 the clypeus is subhorizontal with a lateral constriction, without thickened setae, and the labium is distinctly longer than wide). It differs from Sahastata Benoit, 1968 by a uniseriate calamistrum (consisting in the latter genus of three setae rows) and from Microfilistata Zonstein, 1990 by spinose tarsi in females and pseudosegmented tarsi in males (vs aspinose and integral, respectively). Zaitunia can be recognized due to a gap-setose calamistrum (as shown in Figs 2C-E), a short and wide male palpal tibia (which is longer and more slender in other members of the subfamily; only in Zaitunia is it noticeably wider than the palpal femur) and a characteristic dense comb on the clypeus, composed of stout reclined bristles and much more developed (especially in males) than in other genera of the Filistatinae.

\section{Description}

Size. Small to medium-sized filistatid spiders with body length $2.5-8.0 \mathrm{~mm}$.

COLOUR AND PATTERN. Colour varying from pale yellowish-white to dark brown; carapace with more or less darkened eye tubercle, lateral margins, and foveal area. Pattern of carapace lacking in pale specimens. Legs unicolor or with dark, broad annulations. Abdomen with or without dorsal pattern composed by longitudinal median dark stripe or band and in some species with transverse stripes. Venter of abdomen in most species without pattern, book lungs usually paler than other parts, genital area and area in front of spinnerets darkened in some species.

Prosoma. Carapace distinctly domed, broad oval, widely rounded anteriorly, covered with sparse thick bristles (Figs 1A-B, 42). Some bristles, usually one pair very strong and long (about $1 / 2$ of carapace width). Thoracic fovea opened posteriorly and appears as shallow pit or indistinct. Cephalic area flattened, usually with median row of strong proclined bristles. Clypeus relatively short and subvertical, with \pm developed comb of stout reclined bristles (Fig. 1C). Eye tubercle low. ALE $>$ PLE $\approx$ PME $>$ AME. Median ocular quadrangle wide trapezoidal. Chelicerae small, subvertical; cheliceral furrow and fang very short; cheliceral lamina well-developed. Sternum subcircular, sigillae indistinct. Labium slightly wider than long. Maxilla trapezoidal, with lateral corner about $90^{\circ}$. Palps in females short and thick, with short dentate claw (Fig. 1E).

LEGS. Leg formula 1423 (most species) or 4123. Leg spination very uniform in all species, but as a rule, males have more spines than conspecific females; additionally, these spines in males are usually longer. 

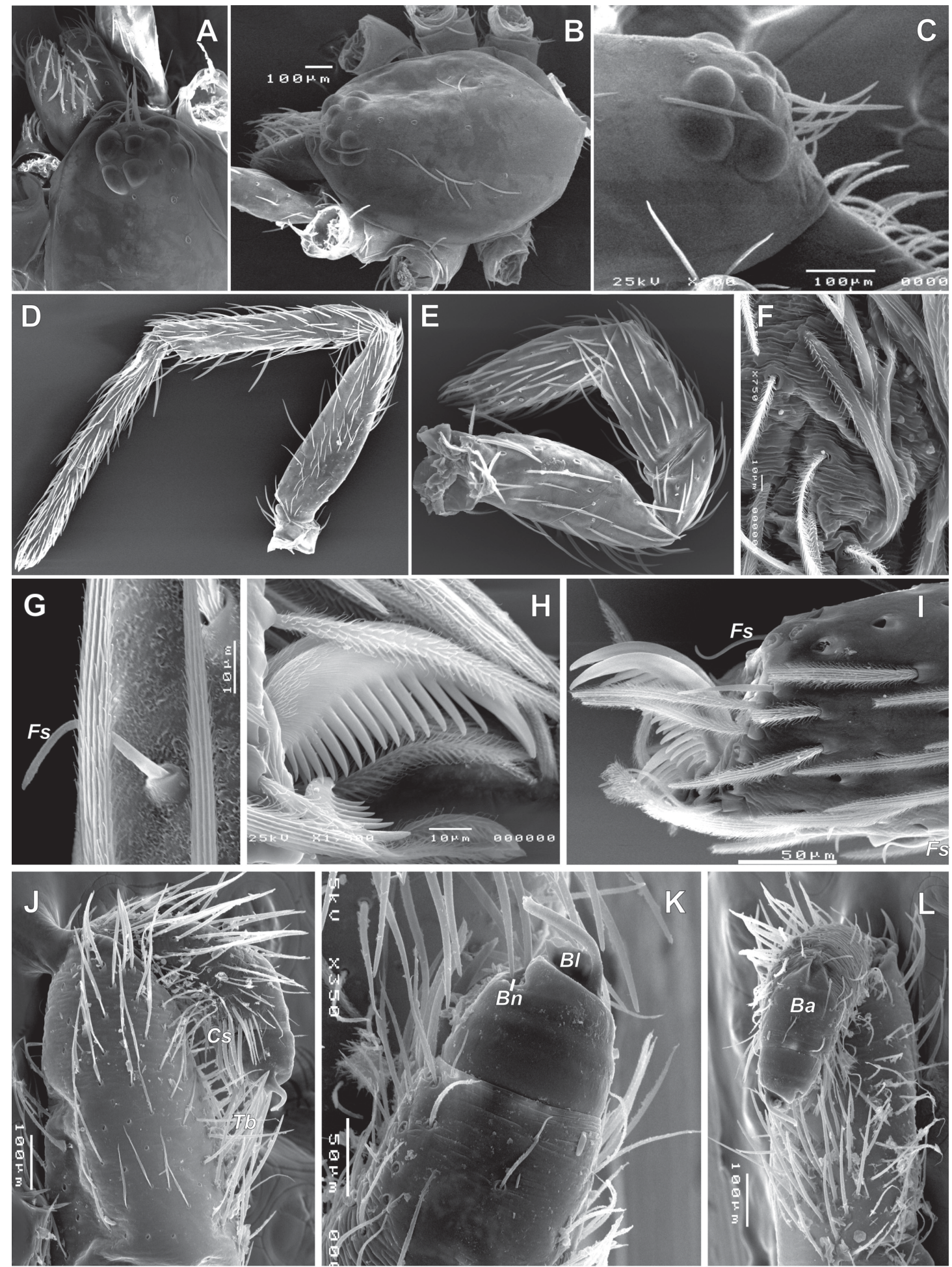

Fig. 1. Morphology of Zaitunia. A-C. Z. martynovae (Andreeva \& Tyshchenko, 1969), subadult $q$

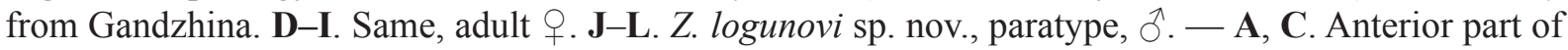
prosoma, dorsal and lateral. B. Prosoma, dorsal. D. Leg IV, prolateral. E. Palp, prolateral. F. Cuticle and setae covering venter of abdomen. G. Leg surface showing large and fine (possibly chemosensory) setae. H-I. Tarsal claws of leg IV, prolateral. J-L. Terminal part of palp, prolateral, dorsal and ventroretrolateral. Abbreviations: see Material and methods. 
All femora with one basodorsal spine and 1-2 smaller spines in pro- and retrodistal position. Patellae unarmed. Tibiae with 2-6 ventral spines (can be absent on tibiae I-II in females). Metatarsi usually long and slender, with 6-9 ventral spines, but in males of Z. psammodroma sp. nov. metatarsi shortened, dilated and covered with numerous ventrodistal spines. Tibiae and metatarsi with few (1-3) inclined trichobothria, which are 1.2-2 times shorter than diameter of the segment. Trichobotrial bases low and inclined, smooth outside and densely rifled inside (Fig. 2H-I). Tarsi ventrally with few small spines, and with short and dense bristles. Male tarsi curved and pseudosegmented. Tarsal organ with wide inclined opening (Fig. 2F-G, J). Calamistrum short, present in females only, formed by one composite row of a few thick, curved and flattened setae on a raised keel (crest); median part of calamistrum without setae (Fig. 2A-E). Paired tarsal claw narrow and slightly curved, with row of 8-15 long, dense teeth (Fig. 1H). Unpaired claw curved, with 5-8 dense teeth (Fig. 1I).

AвDOMEN. Abdomen elongate oval, overhangs posterior part of carapace. Spinnerets shifted anteriorly. Spinneret group set relatively far from posterior edge of abdomen. Cribellum small, bipartite trapezoidal, present in both sexes (Figs 3A, D, 4D) but reduced in size and lacking functional spigots in males. ALS and PLS subequal in size (Figs 3A, C, 4C); PMS much smaller, with two probably paracribellar spigots (Fig. 4F, I). Tracheal spiracle wide and located in posterior $1 / 3$ of abdomen between epigastral furrow and spinnerets (Fig. 3A-C). Tracheae thin and short (about as long as spiracle width). Two pairs of tracheal stems: median branches longer and inclined sideward, lateral branches much shorter (Figs 3B, 33E-F). As in the prosoma and legs, abdomen covered with ciliate hairs only, plumose hairs absent.

MALE PALP. Relatively short compared to other filistatines, although 1.3-1.8 longer than carapace. The shortest palp in comparison to the carapace is in the type species (palp/carapace length $=1.3$ ). Femur unmodified, cylindrical; equal in length to or longer than tibia. Patella unmodified, short, about one third of femur length. Tibia long and swollen, 1.5-2 times thicker than femur; ventromedially with patch of dense, suberect setae.

Cymbium. Conical at base, and the rest is cylindrical. Only Z. logunovi sp. nov. has a conical dorsal outgrowth in the terminal one-third (Fig. 1K-L). Tip of cymbium without dorsoapical excavation, its margin varies from strongly slanting (some specimens of $Z$. schmitzi, Fig. 7A-D) to almost straight (perpendicular to axis of cymbium). Dorsum of cymbium with brush of dense, long suberect hairs; some hairs as long as cymbium. One species, Z. logunovi sp. nov., with set of thick hairs along ventral and lateral edges of cymbium (Fig. 1J). Terminal part of dorsum hairless, semitransparent.

BulB. Ranges from conical (most of the species) to globular (Z. logunovi sp. nov., Z. minoica sp. nov.) and subcylindrical (Z. schmitzi (Kulczyński, 1911)), basal part embedded in cymbium. Length of bulb + embolic part varies from long (longer than cymbium) to short (shorter than cymbium). Spermophore forms 3-4 coils, coils not spaced; spermophore ranges from very thick and occupying the whole bulb (Z. schmitzi) to moderately thin.

EmBolus (embolic part of the bulb). Without distinct separation from the tegulum. We recognize the neck of the embolus ( $N e=$ part of embolic base wider than spermophore) and the embolus "proper" (Em $=$ diameter equal to diameter of spermophore). Embolus can be distinguished from the neck by its dark colour, much darker then rest of the bulb. Embolic part of bulb variable in size and shape, from very short, lacking neck (Z. logunovi sp. nov., Z. schmitzi) to long, longer than bulb and as long as cymbium (Z. minoica sp. nov.). Embolic part from straight to screw-shaped (Z. logunovi sp. nov., Z. schmitzi). Embolic neck in most species with distinct ventral keel or without (Z. minoica sp. nov.). Shape of keel in some cases is species-specific. Tip of embolic part bent ventrally or screw-shaped.

Endogyne (vUlva). Adult females can be hardly recognized. Compared to subadult females, they have a slightly swollen edge of the genital area. Receptacles are enveloped in a trapezoidal or semicircular 

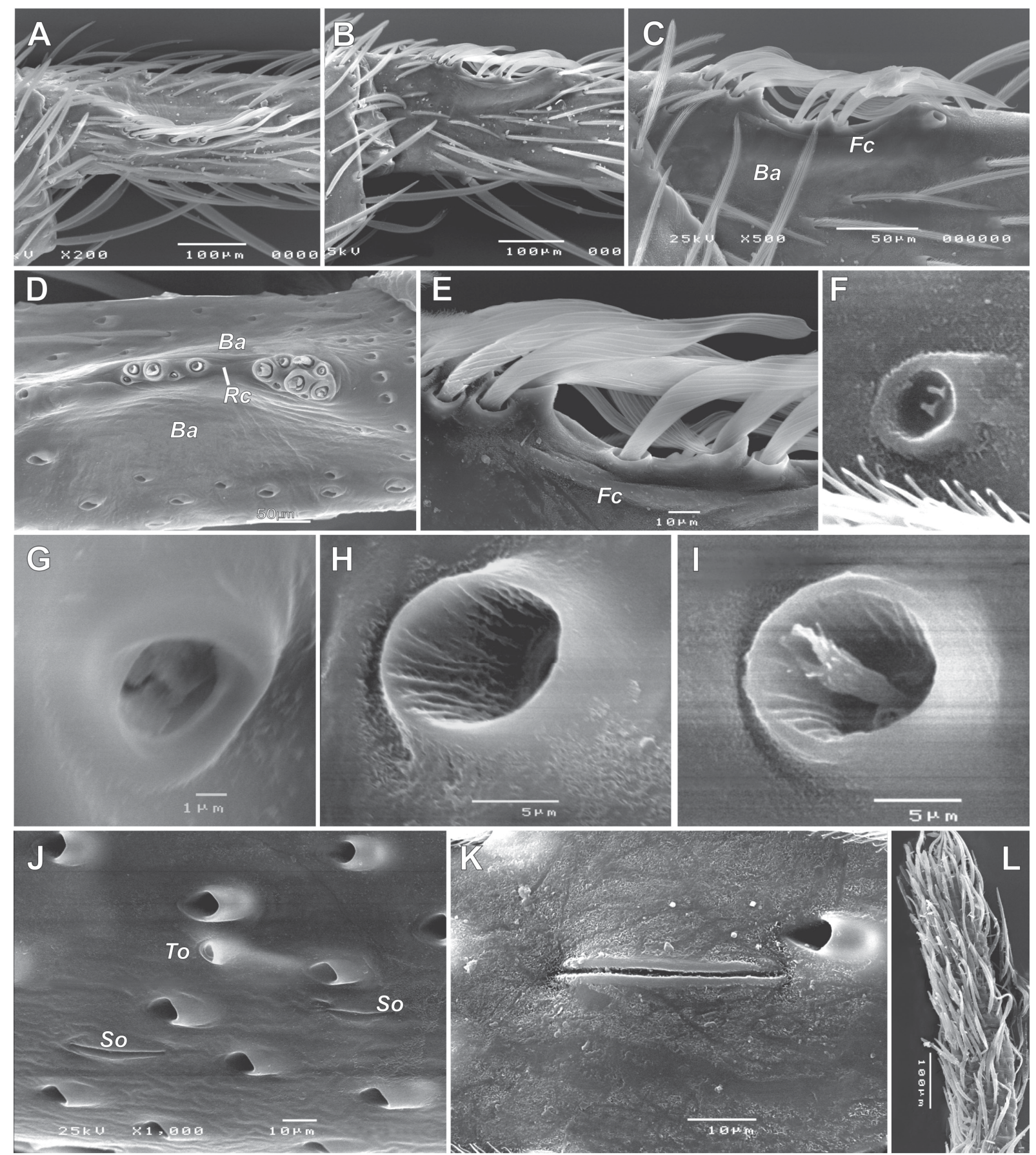

Fig. 2. Morphology of Zaitunia leg. A-K. Z. martynovae (Andreeva \& Tyshchenko, 1969), $q$ from Gandzhina. L. Z. logunovi sp. nov., paratype, Ô. - A. Calamistrum, dorsal. B-C. Same, lateral. D. Calamistral area with removed setae, dorsal. E. Setae of calamistrum, lateral. F-G. Tarsal organ. H-I. Base of trichobothria. J. Part of dorsal leg surface showing two slit organs. K. Long slit organ. L. Part of male tarsus IV, prolateral, showing pseudosegmentation. Abbreviations: see Material and methods. 
fold formed by the epigastric integument (making it difficult to observe and figure correctly). Number of receptacles varies from one to two pairs. In species with four receptacles, all receptacles are usually isolated from each other, but in some cases median and lateral receptacles are connected with each other and can appear as one receptacle with two heads. Shape of receptacles varies and can be cylindrical (Figs 9D-F, 21D-G, 39A-D), globular (Figs 7E-K, 10F-G, 11F-G, 27H, 30C-E), subconical (Fig. 25), or dumbbell- or boomerang-shaped (Z. afghana (Roewer, 1962), Z. brignoliana sp. nov.). Cylindrical receptacles can be bent or straight. Straight cylindrical and subconical receptacles have a corrugated transparent stem. Median (or mesal) receptacles are usually longer and wider than lateral, although in some species the opposite is true. Receptacles bear glandular pores (not recognized in Z. persica Brignoli, 1982). Each pore equipped with a kind of cilia. Pores can be evenly spread along receptacles (in species lacking a corrugated stem) or can be concentrated on the heads. In some species, females are almost indistinguishable from each other by the structure of the endogyne (e.g., Z. ferghanensis sp. nov., Z. maracandica (Charitonov, 1946), Z. wunderlichi sp. nov.), whereas males belonging to the same species are easily differentiated (cf. Figs 33A-B, D, 34E-J, 38E-I and 32C-G, 35A-D, 37A-C, respectively).
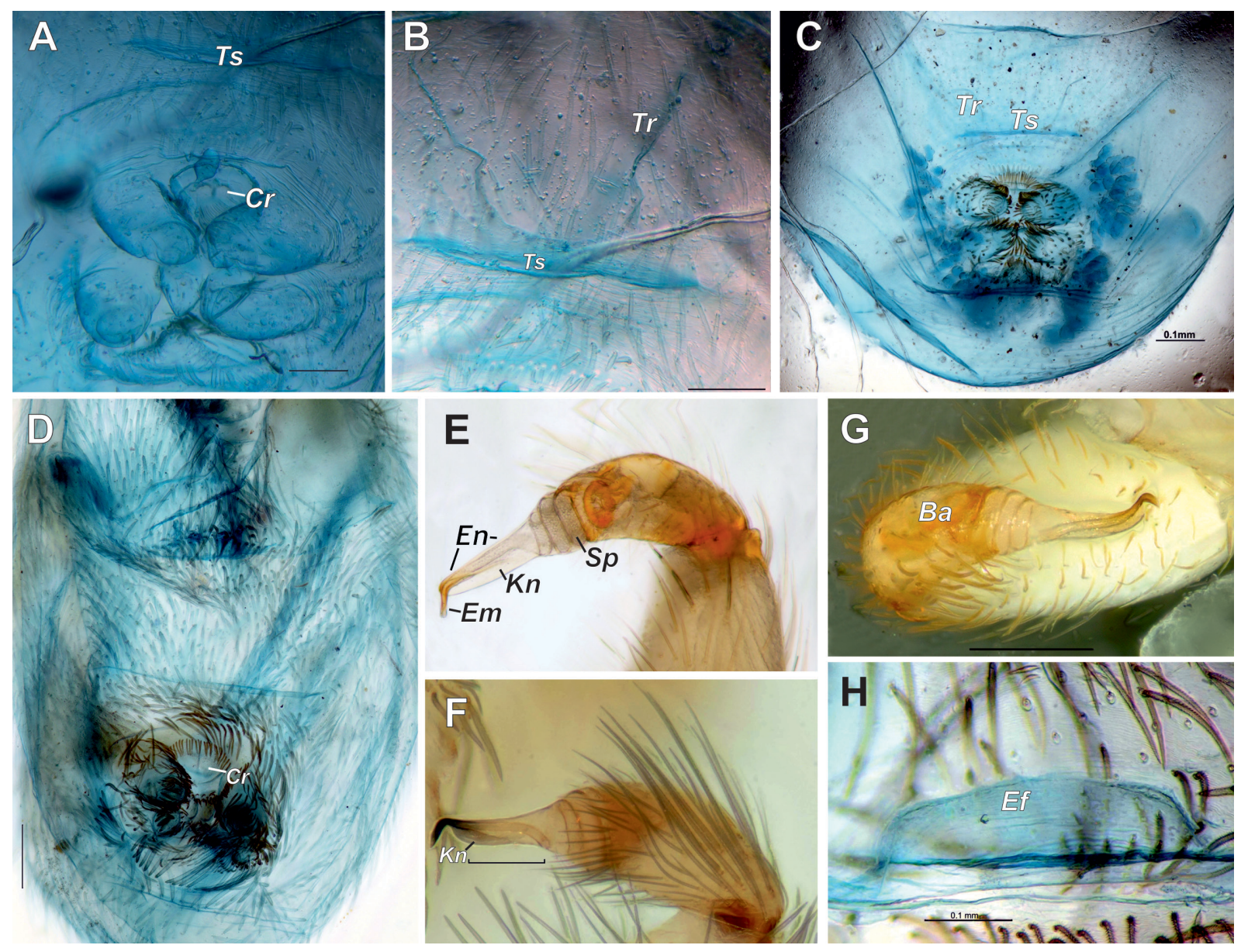

Fig. 3. Morphology of Zaitunia spp. A-B. Z. logunovi sp. nov., paratype, O. C. Z. schmitzi (Kulczyński, 1911), $q$ from Jerusalem area. D, H. Z. martynovae (Andreeva \& Tyshchenko, 1969),, from Gandzhina. E, G. Z. wunderlichi sp. nov., paratype, ô. F. Z. beshkentica (Andreeva \& Tyshchenko, 1969), đ̂ from Khurshedi. - A-D. Abdomen, ventral. E-F. Terminal part of palp, retrolateral. G. Same, dorsal. H. Genital area of subadult female. Abbreviations: see Material and methods. Scale bars: A-B, D, G = $0.2 \mathrm{~mm} ; \mathrm{C}, \mathrm{H}=0.1 \mathrm{~mm}$. 


\section{Composition}

24 species: Z. afghana (Roewer, 1962) (Afghanistan), Z. akhanii Marusik \& Zamani, 2015 (Iran), Z. alexandri Brignoli, 1982 (Iran), Z. annulipes (Kulczyński, 1908) (Cyprus), Z. beshkentica (Andreeva \& Tyshchenko, 1969) (Uzbekistan, Tajikistan), Z. brignoliana sp. nov. (Iran), Z. ferghanensis sp. nov. (Kyrgyzstan, Uzbekistan), Z. feti sp. nov. (Turkmenistan), Z. halepensis sp. nov. (Syria), Z. huberi sp. nov. (Afghanistan), Z. inderensis Ponomarev, 2005 (Kazakhstan), Z. kunti sp. nov. (Turkey, Cyprus), Z. logunovi sp. nov. (Kazakhstan, Kyrgyzstan), Z. maracandica (Charitonov, 1946) (Uzbekistan, Kazakhstan), Z. martynovae (Andreeva \& Tyshchenko, 1969) (Turkmenistan, Tajikistan), Z. medica Brignoli, 1982 (Iran), Z. minoica sp. nov. (Greece), Z. minuta sp. nov. (Uzbekistan), Z. persica Brignoli, 1982 (Iran), Z. psammodroma sp. nov. (Turkmenistan), Z. schmitzi (Kulczyński, 1911) (Egypt, Israel), Z. spinimana sp. nov. (Kazakhstan, Turkmenistan), Z. wunderlichi sp. nov. (Kyrgyzstan) and Z. zonsteini Fomichev \& Marusik, 1969 (Kazakhstan).

\section{Species grouping}

To assist with identifications, the species treated here are assigned to seven informal species groups. These assignments are preliminary, considering that males in many species are unknown, and not based on a monophyletic grouping, though some of the groups may actually reflect phylogenetic relationships.

\section{Distribution}

The genus is known from Crete to Eastern Kazakhstan, south to the Sinai Peninsula in Egypt, Fars and Kerman Provinces of Iran and Southeastern Afghanistan, and north to Northwestern and Northeastern Kazakhstan (Figs 46-49).

\section{Ecology}

Most species inhabit more or less arid habitats: deserts, semi-deserts, steppes, maquis or deciduous shrubland, where spiders may occur under rocks and in crevices of clay or rocky escarps where they build small tubular webs (see Fig. 50). Adult males were collected manually and by pitfall traps, generally during late spring or summer. Only one species, Z. wunderlichi sp. nov., was found in a humid dense broad-leaved and mixed mountain forest dominated by walnut (Juglans regia). Concluding from the known data, Zaitunia avoid the true sandy deserts, with the only exception being Z. psammodroma sp. nov., known currently only from males. Contrary to all other congeners, males of $Z$. psammodroma sp. nov. possess short and distally dilated metatarsi IV with numerous ventrodistal spines, a clear adaptation to moving on loose sandy substrate. Zaitunia species are found from the seashore to altitudes over 2000 m (Z. beshkentica).

\section{Key to the species groups of Zaitunia}

\section{Males}

(Males in the Zaitunia persica-group are unknown.)

1. Cymbium longer than bulb, embolus short, without base, spermophore occupies whole bulb (Figs 7A-

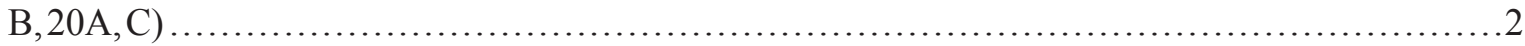

- Cymbium shorter than bulb or subequal in length, embolus with long base, spermophore in base of embolus straight (Figs 9A-C, 10I, 13C-D, 24A-D, 27C, E, 28G-I, 30H-J, 32D-G, 35A-D, 37A-C)

2. Dark coloured, carapace often without pattern, cymbium without retrolateral brush of modified setae, tegulum cylindrical with very wide spermophore occupying whole bulb (Figs 7A-D, 43A) 
- Pale coloured, cymbium with retrolateral brush of modified setae, tegulum rounded, terminal coil of spermophore 2 times thinner than basal coil (Figs 20A-C, 43E) .

3. Pale coloured; base of embolus with more or less developed ventral keel, either embolus completely screw-shaped or tip of embolus hooked or curved gradually (Figs 24A-D, 27C, E, 28G-I, 30H-J, 32D-G, 35A-D, 37A-C, 43F, 44) ...................................................

- Dark coloured; base of embolus without ventral keel, only tip of embolus screw-shaped (Figs 9A-C, 10I, 13C-D, 43B-D)

annulipes-group

4. Embolus curved or hooked apically (Figs 28G-I, 30H-J, 32D-G, 35A-D, 37A-C, 44B-F) .......5

- Embolus screw-shaped (Figs 24A-D, 27C, E, 43F, 44A)

spinimana-group
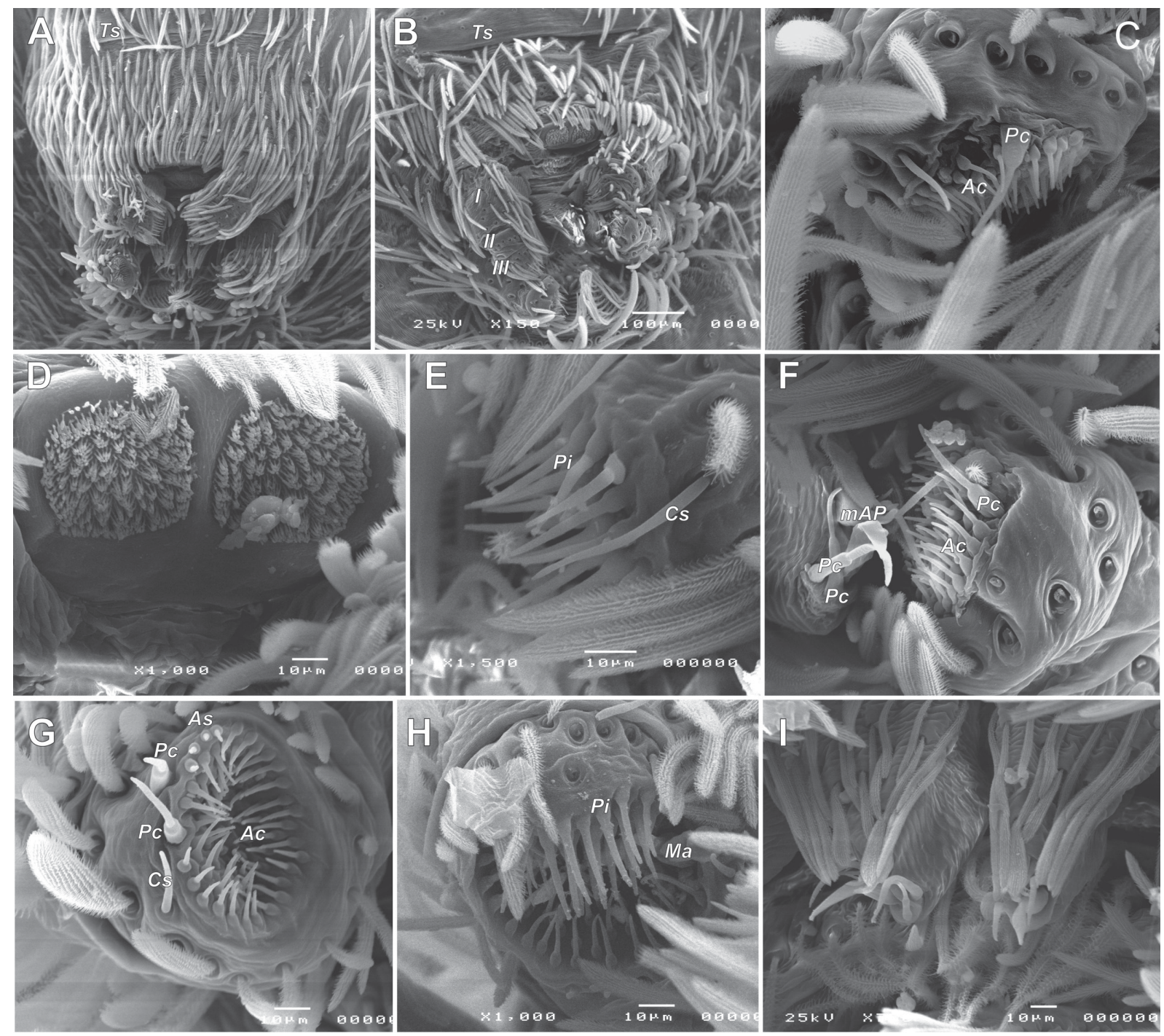

Fig. 4. Spinneret morphology of Zaitunia martynovae (Andreeva \& Tyshchenko, 1969), adult $\varnothing$ from Gandzhina. A-B. Spinnerets and tracheal spiracle. C. Right posterior lateral spinneret. D. Cribellum. E. Left anterior lateral spinneret. F. Left posterior median and lateral spinnerets. G. Right posterior lateral spinneret, frontal. H. Right anterior lateral spinneret. I. Posterior median spinnerets. Abbreviations: see Material and methods. Scale bars: A-B $=100 \mu \mathrm{m} ; \mathrm{C}-\mathrm{I}=10 \mu \mathrm{m}$. 
5. Embolus with raised keel, hooked apically (Figs 28G-I, 30H-J, 32D-G, 44C-D)

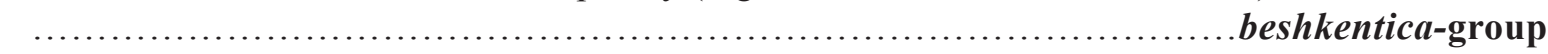

- Embolus with vestigial keel, curved apically (Figs 35A-D, 37A-C, 44E-F) ...maracandica-group

\section{Females}

(Females of the spinimana, beshkentica and maracandica species groups can be confidently distinguished from each other only by the shape of the receptacles, but this feature is not a group-specific character).

1. Intensely brown-coloured spiders; abdomen uniformly brown; legs always with darker though diffuse fasciae (Figs 5A-B, 6A, 8E-G, 10A-E, 11A-E, 12A-B, D-E) ..............................

- Pale yellowish-coloured spiders; abdomen paleyellow or yellowish-grey, with or without darker dorsal pattern; legs often uniformly pale without darker fasciae (Figs 14A-D, 15A-B, 16C, 17A-B, 18A, 19A-D, 22A-G, 26A, 27F, 29A-H, 30A-B, 31A, 34A, C-D, 35K, 36A-C, 38A-D, 39A-C, 41A-C)

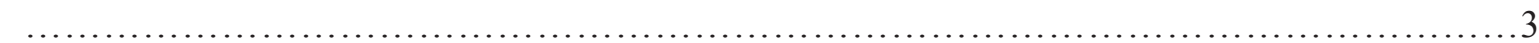

2. Legs I-IV with broader and less contrasting fasciae (Figs 5A-B, 6A); receptacles as in Figs 5C-D, $7 \mathrm{E}-\mathrm{K}$ schmitzi-group

- Legs I-IV with narrower and more contrasting fasciae (Figs 8E-G, 10A-E, 11A-E, 12A-B, D-E); receptacles as in Figs 9D-F, 11F-G, 12G-I annulipes-group

3. Four distinct receptacle heads (Figs 21, 25, 26B-C, E, 27H-I, 29I-K, 30C-E, 32H-I, 35E-J, 36D-E,

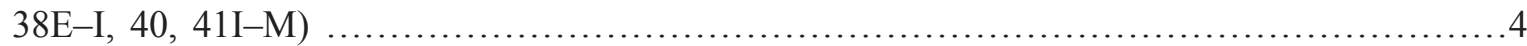

- Two receptacle heads, entire or subdivided (Figs 14G-K, 15E-G, 16A-B, D-F, 17D, F-H, 18D-E) persica-group

4. Median receptacles tubular, not diverging laterally and always considerably longer than lateral pair (Fig. 21)

logunovi-group

- Median receptacles often rounded, of same size or even shorter than lateral pair (Figs 26B-C, E, 27H-I, 30C-E, 33A-B, D, 35E-J, 38E-I, 40, 41I-M); if longer, they diverge laterally as in Figs 25, 29I-K, 36D-E

5. Receptacles as in Figs 25, 26B-C, E, 27H-I

spinimana-group

- Receptacles different (Figs 29I-K, 30C-E, 32H-I, 34E-J, 35D-E, 37E-I, 39, 41I-M) .

6. Receptacles as in Figs 29I-K, 30C-E, 33A-D

beshkentica-group

- Receptacles different (Figs 35E-J, 36D-E, 38E-I, 40, 41I-M) maracandica-group

\section{Zaitunia schmitzi species group}

\section{Remarks}

This group unites intensely dark-coloured species. The clypeus, the eye tubercle and the carapace margins are only slightly darker than the general background colour. The abdomen is uniformly darkcoloured. Legs I-IV dark, with very broad ever darker fasciae. The male palpal tibia is rather short. A long and large tegulum is cigar-shaped; it is subequal in length to the cymbium. The embolus is a short and sideward-directed lamina. The vulva is provided with two pairs of receptacles. Two species are included: Z. schmitzi (Kulczyński, 1911) from Egypt and Israel and (tentatively, due to unknown male characters) $Z$. halepensis sp. nov. from Syria. 
Key to species of the Zaitunia schmitzi-group

(Male of Z. halepensis sp. nov. is unknown.)

1. Males (palpal structures as shown in Fig. 7A-D) Z. schmitzi (Kulczyński, 1911)

- Females

2. Prosoma and legs brown to dark brown; median receptacles minute and globulate, smaller than lateral pair (Fig. 7E-K). Egypt (Sinai) and Israel

Z. schmitzi (Kulczyński, 1911)

- Prosoma and legs deep brownish yellow; median receptacles large and clublike, much longer than small lateral pair (Fig. 5C-D). Syria .

Z. halepensis sp. nov.

\section{Zaitunia halepensis sp. nov. \\ urn:1sid:zoobank.org:act:E56085AC-B0D0-4AF3-8F4A-075C1A563A0F}

Fig. 5

\section{Diagnosis}

The body and leg pattern is similar to that in Z. schmitzi (a uniformly dark abdomen and very wide dark fasciae on the legs) rather than the colouration observed in the members of the annulipes-group. Zaitunia halepensis sp. nov. differs from all other congeners, possessing two pairs of receptacles by configuration of the enlarged median pair which have considerably dilated heads (Fig. 5C-D).

\section{Etymology}

The specific name refers to the type locality: Aleppo (Haleb).

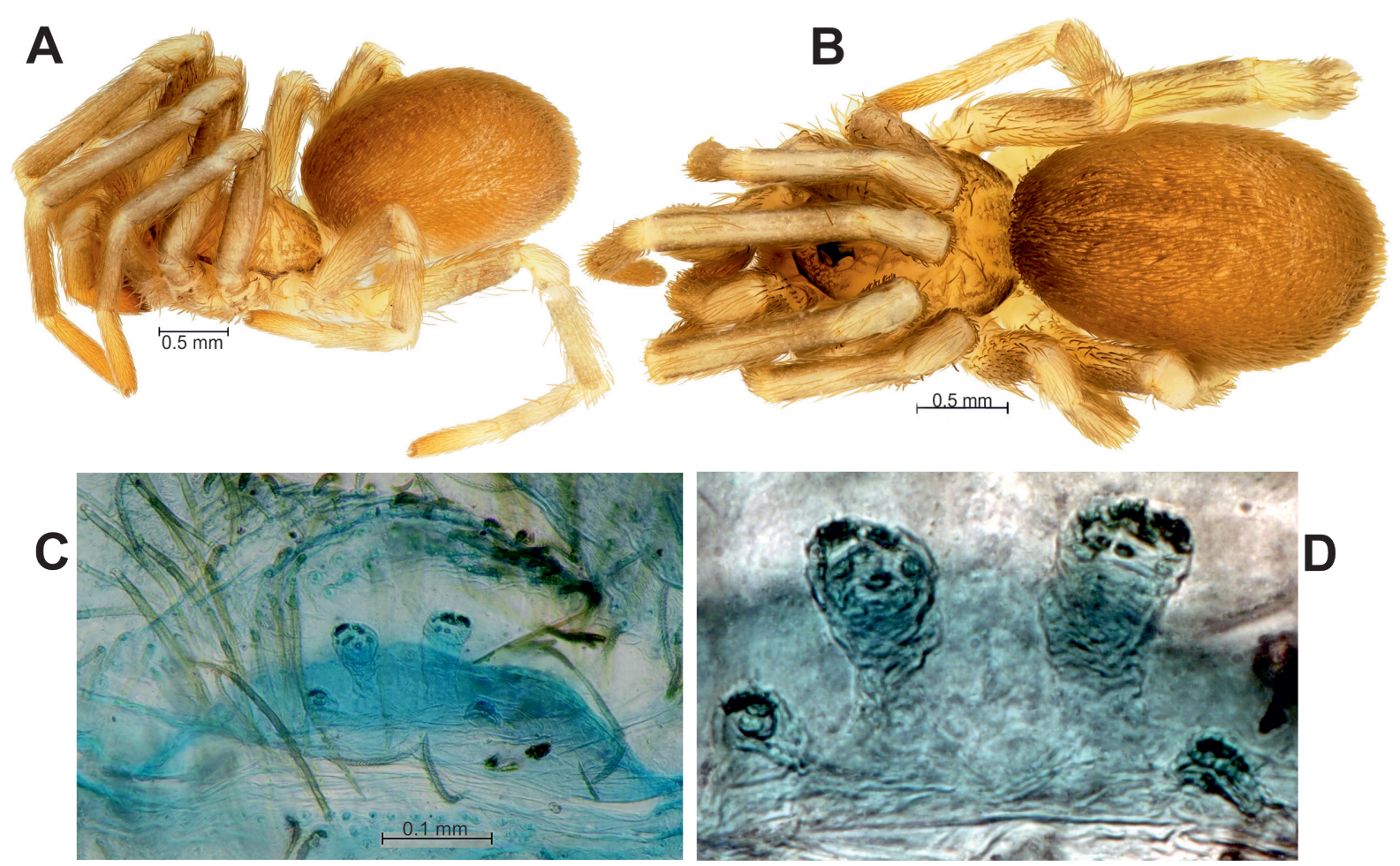

Fig. 5. Zaitunia halepensis sp. nov., holotype, ․ A-B. Habitus, lateral and dorsal. C-D. Endogyne. 


\section{Type material}

\section{Holotype}

SYRIA: + , road from Aleppo to Latakia, eastern slope of Rug rift valley, 20 Mar. 1979, R. Kinzelbach (SMF).

\section{Description}

\section{Female}

Habitus. See Fig. 5A-B.

BODY LENGTH. 3.22.

CoLour. Carapace brownish-yellow with rich darker brownish pattern occupying clypeus, postocular area, radial grooves and, partially, the surface between those grooves; eye tubercle and narrow bands along margins dark brown; labium and sternum pale brownish-yellow; chelicerae, palps and legs light brownish-yellow with darker diffuse brownish spots and fasciae; abdomen uniformly yellowish-brown.

CARAPace. 1.28 long, 1.05 wide.

Eyes. AME 0.07, ALE 0.13, PLE 0.11, PME 0.08, AME-AME 0.05.

LEG MEASUREMENTS.

\begin{tabular}{lcccccc}
\hline & Femur & Patella & Tibia & Metatarsus & Tarsus & Total \\
\hline Palp & 0.65 & 0.27 & 0.45 & - & 0.57 & 1.94 \\
I & 1.35 & 0.43 & 1.32 & 1.18 & 0.86 & 5.14 \\
II & 0.98 & 0.38 & 0.87 & 0.85 & 0.64 & 3.72 \\
III & 0.88 & 0.35 & 0.72 & 0.73 & 0.53 & 3.21 \\
IV & 1.26 & 0.46 & 1.02 & 0.85 & 0.78 & 4.07 \\
\hline
\end{tabular}

Endogyne (Fig. 6C-D). Median receptacles clublike, almost 3 times longer than globular lateral receptacles, and separated by one diameter of their heads.

Male

Unknown.

\section{Distribution}

The species is known only from the type locality (Fig. 46).

Zaitunia schmitzi (Kulczyński, 1911)

Figs 6-7, 43A, 50A

Filistata schmitzi Kulczyński, 1911: 13, pl. 1, fig. 3 (ぷ+o).

Zaitunia schmitzi - Lehtinen 1967: 275, fig. 21 (ぷ゚). —Zonstein 2009b: 127, figs 1-12 (ぷ゚).

\section{Diagnosis}

Males differ from those of all other congeners by a long and large cigar-shaped tegulum, a very thick spermophore occupying the whole bulb, a strongly slanting tip of the cymbium and by the extremely short and sideward-directed embolus (vs smaller coniform and longer forward-directed ones in other species). Females are easily distinguished by their intense dark coloration (darker than that in any other 
species) as well as their low and small globular receptacles, with outer lobe only slightly exceeding the median one in size (Fig. 7E-K).

\section{Type material}

Lectotype (designated by Zonstein 2009b: 127)

ISRAEL: $\widehat{O}$, Jerusalem (the current depository unknown; not examined).

\section{Paralectotype}

ISRAEL: 1 , Galilee (the current depository unknown; not examined).
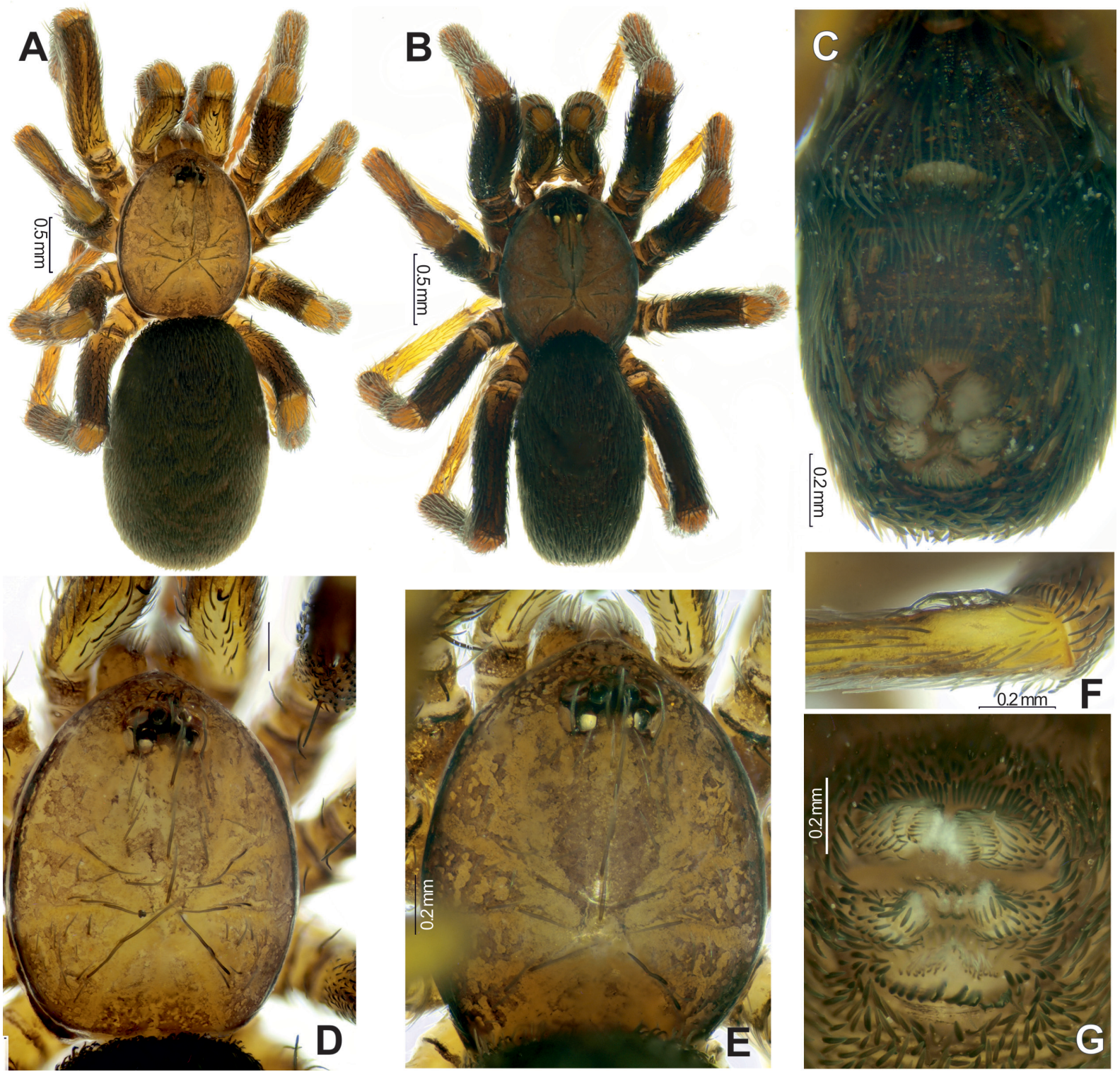

Fig. 6. Somatic characters of Zaitunia schmitzi (Kulczyński, 1911),, (A, C-D, F-G) and $\widehat{\partial}(\mathbf{B}, \mathbf{E})$ from Jerusalem area. - A-B. Habitus, dorsal. C. Abdomen, ventral. D-E. Prosoma, dorsal. F. Calamistrum, dorsal. G. Spinnerets, ventral. 


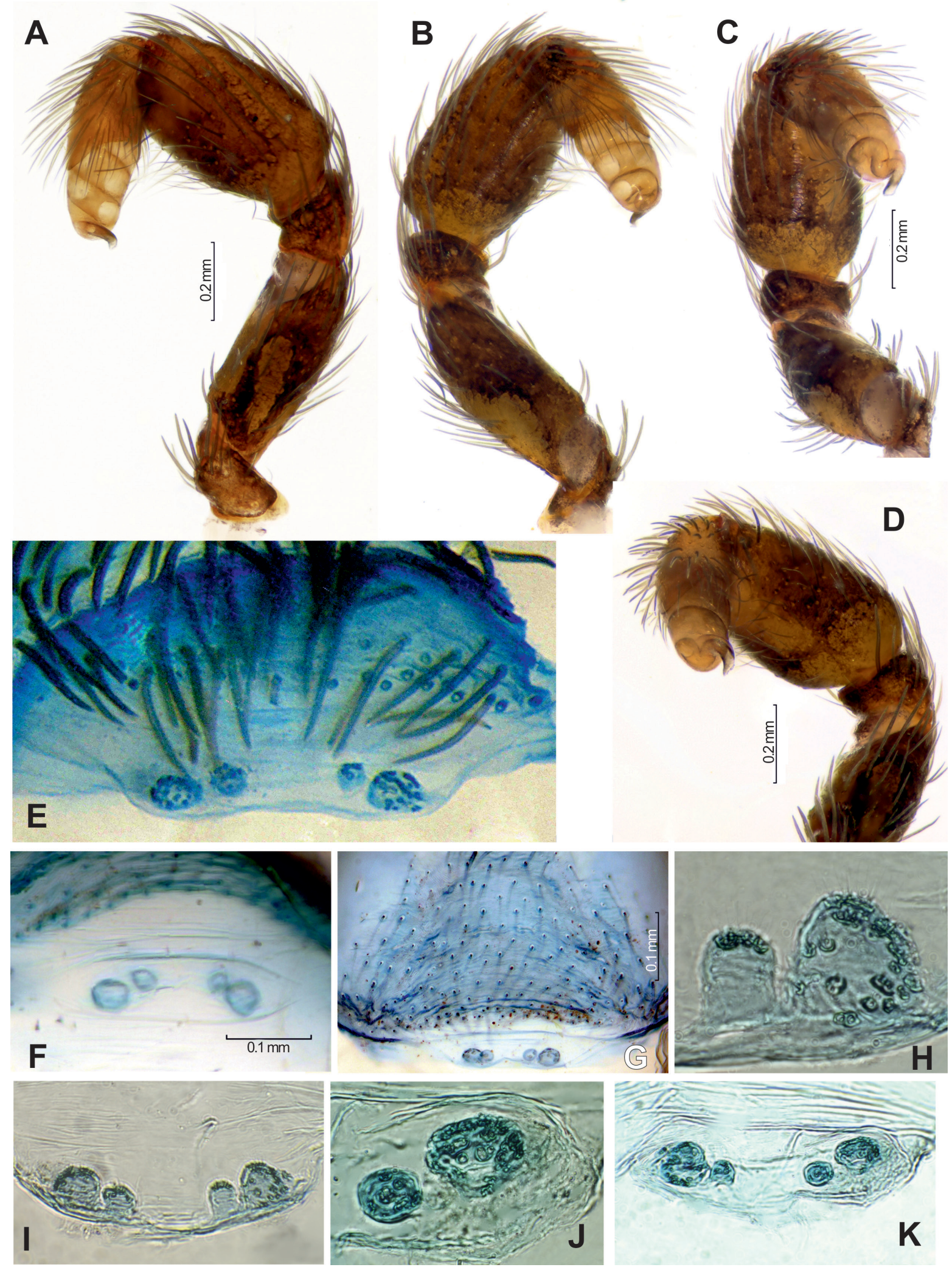

Fig. 7. Copulatory organs of Zaitunia schmitzi (Kulczyński, 1911), $\widehat{o}(\mathbf{A}-\mathbf{D})$ and $q$ (E-K) from Jerusalem area. - A-B. Palp, retrolateral and prolateral. C-D. Same, ventro-prolateral and ventroretrolateral. E, G, K. Endogyne, anterior. F. Same, posterior. H, J. Receptacles, dorsal and anterior. I. Endogyne, dorsal. 


\section{Note}

Lehtinen (1967) indicated the type series as being kept in IZW, but according to Wioletta Wawer, the curator, these types were not found there (pers. comm.).

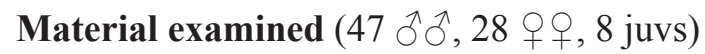

EGYPT: 1 ㅇ, South Sinai, Mt. Catarina, c. 28³3' N, 3357' E, 16 Jun. 1968, unknown collector (HUJ).

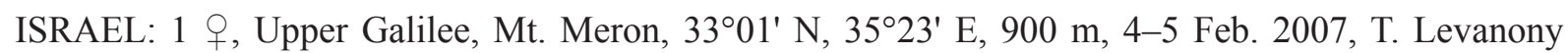
(TAU); 1 $\hat{\jmath}$, same data, but 5-12 Apr. 2007 (TAU); $1 \hat{\jmath}$, same data, but 12-16 May 2007 (TAU);

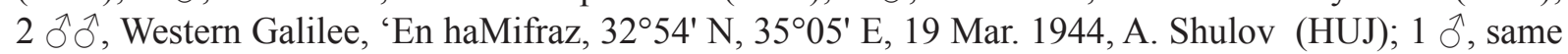

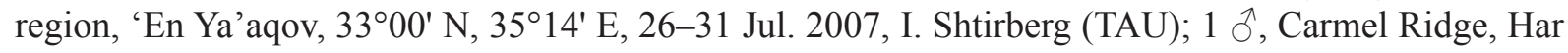

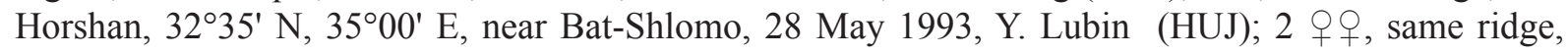

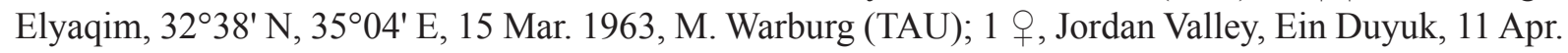
1968, M. Pener (HUJ); 1 q, same locality, 10 Jun. 1970, M. Pener (HUJ); 1 juv., Yizre'el Valley, Bet HaShita, 32 $33^{\prime}$ N, $35^{\circ} 26^{\prime}$ E, 6 Feb. 1937, A. Shulov (TAU); 2 juvs, same region, 'En Harod, 32 $34^{\prime}$ N, 35²3' E, 11 Mar. 1945, A. Shulov (HUJ); 1 ㅇ, Jerusalem, 16 Jul. 1941, A. Shulov (HUJ); 1 juv., same locality, 12 Dec. 1949, A. Shulov (HUJ); 1 q, same locality, 10 Mar. 1961, A. Shulov (HUJ); 1 ,

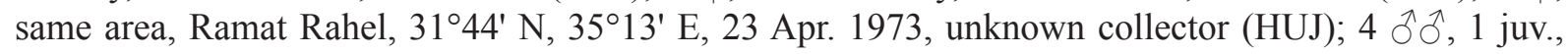

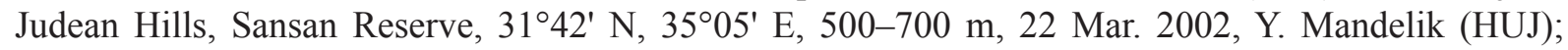

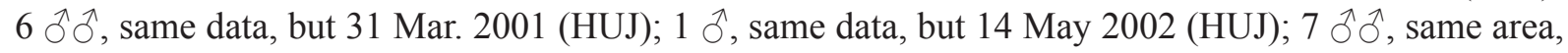

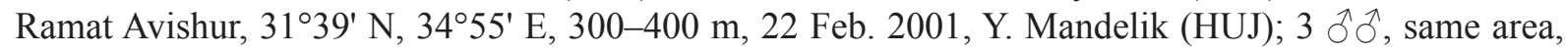

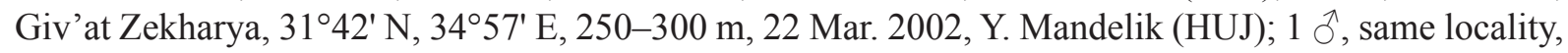

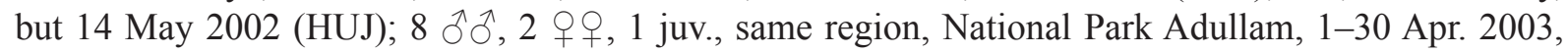

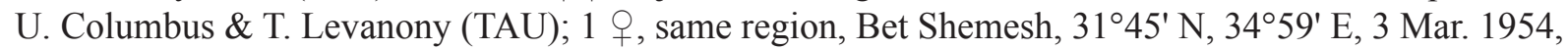

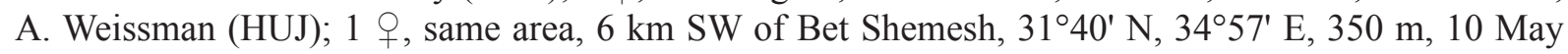

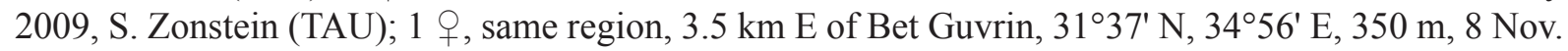

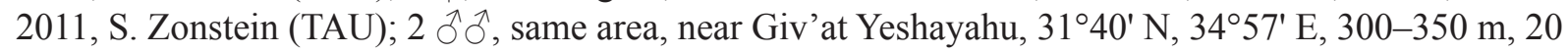
May 2007, O. Skutelsky (TAU); $1 \hat{\jmath}$, same data, but 20 May 2008 (TAU); $1 \hat{\partial}$, same area, Matta, $31^{\circ} 43^{\prime}$

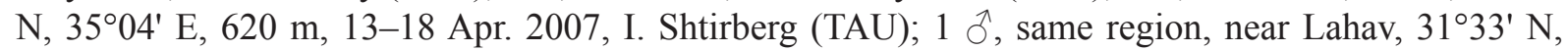
345' E, 500 m, 25-30 Jul. 2006, I. Shtirberg (TAU); 1 Oे, 2 우, same data, but 13-18 Jan. 2007 (TAU); 2 우우, Northern Negev, Dorot - Ruhama, c. 31 ${ }^{\circ} 30^{\prime}$ N, 3441' E, 31 Jan. 1972, I. Vaisberg (HUJ); 1 ô, same region, HaBesor, $31^{\circ} 18^{\prime} \mathrm{N}, 34^{\circ} 29^{\prime} \mathrm{E}, 70 \mathrm{~m}, 2$ Apr. 2010, C. Drees \& L. Friedman (TAU); 1 + , Dead Sea Area, 'Enot Zuqim (En Fashkha), 24 Feb. 1942, A. Shulov (HUJ); 1 ठ, same region, Nahal Perat (Wadi Kelt), 13 Jan. 1945, A. Shulov (HUJ); 1 đ, 3 우, same region, surroundings of 'En Gedi,

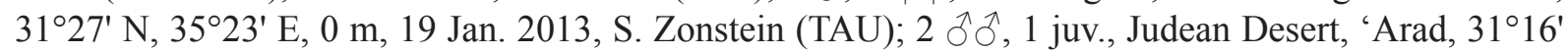
N, 35¹3' E, 20 Dec. 1962, P. Amitai (HUJ); 4 우, 1 juv., same locality, 13 Feb. 1969, M. Warburg (TAU); 1 , Ma'ale Adummim, 30 Apr. 1972, unknown collector (HUJ); 1 \&, Central Negev, Yeroham, 3059' N, 3456' E, 30 Nov. 1964, Blond \& Watz (HUJ); 1 juv., same region, crater Makhtesh Gadol, c. $30^{\circ} 57^{\prime} \mathrm{N}, 35^{\circ} 00^{\prime} \mathrm{E}, 1$ Apr. 1962, A. Shulov (HUJ).

\section{Description}

Male (from Jerusalem area)

Habitus. See Fig. 6B.

BODY LENGTH. 2.83.

CoLour. Carapace dark yellowish-brown with margins, postocular area and eye tubercle dark brown to brownish-black; chelicerae, labium, sternum and maxillae brown; legs brown with diffuse and poorly developed dark-brown fasciae; abdomen uniformly dark brown. 
CARAPACE (Fig. 6E). 1.27 long, 1.03 wide.

EyEs. AME 0.06, ALE 0.11, PLE 0.08, PME 0.06, AME-AME 0.06.

Palp (Figs 7A-D, 43A). Femur equal in length to tibia; tibia thick, uniformly swollen. Cymbium moderately long, with or without small dorsodistal projection. Broad, blunt-tipped tegulum with thick spermophore forming 4 complete coils closely adjoining each other. Embolus short, lacking a neck, flattened and bent retrolaterally.

LEG MEASUREMENTS. $\overbrace{}^{\lambda}(+)$

\begin{tabular}{lcccccc}
\hline & Femur & Patella & Tibia & Metatarsus & Tarsus & Total \\
\hline Palp & $0.61(0.80)$ & $0.25(0.31)$ & $0.59(0.43)$ & - & $0.24(0.79)$ & $1.69(2.33)$ \\
I & $1.31(1.52)$ & $0.49(0.49)$ & $1.28(1.41)$ & $1.10(1.20)$ & $0.73(0.91)$ & $4.91(5.53)$ \\
II & $1.04(1.15)$ & $0.47(0.46)$ & $0.98(0.95)$ & $0.93(0.85)$ & $0.65(0.74)$ & $4.07(4.15)$ \\
III & $0.98(0.97)$ & $0.46(0.46)$ & $0.78(0.59)$ & $0.95(0.74)$ & $0.64(0.65)$ & $3.81(3.41)$ \\
IV & $1.25(1.36)$ & $0.52(0.48)$ & $1.16(1.05)$ & $1.26(1.06)$ & $0.74(0.73)$ & $4.93(4.68)$ \\
\hline
\end{tabular}

Female (from Jerusalem area)

Habitus. See Figs 6A, 50A.

Body LENGTH. 3.85.

Colour. As in male, but carapace, palps and legs slightly lighter; in contrast, fasciae on palps and legs somewhat darker than in male.

CARAPACE (Fig. 6D). 1.52 long, 1.18 wide.

Eyes. AME 0.07, ALE 0.12, PLE 0.10, PME 0.07, AME-AME 0.06.

ENDOGYNE (Fig. 7E-K). With 2 pairs of globular receptacles. Median receptacles two times thinner that lateral; median receptacles separated by 3 diameters; lateral receptacles evenly covered by pores, and median receptacles with pores on head only.

\section{Variation}

Carapace length in males varies from 1.03 to 1.30 , in females from 1.37 to 2.00 ; ground colouration varies from medium yellowish-brown with a darker brown abdomen to an almost uniform dark brown.

\section{Ecology}

The species inhabits many types of habitats, from deserts through steppes and maquis to low oak evergreen forest; in all these habitats, it occurs mainly under rocks (see Fig. 50A).

\section{Distribution}

Egypt (Sinai) and Israel (Fig. 46).

\section{Zaitunia annulipes-group}

\section{Remarks}

This group unites moderately dark-coloured species. The clypeus, the eye tubercle and the carapace margins are noticeably darker than the general background colour. The abdomen is uniformly darkcoloured or with a weak, darker dorsal pattern. Legs I-IV are lighter than the body and provided with 
relatively narrow darker fasciae. The male palpal tibia is moderately short. The conical tegulum is much shorter than the cymbium. The embolus is a relatively long to very long apically twisted lamina. Keel of embolus absent. The vulva has two pairs of receptacles. Three species are included: Zaitunia annulipes (Kulczyński, 1908) from Cyprus, Zaitunia kunti sp. nov. from Cyprus and Turkey, and Zaitunia minoica sp. nov. from Crete.

\section{Key to species of the Zaitunia annulipes-group}

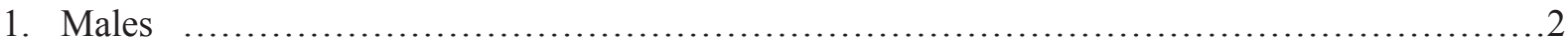

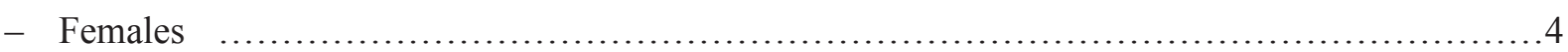

2. Embolus longer than tegulum, twisted or hooked apically (Figs 10I, 13C-D) ..................

- Embolus shorter than tegulum, curved and bent apically (Figs 9A-C, 43B)

3. Embolus moderately long, twisted apically (Figs 10I, 43C) ..................... kunti sp. nov.

- Embolus very long, hooked apically (Figs 13C-D, 43D) ...................... minoica sp. nov.

4. Median receptacles only slightly larger than lateral pair (Figs $11 \mathrm{~F}-\mathrm{G}, 12 \mathrm{G}-\mathrm{I})$...................

- Median receptacles considerably larger than lateral pair (Fig. 9D-F)

Z. annulipes (Kulczyński, 1908)

5. Median and lateral receptacles set very close to each other (Fig. 12G, I) ........ . minoica sp. nov.

- Median and lateral receptacles set more distantly from each other (Fig. 11F-G) ... Z. kunti sp. nov.

Zaitunia annulipes (Kulczyński, 1908)

Figs 8-9, 43B

Filistata annulipes Kulczyński, 1908: 376 (†).

Zaitunia annulipes - Brignoli 1982: 66 (transferred species to Zaitunia).

\section{Diagnosis}

Zaitunia annulipes differs from the congroupers by males possessing a shorter embolus gently curved in the subapical part and by females having the receptacles with the median units considerably larger than the outer ones (in congroupers embolus is considerably longer and more sharply curved subapically, and the median and outer receptacles are subequal in size - cf. Figs 10I, 11F-G, 12G-I, 13C-D).

\section{Type material}

Lectotype (designated here)

CYPRUS: 1 + , with labels [SYNTYPI, Cypr I.Z.P.A.N. Warsawa 40/SLU (or 514)], in poor condition, with broken abdomen and part of legs, IZW, examined.

\section{Paralectotypes}

CYPRUS: 2 juvs, with same collecting data.

\section{Additional material examined}

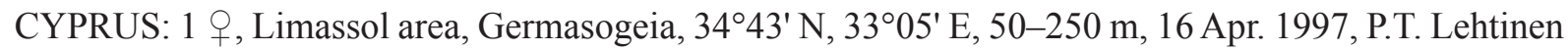

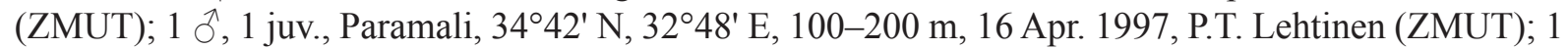
${ }^{\lambda}$, Larnaka area, Vyzakia, west shore of Larnaka salt lake, $34^{\circ} 53^{\prime}$ N, $33^{\circ} 36^{\prime}$ E, c. 10 m, 11-16 Apr. 1997, P.T. Lehtinen (ZMUT); 1 §, same data (TAU); 2 q,+ 1 juv., same data, except 16 Apr. 1997 (ZMUT); 1 , same data (TAU). 


\section{Description}

Male (from Paramali)

Habitus. See Fig. 8A-B, D.

Body LENGTH. 3.19.

CoLour. Carapace and legs mostly light brownish-yellow; cephalic part including eye tubercle and leg fasciae diffuse medium brown; clypeus and lateral margins of carapace more intensive brown to dark

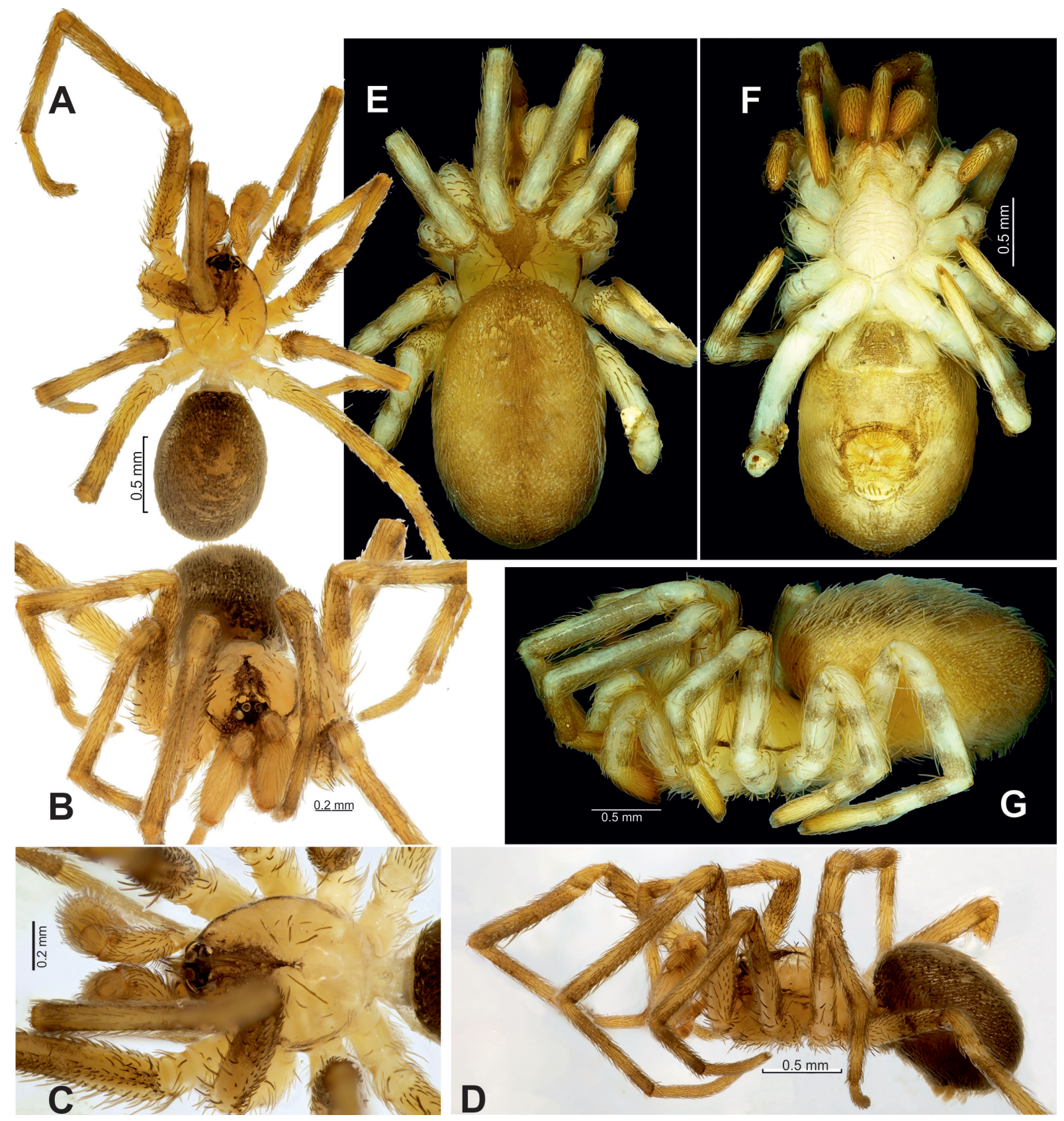

Fig. 8. Somatic characters of Zaitunia annulipes (Kulczyński, 1908), § from Paramali (A-D) and $\odot$ from Germasogenea (E-G). - A, E. Habitus, dorsal. B. Same, frontal. C. Prosoma, dorsal. D, G. Habitus, lateral. F. Same, ventral. Scale bars: A, $D-G=0.5 \mathrm{~mm} ; \mathrm{B}-\mathrm{C}=0.2 \mathrm{~mm}$. 
brown; labium, maxillae, sternum and leg coxae pale brownish-yellow; abdomen uniformly medium brown.

CARAPace (Fig. 8C). 1.28 long, 1.03 wide.

Eyes. AME 0.09, ALE 0.14, PLE 0.13, PME 0.09, AME-AME 0.03.

PaLp (Figs 9A-C, 43B). All segments except cymbium with dark pigmentation; femur longer than tibia. Tibia almost 2 times wider than femur. Cymbium longer than bulb; bulb conical, twice as long as diameter of tegulum. Tip of embolus twisted.

LEG MEASUREMENTS. $\hat{\jmath}(+9)$

\begin{tabular}{lcccccc}
\hline & Femur & Patella & Tibia & Metatarsus & Tarsus & Total \\
\hline Palp & $0.80(0.61)$ & $0.22(0.35)$ & $0.69(0.46)$ & - & $0.31(0.57)$ & $2.02(1.73)$ \\
I & $1.75(1.50)$ & $0.47(0.47)$ & $1.73(1.31)$ & $1.62(1.07)$ & $0.97(0.87)$ & $6.54(5.22)$ \\
II & $1.40(1.07)$ & $0.44(0.43)$ & $1.29(0.81)$ & $1.22(0.67)$ & $0.83(0.58)$ & $5.18(3.56)$ \\
III & $1.18(0.89)$ & $0.38(0.41)$ & $1.11(0.67)$ & $1.19(0.60)$ & $0.74(0.55)$ & $4.60(3.12)$ \\
IV & $1.74(1.29)$ & $0.42(0.44)$ & $1.56(0.93)$ & $1.56(0.91)$ & $0.97(0.67)$ & $6.25(4.24)$ \\
\hline
\end{tabular}

Female (from Germasogenea)

Habitus. See Fig. 8E-G.

BoDy LENGTH. 3.45.
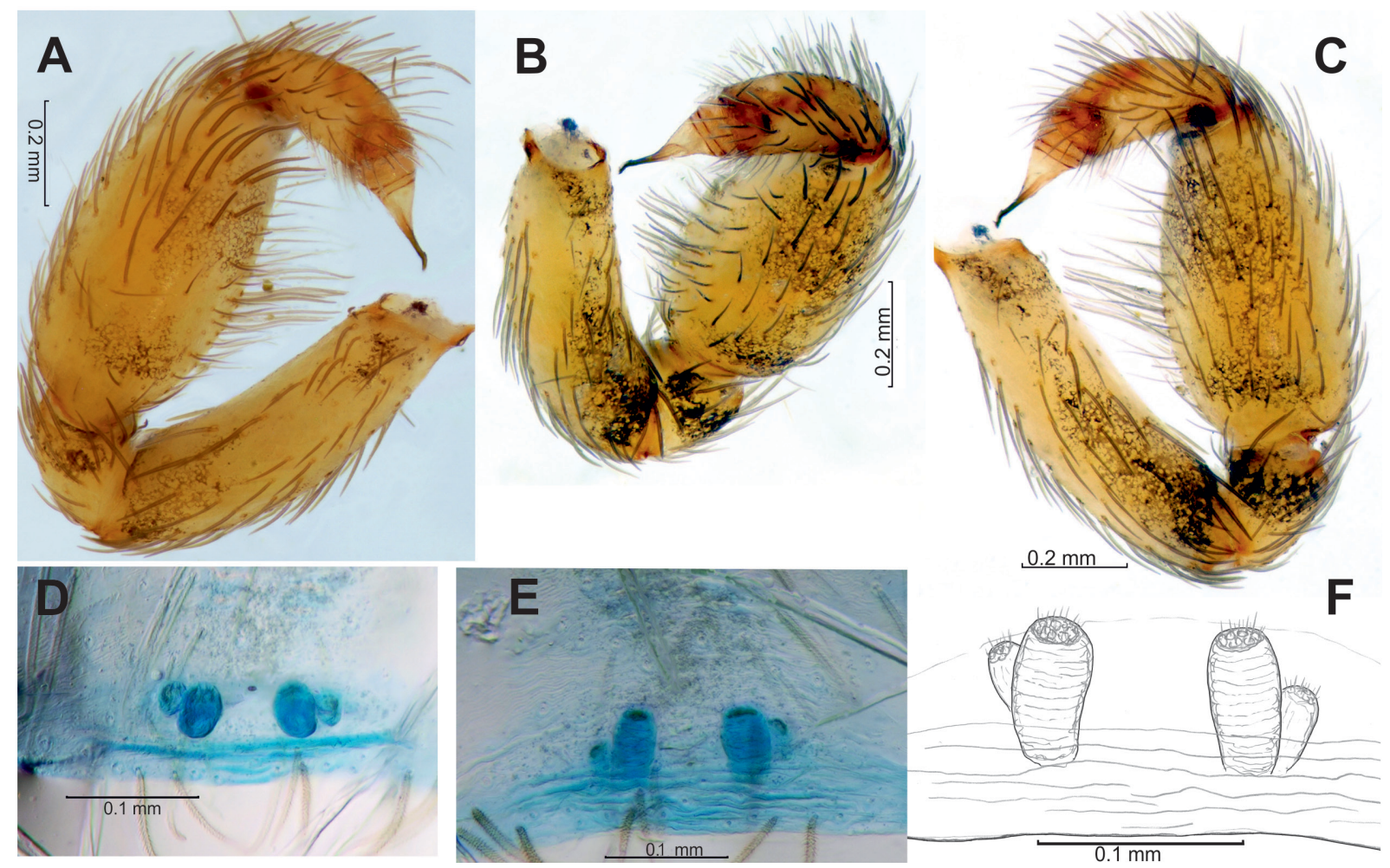

Fig. 9. Copulatory organs of Zaitunia annulipes (Kulczyński, 1908), § from Paramali (A-C) and $q$ from Germasogenea (D-F). - A-C. Palp, prolateral, ventro-retrolateral and retrolateral. D. Endogyne, anterior. E-F. Same, dorsal. Scale bars: A-C $=0.2 \mathrm{~mm}$; D-F $=0.1 \mathrm{~mm}$. 
Colour. As in male.

CARAPACE. 1.26 long, 1.10 wide.

EYES. AME 0.08, ALE 0.15, PLE 0.11, PME 0.09, AME-AME 0.04.

ENDOGYNE (Fig. 9D-F). With 2 pairs of receptacles. Both pairs with corrugated stems; pores located on heads. Median receptacles two times as long as lateral, separated by about 1.5 diameters.

\section{Variation}

Body size in males 3.19-3.67, in females 3.05-3.95. Coloration without noticeable variation.

\section{Note}

Male of this species is described for the first time. Although this species was already transferred to Zaitunia by Brignoli (1982), this nomenclatorial act was overlooked by Brignoli (1983) himself and by subsequent catalogs (Platnick 1989, 1993, 2015; World Spider Catalog 2015).

\section{Ecology}

According to the label data, the species was found in the maquis (Mediterranean shrub) litter.

\section{Distribution}

Cyprus (Fig. 46).

Zaitunia kunti sp. nov. urn:1sid:zoobank.org:act:C7A41607-6945-4838-9001-C8D6471D0A3A

Figs $10-11,43 \mathrm{C}$

\section{Diagnosis}

Zaitunia kunti sp. nov. differs from related species by having the embolus more sharply curved in the subapical part and receptacles subequal in size and clearly separated from each other (in Z. annulipes, the embolus is clearly shorter and more gently curved, and the median receptacles are considerably larger than the outer ones; whereas in Z. minoica sp. nov., a longer embolus is noticeably less sharply curved in the subapical part, and the receptacles, although subequal in size, almost touch each other (cf. Figs 9, 12G-I, 13C-D).

\section{Etymology}

The specific epithet is given after our good friend and colleague, Turkish arachnologist Kadir Boğaç Kunt.

\section{Material examined}

Holotype

TURKEY: Õ๊, "Taurus" (no other data), O. Kraus (SMF 12991).

Paratypes $(2 q \circ)$

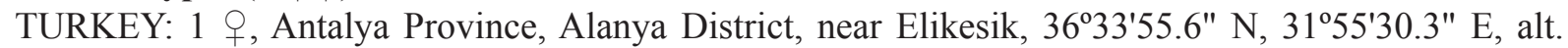
24 m, 8 Jan. 2013, Y.M. Marusik (ZMMU).

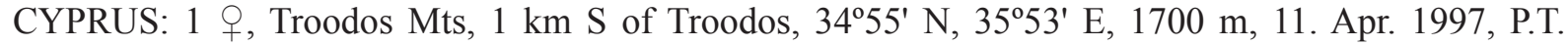
Lehtinen (ZMUT). 

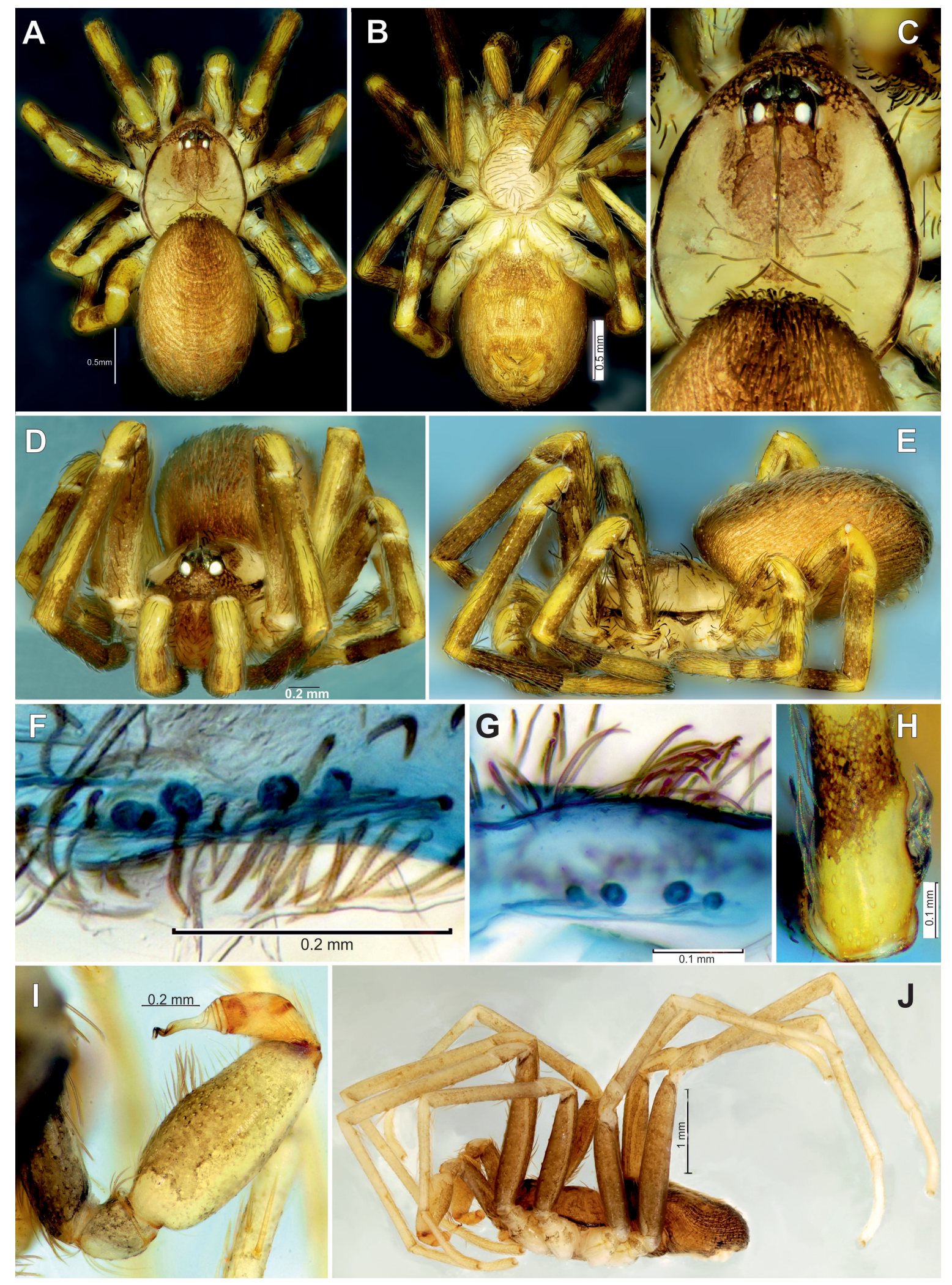

Fig. 10. Somatic characters and copulatory organs of Zaitunia kunti sp. nov., paratype, $q$ from Turkey (A-H) and holotype, $\widehat{\jmath}(\mathbf{I}-\mathbf{J})$. - A-B. Habitus, dorsal and ventral. C. Prosoma, dorsal. D-E. Habitus, frontal and lateral. F-G. Endogyne, dorsal. H. Calamistrum, dorsal. I. Palp, retrolateral. J. Habitus, lateral. Scale bars: A-B $=0.5 \mathrm{~mm} ; \mathrm{D}-\mathrm{F}, \mathrm{I}=0.2 \mathrm{~mm} ; \mathrm{G}-\mathrm{H}=0.1 \mathrm{~mm} ; \mathrm{J}=1.0 \mathrm{~mm}$. 


\section{Description}

\section{Male}

Habitus. See Fig. 10J.

BODY LENGTH. 3.05.

Colour. Carapace dark yellow with brown wide margins, clypeus and postocular area; eye tubercle blackish-brown; chelicerae, all femora and abdomen uniformly yellowish-brown; other parts of body and legs pale brownish-yellow.

Carapace. 1.47 long, 1.28 wide.
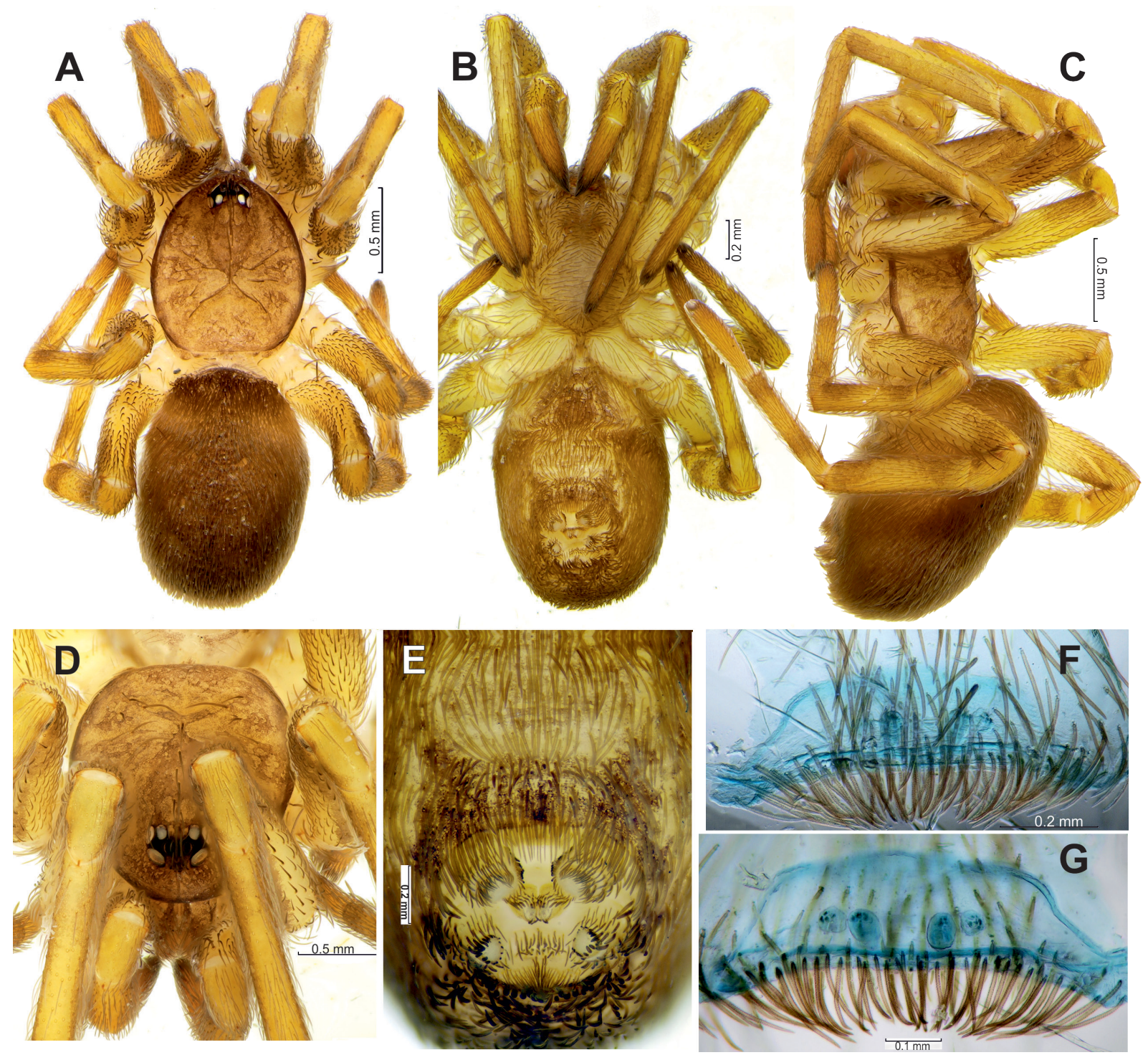

Fig. 11. Somatic characters and endogyne of Zaitunia kunti sp. nov., paratype, $q$ from Cyprus. A-C. Habitus, dorsal, ventral and lateral. D. Prosoma, frontal. E. Posterior part of abdomen, showing tracheal spiracle and spinnerets. F-G. Endogyne, ventral and dorsal. Scale bars: A, C-D = $0.5 \mathrm{~mm}$; B, $\mathrm{E}-\mathrm{F}=0.2 \mathrm{~mm} ; \mathrm{G}=0.1 \mathrm{~mm}$. 
Eyes. AME 0.12, ALE 0.22, PLE 0.19, PME 0.18, AME-AME 0.10.

PALP (Figs 10I, 43C). All segments with dark pigmentation; femur slightly longer than tibia; tibia 1.1 wider than femur. Cymbium with small dorsal hump, longer than bulb. Tegular part conical; embolic part cylindrical (in lateral view), spermophore meandering in embolic part; tip of embolus screw-shaped.

LEG MEASUREMENTS. $\widehat{\jmath}(+)$

\begin{tabular}{lcccccc}
\hline & Femur & Patella & Tibia & Metatarsus & Tarsus & Total \\
\hline Palp & $0.90(0.55)$ & $0.42(0.27)$ & $0.85(0.36)$ & - & $0.32(0.50)$ & $2.49(1.68)$ \\
I & $2.23(1.17)$ & $0.72(0.41)$ & $1.54(1.14)$ & $1.65(0.95)$ & $0.90(0.80)$ & $7.04(4.47)$ \\
II & $1.86(0.91)$ & $0.65(0.39)$ & $1.32(0,69)$ & $1.51(0.65)$ & $0.68(0.58)$ & $6.02(3.22)$ \\
III & $1.78(0.76)$ & $0.67(0.32)$ & $1.32(0.54)$ & $1.30(0.56)$ & $0.53(0.46)$ & $5.60(2.64)$ \\
IV & $2.13(1.03)$ & $0.75(0.38)$ & $1.29(0.81)$ & $1.53(0.79)$ & $0.61(0.54)$ & $6.31(3.55)$ \\
\hline
\end{tabular}

Female (from Elikesik)

Habitus. See Fig. 10A-B, D-E.

BODY LENGTH. 2.54.

Colour. Carapace, chelicerae and legs mostly medium brownish-yellow; abdomen dorsally, diffuse leg fasciae, cephalic area and reticulate clypeal pattern medium violet-brown; eye tubercle and carapace margins dark violet-brown; sternum light yellow with brownish margins; abdomen ventrally and spinnerets light violet-brown.

Carapace (Fig. 10C). 1.13 long, 0.94 wide.

Eyes. AME 0.06, ALE 0.11, PLE 0.09, PME 0.07, AME-AME 0.03.

Endogyne (Fig. 10F-G). Median receptacles oval, lateral receptacles globular, both pairs without goffering. Heads covered with pores. Median receptacles separated by about 1.5 diameters.

\section{Variation}

Carapace length in female paratype from Cyprus 1.68; this specimen has body and leg pattern slightly more contrast than those in female paratype from Turkey (Fig. 11A-C), but the relative size and arrangement of darker marks do not differ sufficiently.

\section{Ecology}

The type locality in Turkey belongs to the coastal maquis zone; the female paratype from Cyprus was collected in the highlands $(1700 \mathrm{~m})$.

\section{Distribution}

South Turkey and Cyprus (Fig. 46).

$$
\begin{aligned}
& \text { Zaitunia minoica } \text { sp. nov. } \\
& \text { urn:1sid:zoobank.org:act:3409E2F9-90A8-41A5-869B-F80B553ED136 }
\end{aligned}
$$

Figs $12-13,43 \mathrm{D}$

\section{Diagnosis}

Zaitunia minoica sp. nov. differs from other species of its group by having a longer embolus gradually curved in the subapical part, and by the receptacles subequal in size with widely spaced (more than 


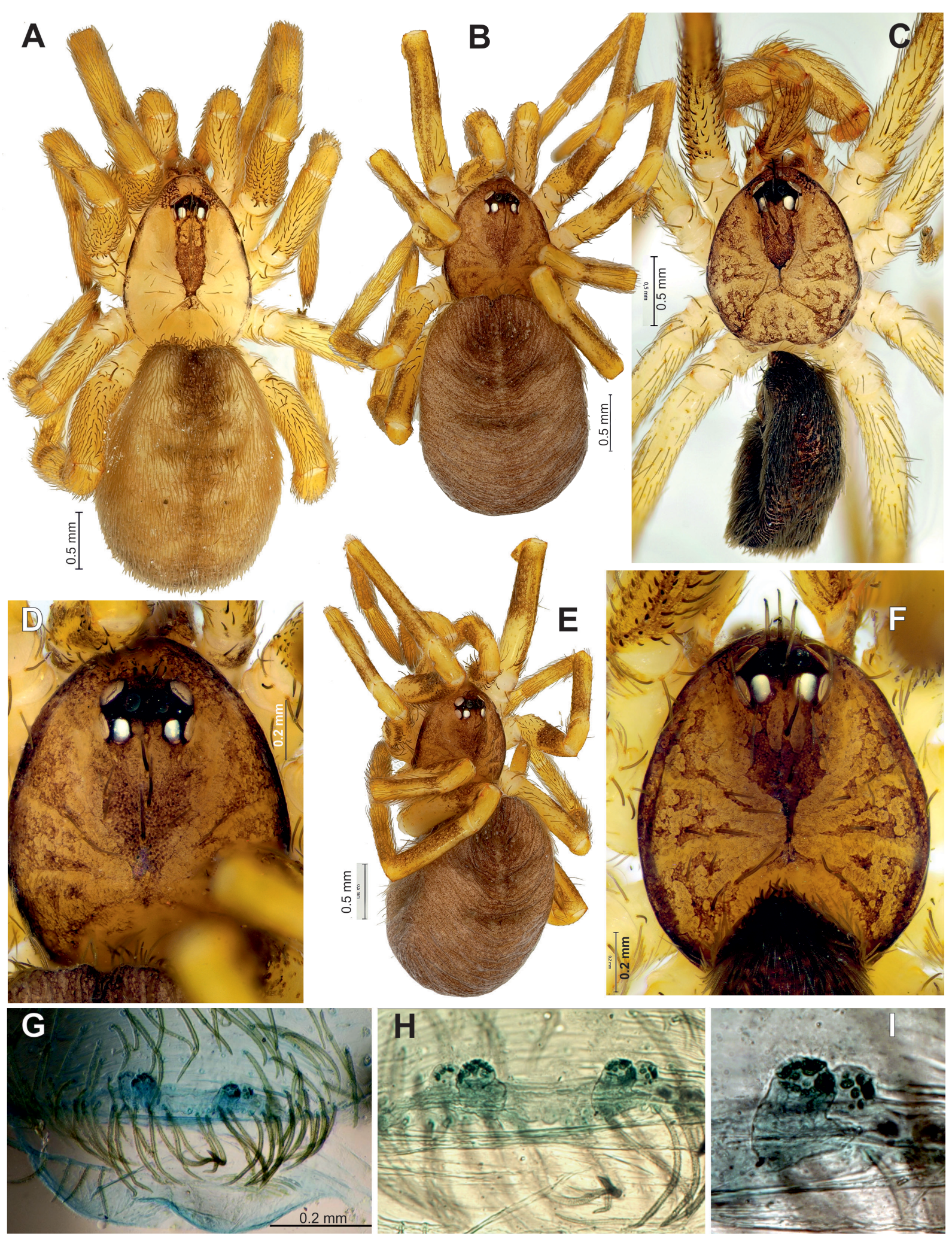

Fig. 12. Somatic characters and endogyne of Zaitunia minoica sp. nov., paratypes, $q$ ( $(\mathbf{A}-\mathbf{B}, \mathbf{D}-\mathbf{E}, \mathbf{G}-\mathbf{I})$ and holotype, $\widehat{o}(\mathbf{C}, \mathbf{F})$. - A-C. Habitus, dorsal. D, F. Prosoma, dorsal. E. Habitus, dorso-sublateral. G-H. Endogyne, dorsal. I. Right pair of receptacles, dorsal. Scale bars: A-C, E $=0.5 \mathrm{~mm}$; D, F-G $=$ $0.2 \mathrm{~mm}$. 


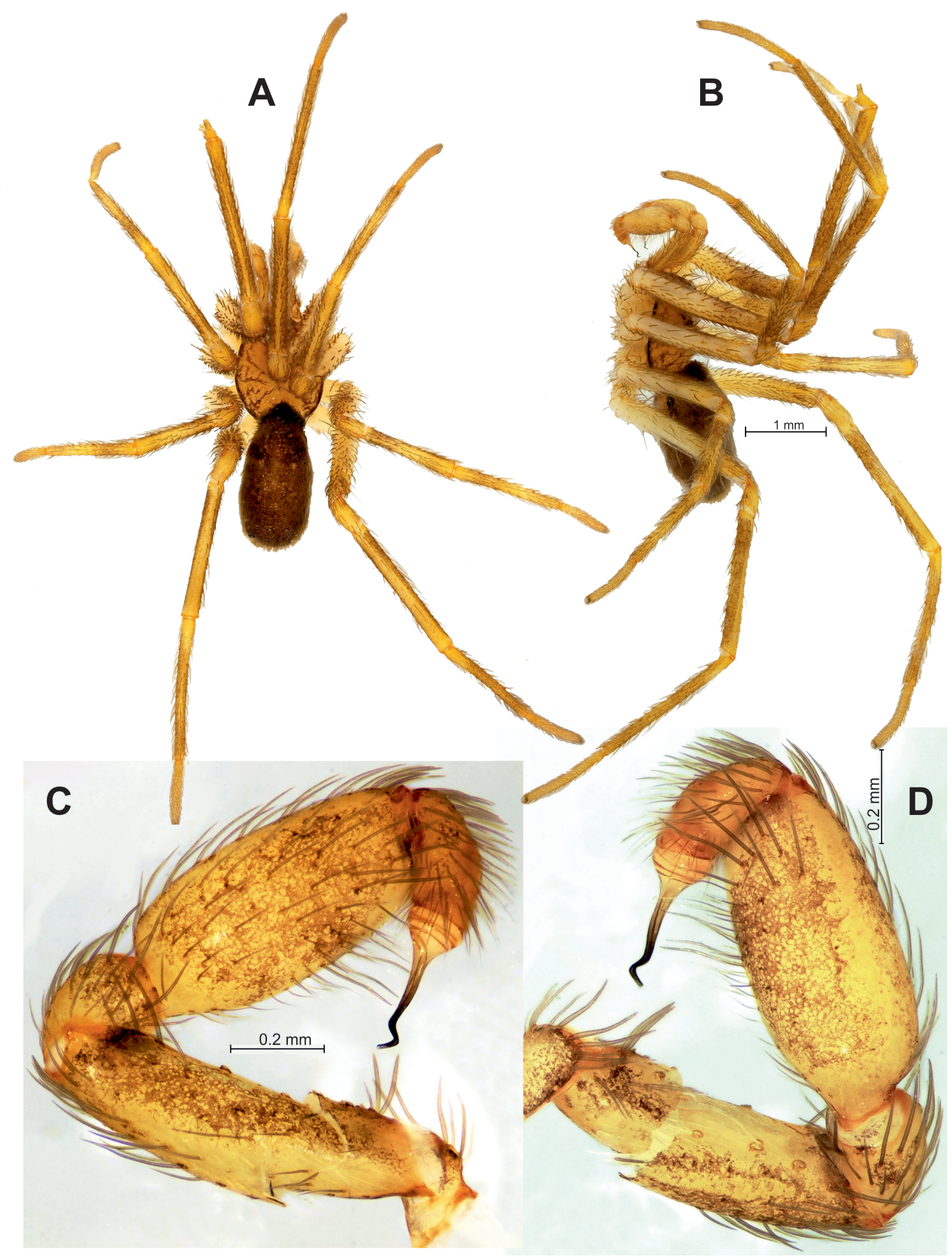

Fig. 13. Somatic characters and palp of Zaitunia minoica sp. nov., holotype, $\widehat{\partial}$. A-B. Habitus, dorsal and lateral. C-D. Palp, pro- and retrolateral. Scale bars: A-B $=1.0 \mathrm{~mm}$. C-D $=0.2 \mathrm{~mm}$. 
2 diameters) median pair (in Z. annulipes, the embolus is noticeably shorter and more gently curved, and the median receptacles are considerably larger than the outer ones; whereas in Z. kunti sp. nov., the slightly shorter embolus is more sharply curved subapically, and the receptacles are close together (about 1.5 of their diameter) - cf. Figs 9, 10F-G, I).

\section{Etymology}

The specific epithet is given after the Minoan civilisation, which flourished during the Bronze Age in Crete.

\section{Material examined}

Holotype

GREECE: ${ }^{\Uparrow}$, Crete Isl., Gouves 16 km E of Iraklion, 1 May 2008, H. Eikamp \& U. Kluge (SMF).

Paratypes $(5 \hat{\jmath} \widehat{\partial}, 16$ 우)

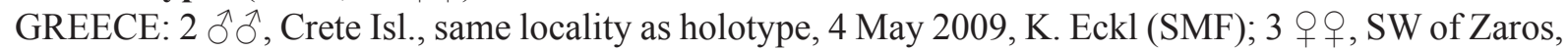
5 Apr. 1958, H. Kahmann (SMF); 1 q, W of Camaris, 600-800 m, 6 Apr. 1958, H. Kahmann (SMF); 2 우, Gortys near Ajil Deka, 85-100 m, 9 Apr. 1958, H. Kahmann (SMF); 1 ô, 2 우, same, 11 Apr.

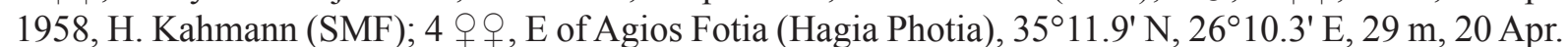

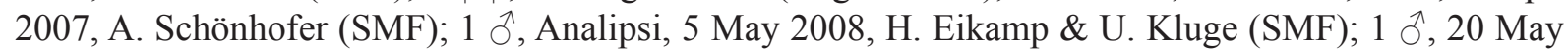
2009, K. Eckl (SMF); 1 +, Kastri-Arvi, 3 May 2009, K. Eskl (SMF); 1 , Kavousi, 10 May 2009, H. Eikamp \& U. Kluge (SMF); 1 \&, Arvi, Keratokampos, 11 May 2009, K. Esk1 \& U. Kluge (SMF); 1 , , Anogia, 30 km SW of Iraklion, 17 May 2010, K. Eskl \& H. Eikamp (SMF).

\section{Description}

Male (holotype)

Habitus. See Figs 12C, 13A-B.

BoDy LENGTH. 2.97.

CoLour. Carapace dark ochre-yellow, with brownish clypeus, narrow marginal bands, postocular area and radial grooves; eye tubercle brownish-black; labium, sternum and maxillae yellow; chelicerae, palps and legs yellow with diffuse brownish spots and fasciae; abdomen uniformly dark brown.

Carapace (Fig. 12F). 1.35 long, 1.08 wide.

Eyes. AME 0.09, ALE 0.13, PLE 0.12, PME 0.10, AME-AME 0.06.

PaLP (Figs 13C-D, 43D). Femur as long as tibia; tibia 1.5 times thicker than femur. Cymbium moderately long and slightly curved, without dorsal hump. Tegulum globular. Embolus long, gradually tapering near base and with parallel margins in mid-part, spermophore in embolus straight, tip of embolus screwshaped.

LEG MEASUREMENTS. $\widehat{\jmath}(+)$

\begin{tabular}{lcccccc}
\hline & Femur & Patella & Tibia & Metatarsus & Tarsus & Total \\
\hline Palp & $0.86(0.73)$ & $0.25(0.34)$ & $0.67(0.55)$ & - & $0.29(0.63)$ & $2.07(2.25)$ \\
I & $2.02(1.85)$ & $0.57(0.58)$ & $2.20(1.87)$ & $2.11(1.51)$ & $1.38(1.08)$ & $8.28(6.89)$ \\
II & $1.59(1.38)$ & $0.46(0.54)$ & $1.53(1.22)$ & $1.52(1.03)$ & $1.03(0.78)$ & $6.13(4.95)$ \\
III & $1.37(1.22)$ & $0.44(0.51)$ & $1.29(0.83)$ & $1.53(0.97)$ & $0.72(0.61)$ & $5.35(4.14)$ \\
IV & $1.95(1.57)$ & $0.51(0.57)$ & $1.94(1.28)$ & $2.07(1.28)$ & $1.10(0.76)$ & $7.57(5.46)$ \\
\hline
\end{tabular}


Female (paratype from Gortys)

Habitus. See Fig. 12A.

BODY LENGTH. 3.87.

CoLour. As in male, but abdomen dorsally, carapace margins and fasciae on palps and legs are somewhat darker.

CARAPACE. 1.63 long, 1.31 wide.

Eyes. AME 0.09, ALE 0.15, PLE 0.14, PME 0.10, AME-AME 0.05.

ENDOGYNE (Fig. 12G-I). Both pairs of receptacles subglobular, median pair slightly elongate. Median and lateral receptacles close together. Median receptacles separated by more than 2 diameters.

\section{Variation}

Carapace length in males varies from 1.25 to 1.47 , in females from 1.40 to 1.65 . Some specimens have less contrast, with a darker and more diffuse coloration (Fig. 12B, D-E).

\section{Ecology}

According to the label data, the species inhabits rocky slopes from seashore to $800 \mathrm{~m}$, covered by shrubs and steppe vegetation, where spiders occur under the stones.

\section{Distribution}

Known only from Crete (Fig. 46).

\section{Zaitunia persica species group}

\section{Remarks}

The group unites almost uniformly light-coloured species with females possessing only one pair of receptacles (entire or subdivided). Males and their characters are unknown for this group. Six members are included: Z. afghana (Roewer, 1962) from Afghanistan, and five species from Iran: Z. akhanii Marusik \& Zamani, 2015, Z. alexandri Brignoli, 1982, Z. brignoliana sp. nov., Z. medica Brignoli, 1982 and Z. persica Brignoli, 1982.

\section{Key to species of the Zaitunia persica species group}

(Only females; males of all included species are unknown.)

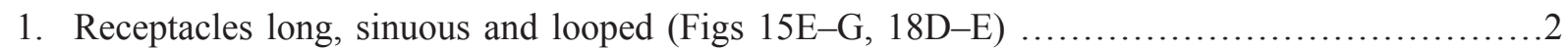

- Receptacles short, without loops (Figs 14G-K, 16A-B, D-F, 17D, F-J) ........................

2. Receptacles longer, with four loops (Fig. 18D-E); southern Iran ......... persica Brignoli, 1982

- Receptacles shorter, with two loops (Fig. 15E-G); northern Iran

Z. akhanii Marusik \& Zamani, 2015

3. Receptacles undivided (Figs 16A, D, 17D, F-J) ......................................

- Receptacles subdivided (Figs 14G-K, 16D-F) ..........................................

4. Receptacles longer, sac-shaped (Fig. 16A-B); southern Iran......... alexandri Brignoli, 1982

- Receptacles shorter, knob-shaped (Fig. 17D, F-J), central Iran ............ medica Brignoli, 1982 
5. Receptacles with stems and subdivided dumbbell-shaped head (Fig. 14G-K); Afghanistan

- Receptacles without stems, boomerang-shaped (Fig. 16D-F); Iran Z. brignoliana sp. nov.

Zaitunia afghana (Roewer, 1962)

Fig. 14

Filistata afghana Roewer, 1962: 12 (P). Note: figs 6 and 9 labeled as F. afghana refer to Z. huberi sp. nov.

Zaitunia afghana - Zonstein et al. 2013: 69 (transfer from Filistata).

\section{Diagnosis}

Zaitunia afghana can easily be distinguished from other species of the group, except Z. brignoliana sp. nov., by having the receptacles subdivided apically and with a distinct stem (the receptacles are undivided in most other species and a stem is lacking; in Z. brignoliana sp. nov., the subdivided receptacles are wider - cf. Fig. 16D-F).

\section{Material examined}

\section{Holotype}

AFGHANISTAN: 9 , Helmand Province, Tchehel Dokhteran Cave, Kouh-Ghoramban, near Tchongoulak,

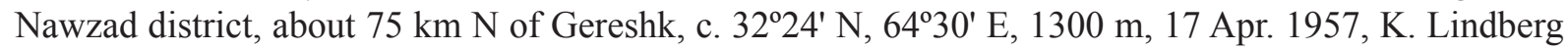
(ZMLS L57/3752, A.206; examined). Almost all legs except left legs I and IV are partially missing in the holotype. Paratype of $F$. afghana actually belongs to $Z$. huberi sp. nov.

\section{Description}

\section{Female}

Habitus. See Fig. 14A-B, D.

Body LENGTH. 6.20.

Colour. Whole body and legs light brownish-yellow, carapace with darker brown clypeus (however, with lighter yellow median stripe), long but narrow median spot dilated anteriorly; eye tubercle and narrow bands along carapace margins dark brown; chelicerae with narrow median brownish stripes; palpal and leg femora with narrow and incomplete light brown fasciae; abdomen without dorsal pattern.

CARAPace (Fig. 14C). 2.52 long, 1.90 wide.

Eyes. AME 0.09, ALE 0.21, PLE 0.18, PME 0.17, AME-AME 0.04.

Endogyne (Fig. 14G-K). Receptacles with distinct stem and dumbbell-shaped transversal head. Pores cover only the head. Heads separated by distance of twice their diameters.

LEG MEASUREMENTS.

\begin{tabular}{lcccccc}
\hline & Femur & Patella & Tibia & Metatarsus & Tarsus & Total \\
\hline Palp & 1.55 & 0.63 & 0.89 & - & 0.98 & 4.05 \\
I & 3.29 & 0.95 & 3.23 & 2.74 & 1.65 & 11.86 \\
II & 2.52 & 0.86 & - & - & - & - \\
III & 1.88 & 0.80 & - & - & - & - \\
IV & 2.78 & 0.93 & 2.07 & 2.00 & 1.13 & 8.91 \\
\hline
\end{tabular}




\section{Male}

Unknown.

\section{Remarks}

During the present study, we found that Roewer (1962) erroneously assigned two different species of Zaitunia, almost indistinguishable from each other by habitus, to the type series. Hence, we redescribe the holotype, but the paratype of Filistata afghana, previously redescribed by Zonstein et al. (2013), is considered to represent a new species, Z. huberi sp. nov., listed and described below.
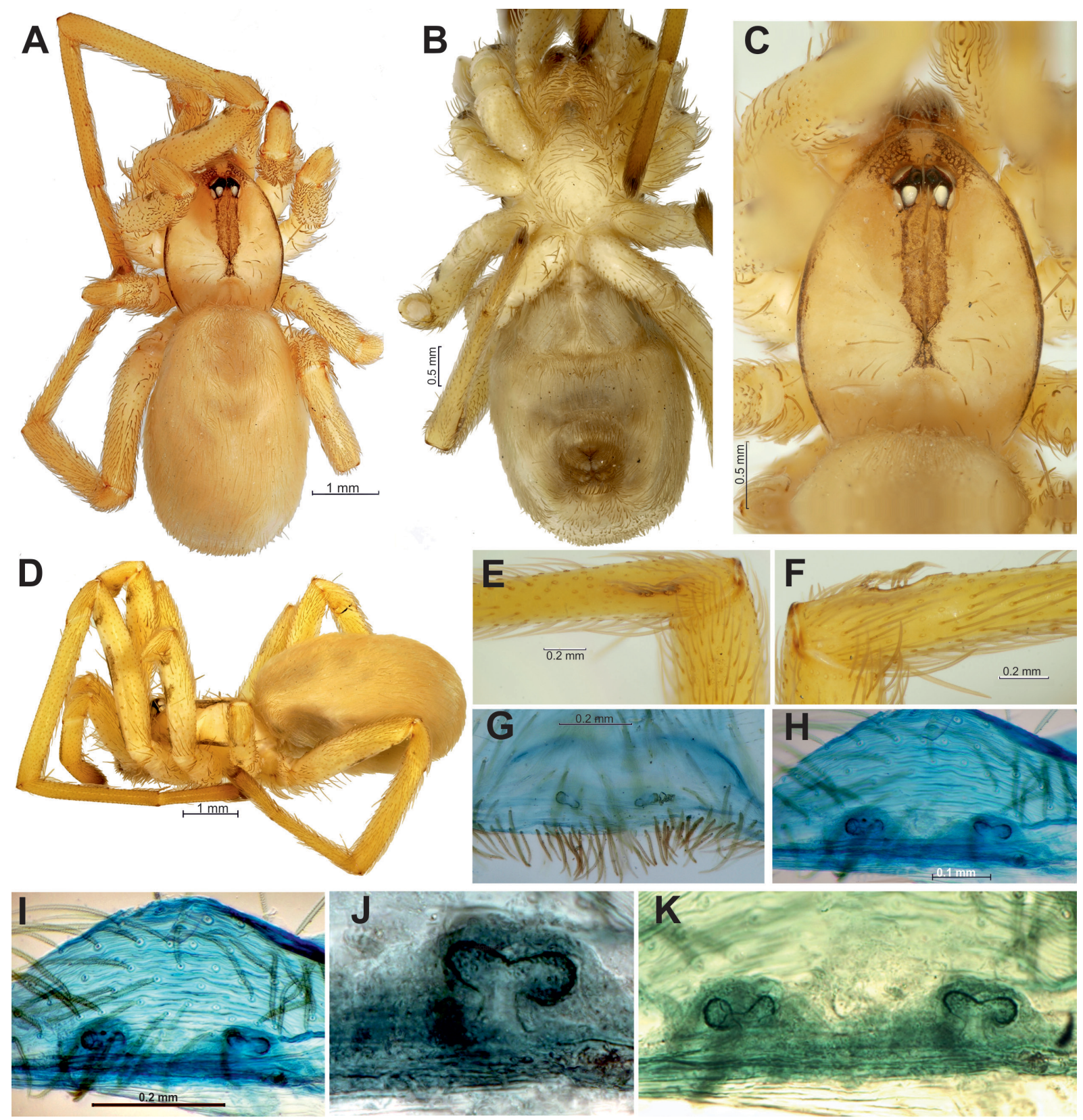

Fig. 14. Somatic characters and endogyne of Zaitunia afghana (Roewer, 1962), holotype, + . A-B. Habitus, dorsal and ventral. C. Prosoma, dorsal. D. Habitus, lateral. E-F. Calamistrum from above and lateral. G-I, K. Endogyne, dorsal. J. Right receptacle, dorsal. Scale bars: A, D = $1.0 \mathrm{~mm}$; $\mathrm{B}-\mathrm{C}=0.5 \mathrm{~mm} ; \mathrm{E}-\mathrm{G}, \mathrm{I}=0.2 \mathrm{~mm} ; \mathrm{H}=1.0 \mathrm{~mm}$. 


\section{Ecology}

According to the label data, the holotype was collected in a cave; other information is not available.

\section{Distribution}

Known only from the type locality (Fig. 47).

\section{Zaitunia akhanii Marusik \& Zamani, 2015}

Fig. 15

Zaitunia akhanii Marusik \& Zamani, 2015: 129, figs 4a-f(P).

\section{Diagnosis}

Females of $Z$. akhanii resemble those of $Z$. persica Brignoli, 1982 by having sinuous tube-like receptacles, but the receptacles of $Z$. akhanii have two loops, whereas those of Z. persica have four.

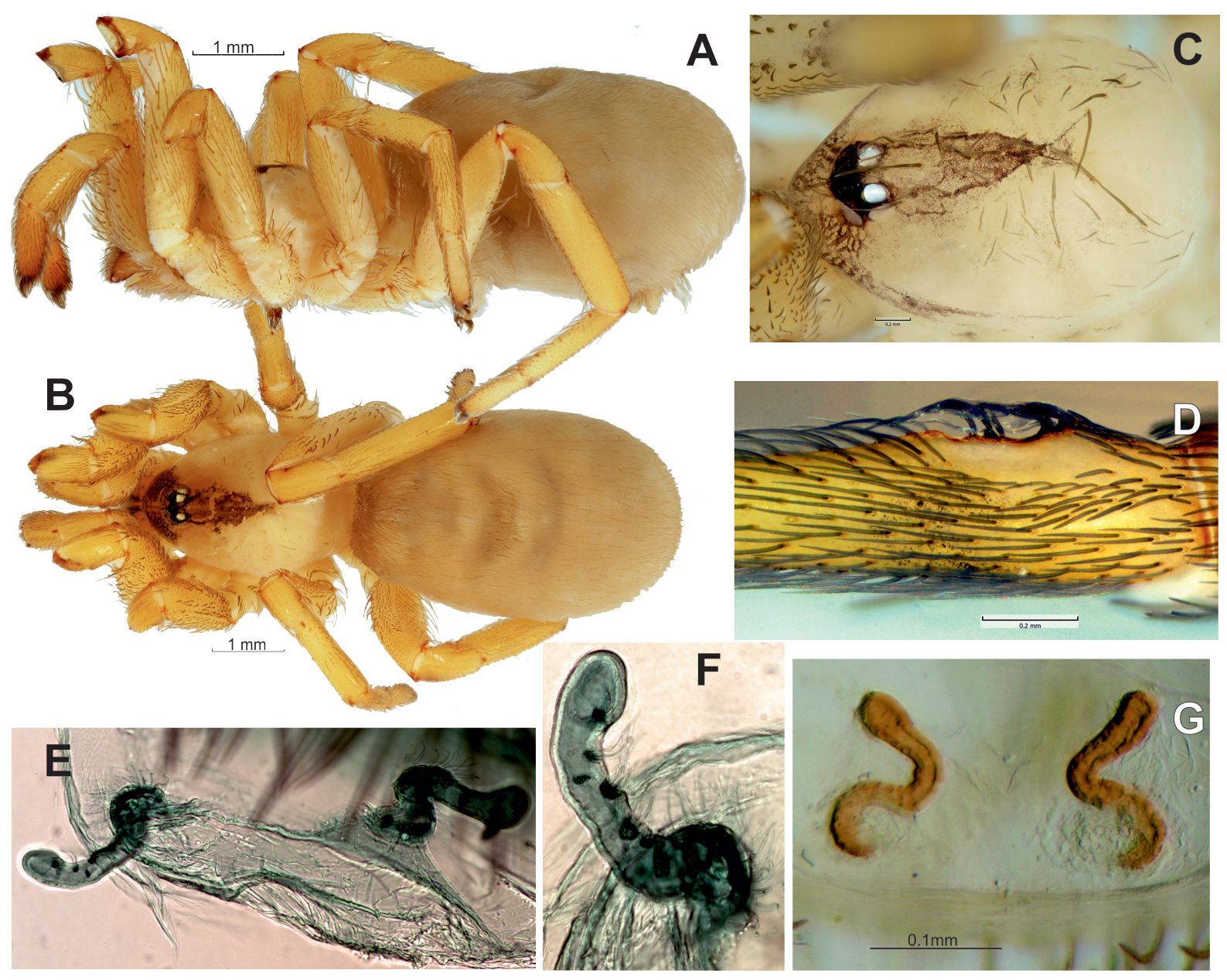

Fig. 15. Somatic characters and endogyne of Zaitunia akhanii Marusik \& Zamani, 2015, holotype, q. A-B. Habitus, lateral and dorsal. C. Prosoma, dorsal. D. Calamistrum lateral. E, G. Endogyne, dorsal. F. Left receptacle, ventral. Scale bars: A-B $=1.0 \mathrm{~mm} ; \mathrm{C}-\mathrm{D}=0.2 \mathrm{~mm} ; \mathrm{G}=0.1 \mathrm{~mm}$. 


\section{Material examined}

\section{Holotype}

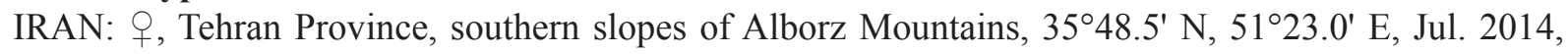
A. Zamani (SMF).

\section{Paratypes}

IRAN: 7 우, same data as holotype (ZMMU, ZMUT).

\section{Description}

Female (paratype)

Habitus. See Fig. 15A-B.

BODY LENGTH. 5.20.

CoLour. Light yellowish, with distinct pattern on carapace and legs: clypeus entirely dark, wide dark median band terminating near fovea; femora I-III with median-ventral spot. Abdomen uniformly yellowish-grey, without darker pattern.

CARAPACE (Fig. 15C). 2.16 long, 1.60 wide.

Eyes. AME 0.09, ALE 0.16, PLE 0.11, PME 0.12, AME-AME 0.03.

Endogyne (Fig. 15E-G). With one pair of sinuous tube-like receptacles. Receptacles wavy, bent twice, gland pores not distinct in low magnification but easily visible after contrast coloring (Fig. 15F); pores distributed evenly along receptacle while absent on heads. Receptacles spaced in mid-part by more than 4 diameters.

Leg MeASUREMENTS. Paratype + .

\begin{tabular}{lcccccc}
\hline & Femur & Patella & Tibia & Metatarsus & Tarsus & Total \\
\hline Palp & 1.20 & 0.60 & 0.68 & - & 0.80 & 3.28 \\
I & 3.12 & 0.80 & 2.28 & 2.00 & 1.20 & 9.40 \\
II & 1.76 & 0.72 & 1.48 & 1.44 & 0.88 & 6.28 \\
III & 1.52 & 0.60 & 1.20 & 1.20 & 0.76 & 5.28 \\
IV & 2.08 & 0.80 & 1.68 & 1.68 & 0.88 & 7.12 \\
\hline
\end{tabular}

Male

Unknown.

\section{Variation}

Total body length 4.80-7.20. Pale specimens may have light clypeus and may lack spots on femora.

\section{Ecology}

Specimens were found in large, dusty cribellate webs made around human dwellings.

\section{Distribution}

Known only from the type locality in Tehran (Fig. 47). 


\section{Zaitunia alexandri Brignoli, 1982}

Fig. 16A-B

Zaitunia alexandri Brignoli, 1982: 74, fig. 15 ().

Zaitunia alexandri - Marusik \& Zamani 2015: 131, fig. 5b ().

\section{Diagnosis}

By structure of the endogyne, Z. alexandri resembles Z. medica, but differs from it and all other congeners by their entire, relatively short and robust sac-shaped receptacles (Fig. 16A-B).
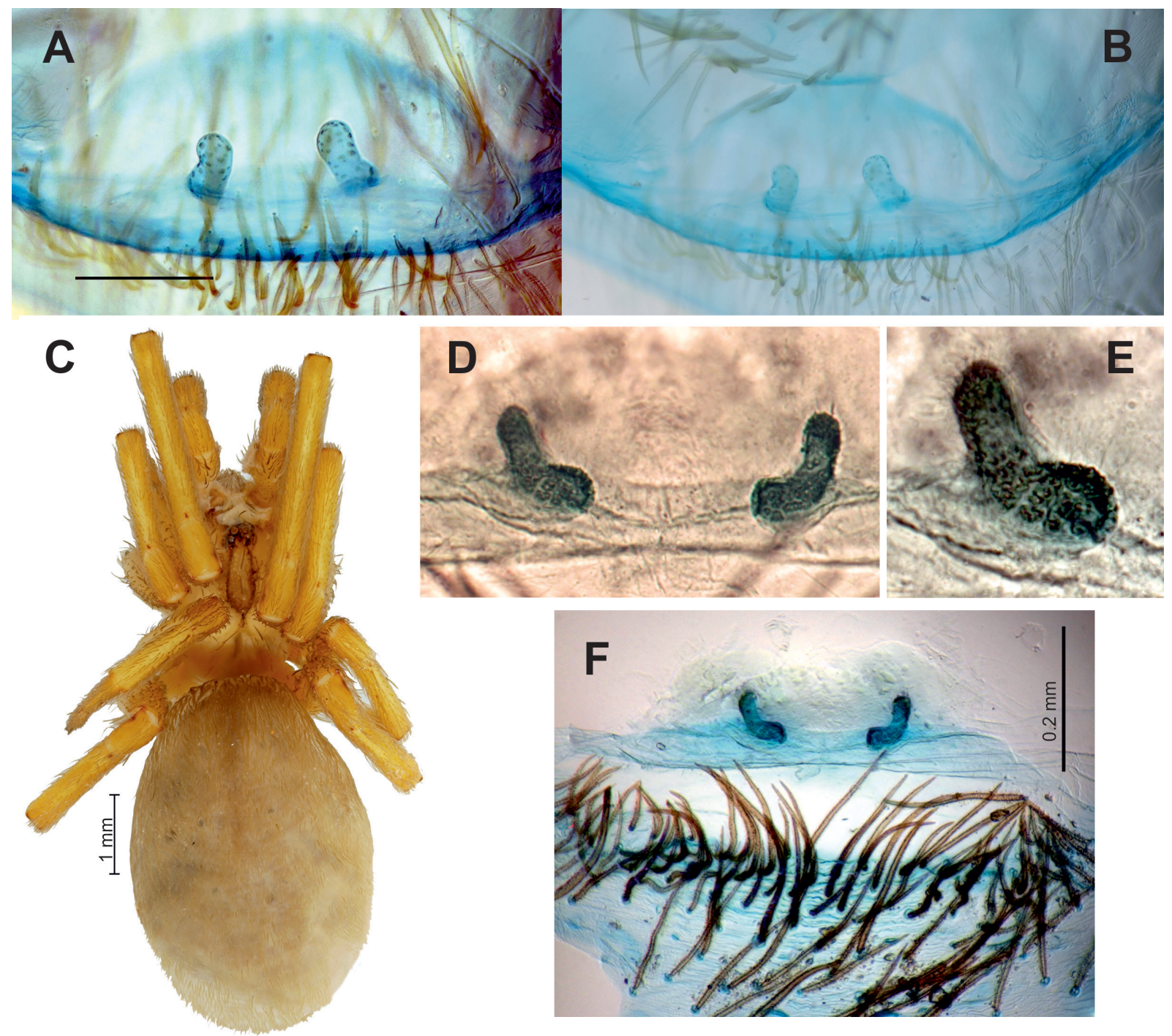

Fig. 16. Zaitunia alexandri Brignoli, 1982 (A-B) and Z. brignoliana sp. nov. (C-F), holotype; 우우, habitus and structure of endogyne. - A-B, D, F. Endogyne, dorsal. C. Habitus, dorsal. E. Left receptacle, dorsal. Scale bars: A, F $=0.2 \mathrm{~mm} ; \mathrm{C}=1.0 \mathrm{~mm}$. 


\section{Material examined}

\section{Holotype}

IRAN: +, Fars Province, vicinity of Kuhenjan, 29 ${ }^{\circ} 14^{\prime}$ N, 5257' E, 1500 m, 27 May 1976, S. Zerunian (MSNV).

\section{Description}

\section{Female}

BODY LENGTH. 5.32.

CoLour. Carapace, chelicerae, labium and sternum pale yellowish-brown, carapace with darker brownish margins, clypeus and postocular area; eye tubercle dark brown; palps and legs with weak, diffuse darker brown spots; abdomen uniformly greyish-yellow.

CARAPaCe. 1.68 long, 1.33 wide.

Eyes. AME 0.08, ALE 0.15, PLE 0.12, PME 0.10, AME-AME: 0.05.

Endogyne (Fig. 16A-B). Receptacles sac-like, with cylindrical body and rounded tip, not corrugated; gland pores distributed evenly and not forming clusters. Receptacles separated by 2.5 diameters.

LEG MEASUREMENTS.

\begin{tabular}{lcccccc}
\hline & Femur & Patella & Tibia & Metatarsus & Tarsus & Total \\
\hline Palp & 1.05 & 0.44 & 0.58 & - & 0.81 & 2.95 \\
I & 1.82 & 0.65 & 1.68 & 1.42 & 0.98 & 6.91 \\
II & 1.31 & 0.56 & 1.02 & 0.96 & 0.71 & 5.11 \\
III & 1.10 & 0.52 & 0.89 & 0.85 & 0.58 & 4.46 \\
IV & 1.62 & 0.70 & 1.32 & 1.18 & 0.65 & 6.04 \\
\hline
\end{tabular}

Male

Unknown.

Distribution

Known only from the type locality (Fig. 47).

Zaitunia brignoliana sp. nov. urn:1sid:zoobank.org:act:3E52AB5D-C6E9-44C0-AF4C-CE5975C739A4

Fig. 16C-F

\section{Diagnosis}

Zaitunia brignoliana sp. nov. is easily distinguished from other species of the group, except Z. afghana, by having boomerang-shaped receptacles subdivided into two lobes and lacking a stem (undivided in most other members; whereas $Z$. afghana have a distinct stem and the receptacles are dumbbell-shaped - cf. Figs 16D-F and 14G-K, respectively).

\section{Etymology}

The specific epithet is given after the prominent Italian arachnologist Paolo Marcello Brignoli (19421986) who described three species of Zaitunia from Iran. 


\section{Material examined}

\section{Holotype}

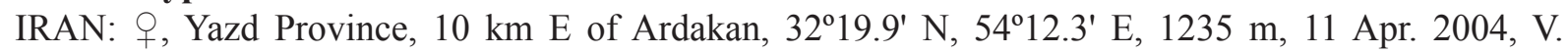
Vignoli \& P. Crucitti (SMF).

\section{Description}

\section{Female}

Habitus. See Fig. 16C.

BODY LENGTH. 2.54.

CoLour. Carapace, chelicerae and legs mostly medium brownish-yellow; abdomen dorsally, diffuse leg fasciae, cephalic area and reticulate clypeal pattern medium violet-brown; eye tubercle and carapace margins dark violet-brown; sternum light yellow with brownish margins; abdomen ventrally and spinnerets light violet-brown.

Carapace. 1.13 long, 0.94 wide.

EyEs. AME 0.06, ALE 0.11, PLE 0.09, PME 0.07, AME-AME 0.03.

ENdOGYNE (Fig. 16D-F). Receptacles without stems, boomerang-shaped, wider than high; whole receptacle densely covered by glandular pores; inner margins of receptacle bases separated by 4 diameters.

LEG MEASUREMENTS.

\begin{tabular}{lcccccc}
\hline & Femur & Patella & Tibia & Metatarsus & Tarsus & Total \\
\hline Palp & 0.55 & 0.27 & 0.36 & - & 0.50 & 1.68 \\
I & 1.17 & 0.41 & 1.14 & 0.95 & 0.80 & 4.47 \\
II & 0.91 & 0.39 & 0.69 & 0.65 & 0.58 & 3.22 \\
III & 0.76 & 0.32 & 0.54 & 0.56 & 0.46 & 2.64 \\
IV & 1.03 & 0.38 & 0.81 & 0.79 & 0.54 & 3.55 \\
\hline
\end{tabular}

Male

Unknown.

\section{Distribution}

Known only from the type locality (Fig. 47).

Zaitunia medica (Brignoli, 1982)

Fig. 17

Zaitunia medica Brignoli, 1982: 72, fig. 16 ().

Zaitunia medica - Marusik \& Zamani 2015: 131, figs 5c-d (ㅇ).

\section{Material examined}

Holotype

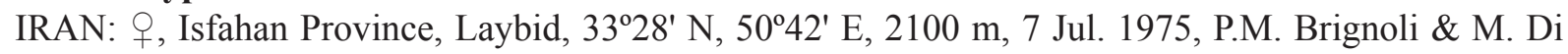
Rao (MSNV). 


\section{Paratype}

IRAN: 1 , same data as holotype.

\section{Diagnosis}

In structure of the vulva, females of $Z$. medica resemble those of $Z$. alexandri, but differ from them and all other congeners by their unpaired, very short and robust knob-shaped (transverse oval) receptacles (Fig. 17D, F-H).

\section{Description}

Female (holotype)

Habitus. See Fig. 17A-B.

Body LENGTH. C. 8.00 (pro- and opisthosoma are separate).

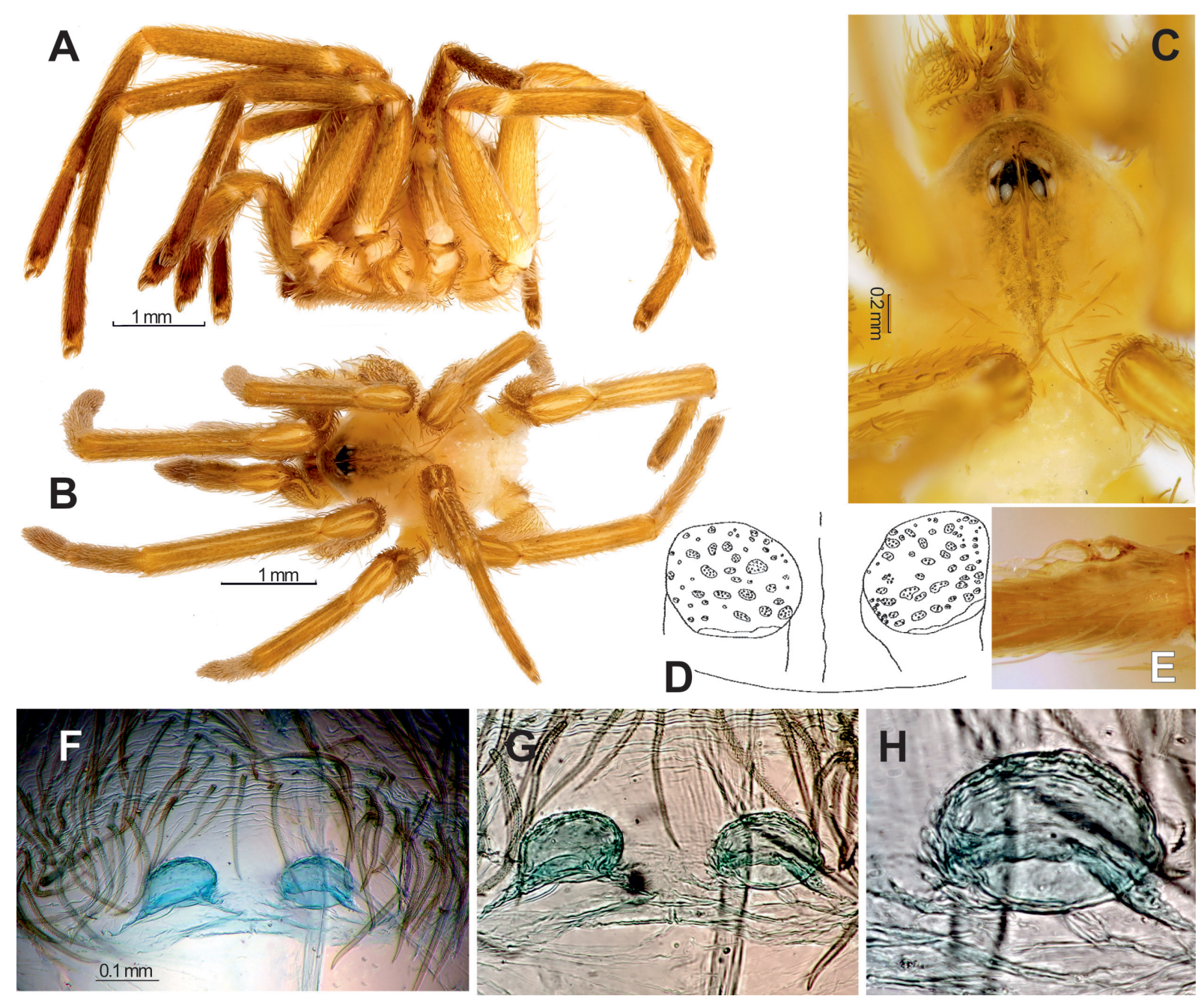

Fig. 17. Somatic characters and endogyne of Zaitunia medica Brignoli, 1982, holotype, $q$. A. Prosoma, lateral. B-C. Prosoma, dorsal. D, F-G. Endogyne, dorsal (D: after Brignoli 1982). E. Calamistrum, dorsal. H. Right receptacle, dorsal. Scale bars: A, B $=1.0 \mathrm{~mm} ; \mathrm{C}=0.2 \mathrm{~mm} ; \mathrm{F}=0.1 \mathrm{~mm}$. 
CoLour. Whole spider pale brownish-yellow; eye tubercle brownish-black; chelicerae and distal segments of legs I-IV light reddish-brown; carapace (except clypeus) and abdomen without discernible pattern.

Carapace (Fig. 17C). 3.04 long, 2.36 wide.

Eyes. AME 0.10, ALE 0.21, PLE 0.18, PME 0.17, AME-AME 0.07.

EndogYNe (Fig. 17F-H). Receptacles hemispherical to transverse oval, wider than high, separated by their width, covered by a few fine pores (Fig. 17D).

LEG MEASUREMENTS (holotype).

\begin{tabular}{lcccccr}
\hline & Femur & Patella & Tibia & Metatarsus & Tarsus & \multicolumn{1}{c}{ Total } \\
\hline Palp & 1.40 & 0.81 & 0.98 & - & 1.17 & 4.36 \\
I & 3.17 & 1.18 & 2.89 & 2.82 & 1.76 & 11.82 \\
II & 2.50 & 1.04 & 2.01 & 1.98 & 1.31 & 8.84 \\
III & 2.12 & 0.82 & 1.51 & 1.54 & 0.93 & 6.92 \\
IV & 2.82 & 1.11 & 2.42 & 2.37 & 1.30 & 10.02 \\
\hline
\end{tabular}

\section{Note}

It is worth noting that Brignoli (1982) illustrated a more elongate receptacle with a stem that had distinct pores on the top, whereas the examined holotype has receptacles lacking a stem and covered with less distinct pores.

\section{Male}

Unknown.

\section{Distribution}

Known only from the type locality (Fig. 47).

Zaitunia persica Brignoli, 1982

Fig. 18

Zaitunia persica Brignoli, 1982: 70, figs 13-14 (ㅇ).

Zaitunia persica - Marusik \& Zamani 2015: 133, fig. 5a (†).

\section{Diagnosis}

Females of $Z$. persica resemble those of $Z$. akhanii by having sinuous, tube-like receptacles, but $Z$. persica has four loops (or bends), whereas $Z$. akhanii has only two loops.

\section{Material examined}

\section{Holotype}

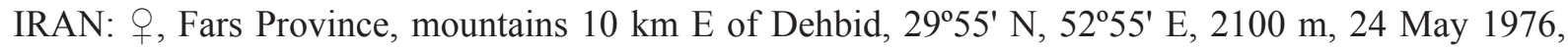
P.M. Brignoli (MSNV).

\section{Paratype}

IRAN: 1 , same data as holotype. 


\section{Description}

Female (holotype)

Habitus. See Fig. 18A.

Body Length. 5.90.

Colour. Carapace and chelicerae brownish-yellow; carapace with brown to dark brown central area, clypeus and margins; eye tubercle brownish-black; maxillae, labium, sternum and leg coxae pale brownish-yellow; palps and legs medium brownish-yellow with incomplete brownish fasciae; abdomen uniformly pale yellowish-grey without darker pattern.

Carapace (Fig. 18B). 1.41 long, 1.23 wide.

Eyes. AME 0.07, ALE 0.14, PLE 0.13, PME 0.11, AME-AME 0.04.
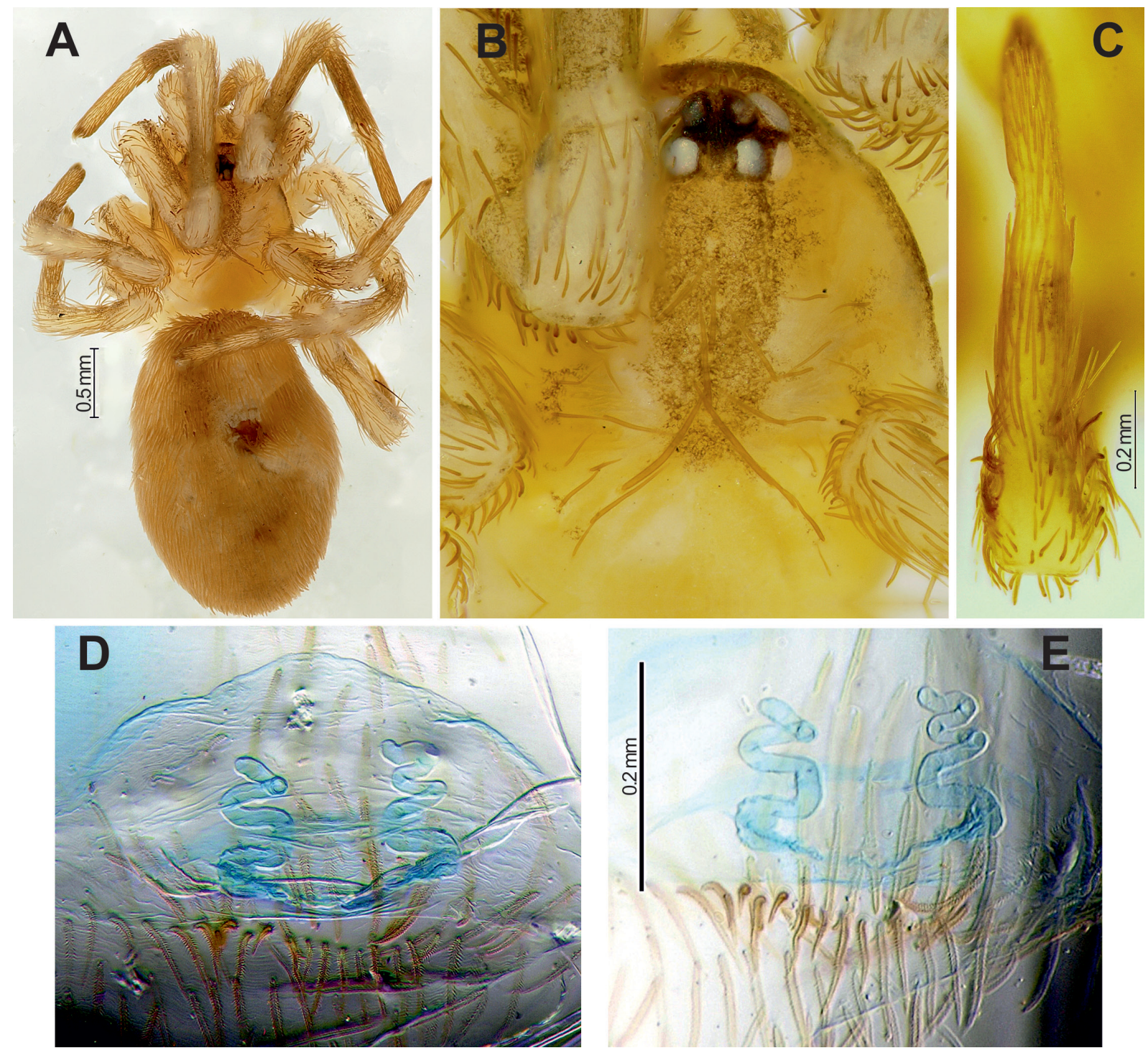

Fig. 18. Somatic characters and endogyne of Zaitunia persica Brignoli, 1982, holotype, $\circ$. A. Habitus, dorsal. B. Prosoma, dorsal. C. Metatarsus and tarsus IV, dorsal. D-E. Endogyne, dorsal. Scale bars: $\mathrm{A}=0.5 \mathrm{~mm} ; \mathrm{C}, \mathrm{E}=0.2 \mathrm{~mm}$. 
Endogyne (Fig. 18D-E). Receptacle long, cylindrical, tube-like, bent 4-5 times. Glandular pores indistinct.

LEG MEASUREMENTS (holotype).

\begin{tabular}{lcccccc}
\hline & Femur & Patella & Tibia & Metatarsus & Tarsus & Total \\
\hline Palp & 0.84 & 0.42 & 0.49 & - & 0.63 & 2.38 \\
I & 1.52 & 0.64 & 1.54 & 1.31 & 0.90 & 5.91 \\
II & 1.21 & 0.57 & 0.99 & 0.97 & 0.68 & 4.42 \\
III & 1.07 & 0.46 & 0.71 & 0.76 & 0.53 & 3.53 \\
IV & 1.48 & 0.61 & 1.23 & 1.08 & 0.61 & 5.01 \\
\hline
\end{tabular}

Male

Unknown.

\section{Distribution}

Known only from the type locality (Fig. 47).

\section{Zaitunia logunovi-group}

\section{Remarks}

This group includes only one light-coloured species. The dorsal body and legs with very weak darker pattern. Cymbium with brush of thick and dense setae on ventral and lateral edges (lacking in other groups). The cap-shaped tegulum is much shorter than the relatively long cymbium. The embolus is very short and twisted. The endogyne has two pairs of receptacles. The only member of this group, Z. logunovi sp. nov., is found in Kazakhstan and Kyrgyzstan.

\section{Zaitunia logunovi sp. nov. urn:1sid:zoobank.org:act:116A2332-4326-4AAE-9878-0827BC1CB330}

Figs 19-21, 42A-B, 43E

\section{Diagnosis}

Males of Z. logunovi sp. nov. differ from other congeners by a very short embolus directed forward (only Z. schmitzi possesses a similarly short embolus, but in the latter case the embolus is sidewarddirected, cf. Fig. 7A-D). The ventral brush of setae on the cymbium adjoining the bulb is more welldeveloped than in any other congener (cf. Figs 24C, 28G-I, 30I). Females are easily distinguished from all other female congeners except $Z$. annulipes and $Z$. halepensis sp. nov. by having long, non-divergent median receptacles considerably exceeding the small and globular lateral pair in size (Fig. 21). Females of Z. logunovi sp. nov. differ from those of Z. annulipes and Z. halepensis sp. nov. by the shape of their digitiform (not clublike) median receptacles, which are considerably thinner than in the two latter species (cf. Figs 5C-D, 9D-F).

\section{Etymology}

This species is named after our friend and colleague Dmitri Logunov (University of Manchester, Manchester, UK).

\section{Material examined}

\section{Holotype}

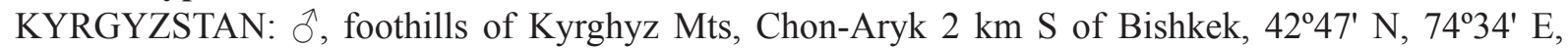
1100-1200 m, 20 May 1984, S.V. Ovchinnikov (TAU). 

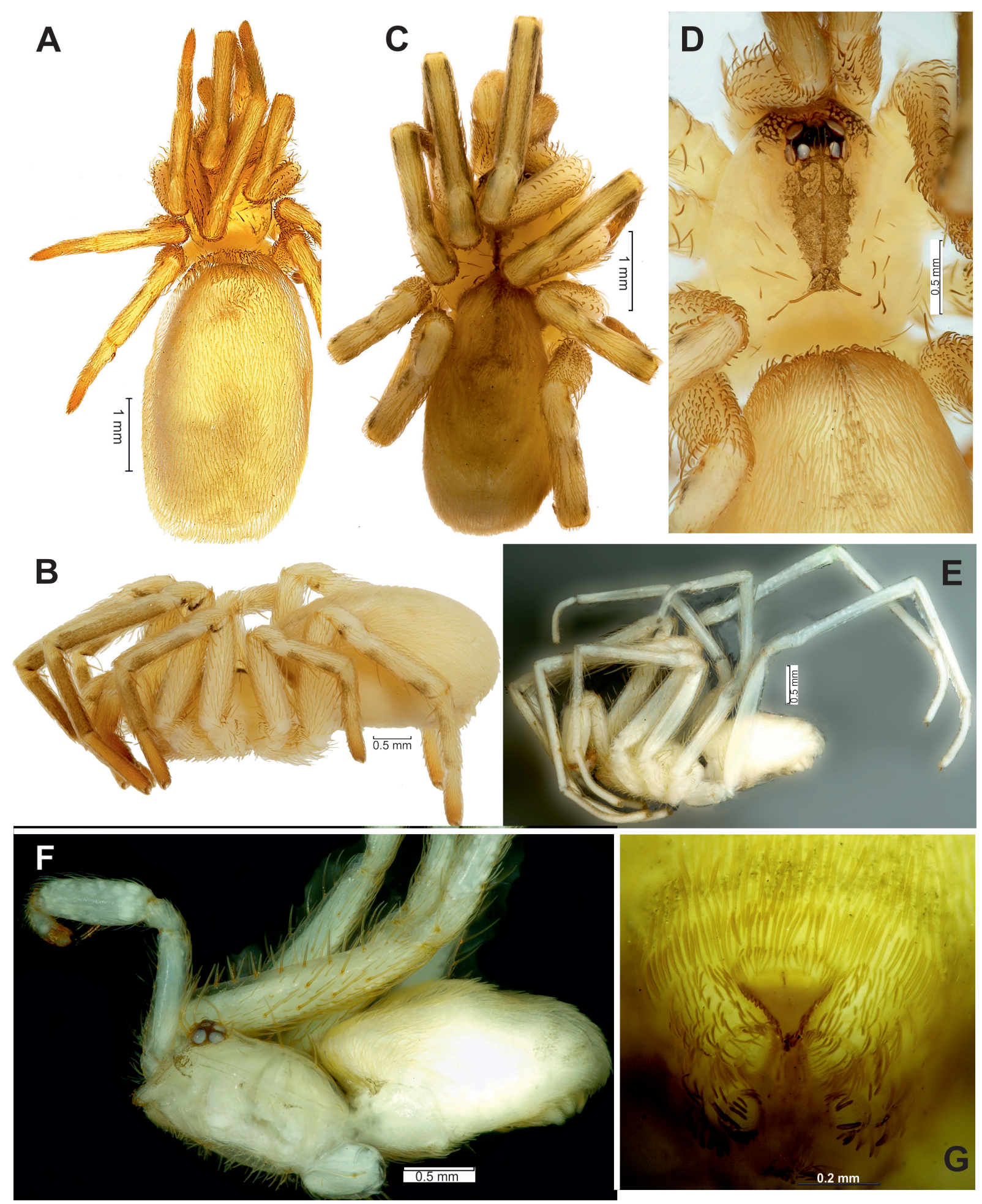

Fig. 19. Somatic characters of Zaitunia logunovi sp. nov., paratypes, $q$ ㅇ $(\mathbf{A}-\mathbf{D}, \mathbf{G})$, and holotype $(\mathbf{E})$ and paratype $(\mathbf{F}), \widehat{\jmath}$. - A, C. Habitus, dorsal. B, E-F. Same, lateral. D. Prosoma, dorsal. G. Spinnerets, ventral. Scale bars: $A, C=1.0 \mathrm{~mm} ; B, D-F=0.5 \mathrm{~mm} ; G=0.2 \mathrm{~mm}$. 


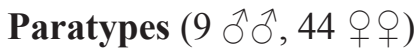

KYRGYZSTAN: 1 Oे, 8 우, same data as holotype.

KAZAKHSTAN: 6 우, $1 q$ subad., north-western foothills of Trans-Ili Mts, Argaity gorge, $4 \mathrm{~km} \mathrm{SE}$ of Akterek town, $43^{\circ} 15^{\prime}$ N, $75^{\circ} 25^{\prime}$ E, c. 1200 m, 22 May 1988, I.N. Smigunova (TAU); $3 \overbrace{}^{\lambda} \partial^{\lambda}$, surroundings
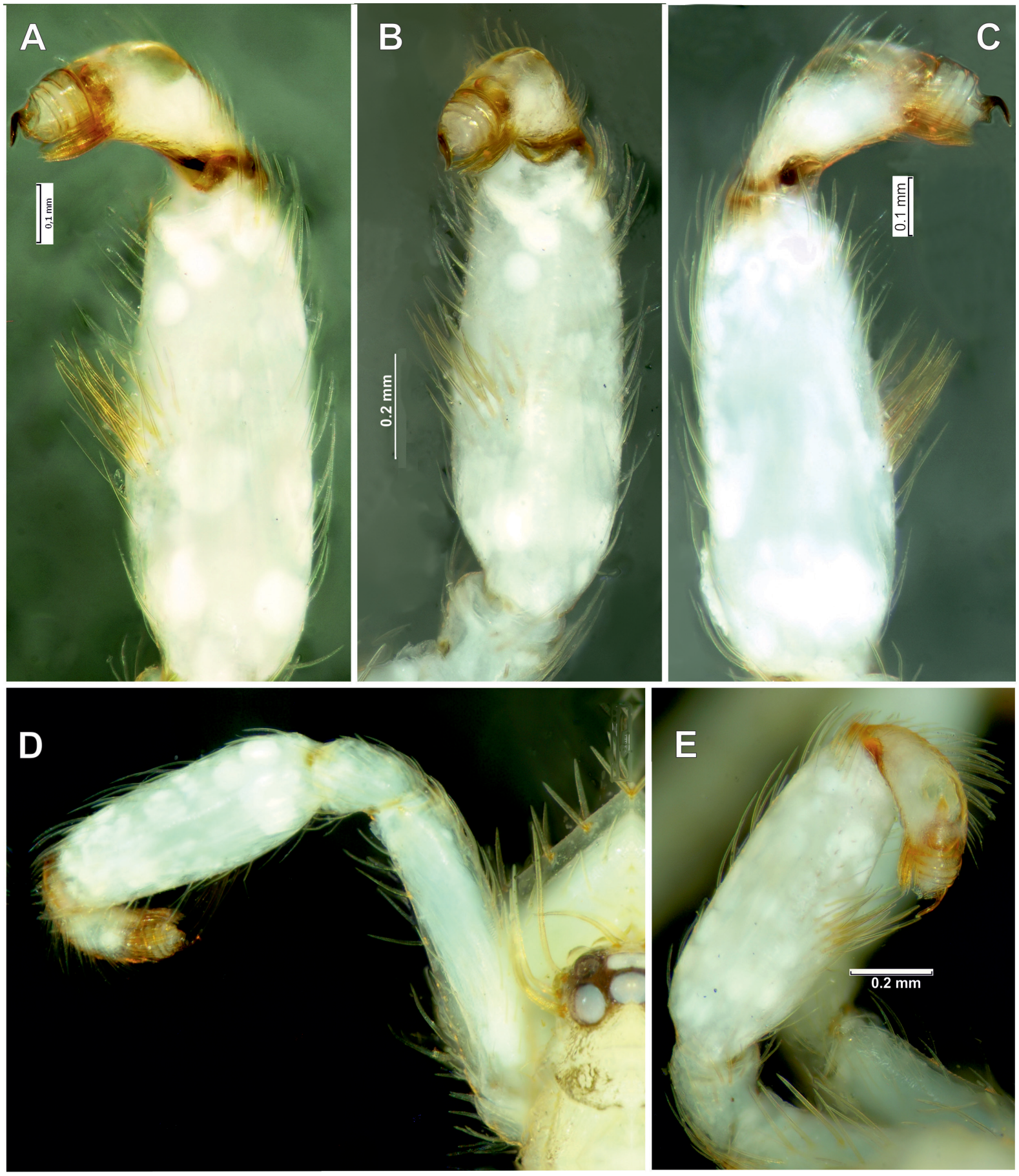

Fig. 20. Palp of Zaitunia logunovi sp. nov., paratype, đ. A-C. Terminal part, retrolateral, ventroretrolateral and prolateral. D-E. Entire palp, prolateral and proventral. Scale bars: A, C $=0.1 \mathrm{~mm}$; B, $\mathrm{E}=0.2 \mathrm{~mm}$. 


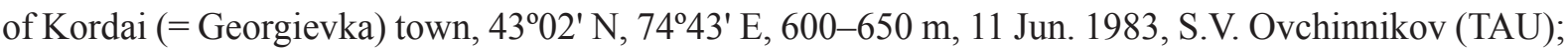

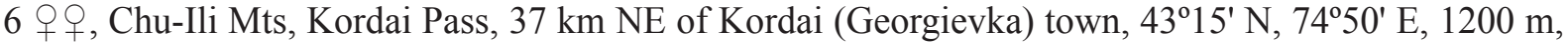

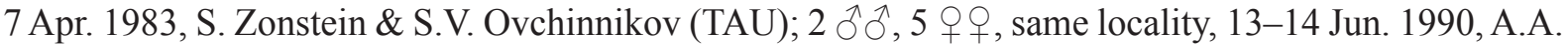
Feodorov \& A.A. Zyuzin (TAU); 10 우옹 same region, mountains $4-5 \mathrm{~km} \mathrm{~N}$ of Otar town, $43^{\circ} 32^{\prime} \mathrm{N}$,

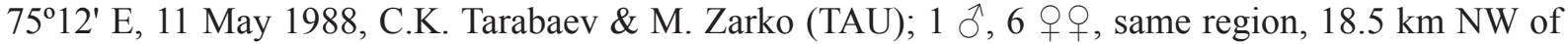

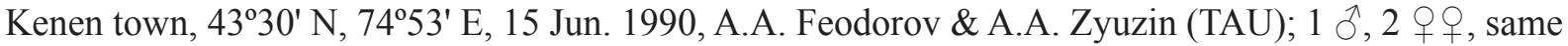
data (ZMMU); 1 ते, same region, $61 \mathrm{~km}$ on the Kopa-Kolshengel road, $4 \mathrm{~km}$ E of road, hills, $43^{\circ} 38.5^{\prime}$ N, 7548.2' E, 26 May 2003, A. Feodorov \& N. Poddubskii (AMNH).

\section{Description}

Male (holotype)

Habitus. See Fig. 19E.

Body LENGTH. 2.82.

CoLour. Whole spider pale greyish-yellow; eye tubercle brownish-black; Y-shaped median spot occupying cephalic portion and extending to clypeus, and narrow margins of carapace light brown, as well as a weak and diffuse dorsal abdominal pattern consisting of interrupted median line anteriorly and a few transverse fasciae posteriorly.

CARApace (Fig. 42A). 1.24 long, 1.03 wide.

Eyes. AME 0.07, ALE 0.13, PLE 0.12, PME 0.10, AME-AME 0.04.
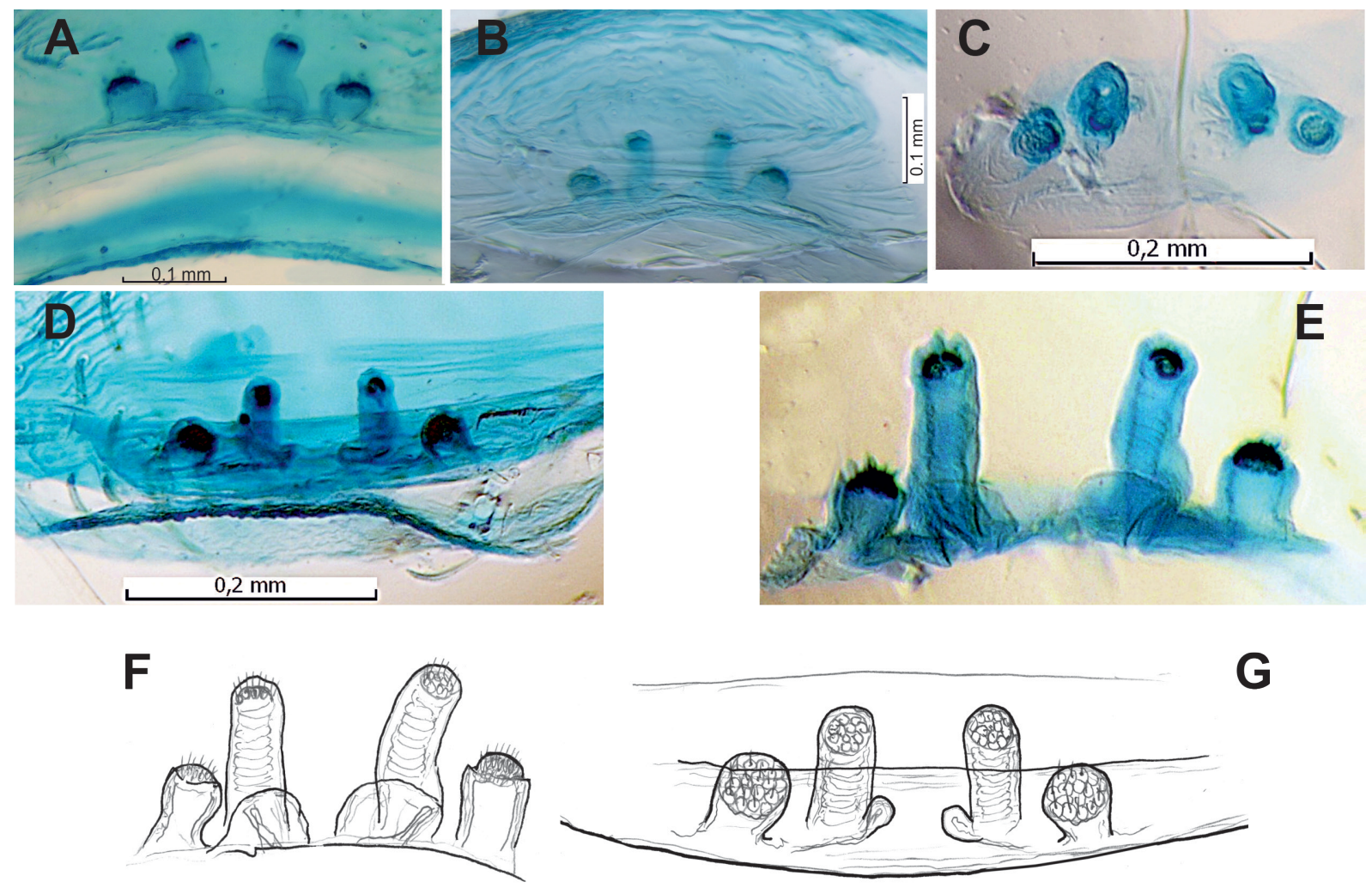

Fig. 21. Endogyne of Zaitunia logunovi sp. nov., paratype, $q$. A-B, E-F. Endogyne, dorsal. C. Receptacles, posterior. D, G. Endogyne, dorsal-anterior. Scale bars: A-B $=0.1 \mathrm{~mm}$; C-D $=0.2 \mathrm{~mm}$. 
Palp (Figs 20, 43E; paratype from the type locality). Relatively long and slender; pale, without pigmentation; femur slightly longer than tibia; diameter of tibia 1.33 times wider than in femur; cymbium with distinct dorsal hump, about 2 times longer than bulb, retro- and proventral edge of cymbium with brush of thick and dense setae; bulb hemispherical; embolus short and screw-shaped, without a neck.

LEG MEASUREMENTS $\hat{\jmath}(P)$.

\begin{tabular}{lcccccc}
\hline & Femur & Patella & Tibia & Metatarsus & Tarsus & Total \\
\hline Palp & $0.82(0.61)$ & $0.28(0.35)$ & $0.79(0.46)$ & - & $0.32(0.57)$ & $2.02(1.73)$ \\
I & $1.93(1.50)$ & $0.52(0.47)$ & $1.83(1.31)$ & $1.81(1.07)$ & $1.15(0.87)$ & $6.54(5.22)$ \\
II & $1.49(1.07)$ & $0.45(0.43)$ & $1.39(0.81)$ & $1.43(0.67)$ & $0.90(0.58)$ & $5.18(3.56)$ \\
III & $1.34(0.89)$ & $0.43(0.41)$ & $1.17(0.67)$ & $1.37(0.60)$ & $0.83(0.55)$ & $4.60(3.12)$ \\
IV & $1.88(1.29)$ & $0.54(0.44)$ & $1.76(0.93)$ & $1.94(0.91)$ & $1.09(0.67)$ & $6.25(4.24)$ \\
\hline
\end{tabular}

Female (paratype from Kordai)

Habitus. See Fig. 19C.

BoDy LENGTH. 4.67.

Colour. As in male, but darker brownish pattern of carapace is more developed; dorsal abdominal pattern weaker; legs with a few incomplete darker fasciae.

Carapace (Figs 19D, 42B). 1.78 long, 1.43 wide.

Eyes. AME 0.07, ALE 0.17, PLE 0.15, PME 0.10, AME-AME 0.05.

ENDOGYNE (Fig. 21). Both pairs of receptacles cylindrical and with corrugated stems; median receptacles twice as long as laterals and about 1.3 times thinner, median receptacles with wide base and, in anterior view (Fig. 21C), both pairs of same diameter; gland pores cover only tips of receptacles.

\section{Variations}

Carapace length in males varies from 1.15 to 1.40 , in females from 1.47 to 1.85 . Darker pattern and markings in some specimens are almost indistinct (Fig. 19A).

\section{Ecology}

The species was found in steppe habitats in foothills and low mountains.

\section{Distribution}

Southeastern Kazakhstan and northern Kyrgyzstan (Fig. 48).

\section{Zaitunia spinimana-group}

\section{Remarks}

This group includes relatively pale-coloured species. Only the clypeus, post-ocular area and dorsal abdominal pattern are slightly darker than the pale background colour. Legs I-IV mostly lacking darker fasciae and are concolorous with the prosoma. The conical tegulum is much shorter than the cymbium. The embolus is relatively long to very long. The endogyne with two pairs of receptacles. Three species are included: Z. martynovae (Andreeva \& Tyshchenko, 1969) from Tajikistan, Z. spinimana sp. nov. from Turkmenistan and Kazakhstan, and (tentatively, because of the unknown male) Zaitunia inderensis Ponomarev, 2005 from western Kazakhstan. 
Key to species of Zaitunia spinimana-group

(Male of $Z$. inderensis is unknown.)

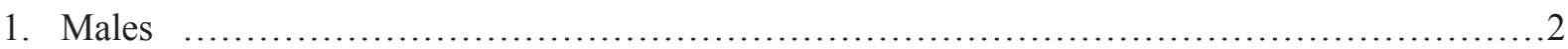

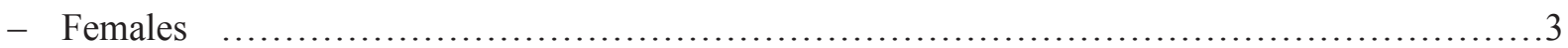

2. Femur, tibia and metatarsus I with numerous long ventral and prolateral spines (Fig. 27A); basal embolic keel absent; embolus shorter, with one loop (Figs 27C-E, 44A); northwestern Turkmenistan, southwestern Kazakhstan ................................. spinimana sp. nov.

- Femur, tibia and metatarsus I armed with a few unmodified spines (Fig. 23C); basal embolic keel present; embolus longer, with two loops (Figs 24A-D, 43F); Tajikistan, southern Turkmenistan

Z. martynovae (Andreeva \& Tyshchenko, 1969)

3. All receptacles are subequal in size (Fig. 27H-I)

Z. spinimana sp. nov.

- Median and lateral receptacles differ in size (Figs 25, 26B-C, E) .......................

4. Median receptacles considerably smaller than lateral pair (Fig. 26B-C, E); western Kazakhstan

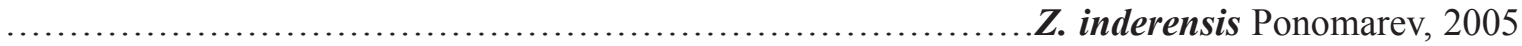

- Median receptacles considerably larger than lateral pair (Fig. 25)

Z. martynovae (Andreeva \& Tyshchenko, 1969)

Zaitunia inderensis Ponomarev, 2005

Figs 22, 42C

Zaitunia inderensis Ponomarev, 2005: 43, fig. 1a-b (†).

Zaitunia inderensis - Fomichev \& Marusik 2013: 85, figs 10-11, 15 ().

\section{Diagnosis}

By the structure of the vulva, females of $Z$. inderensis resemble $Z$. spinimana sp. nov., but differ from it and all other congeners by the enlarged lateral receptacles which are considerably larger and more robust than the median pair (Fig. 22E).

\section{Material examined}

Holotype

KAZAKHSTAN: $\odot$, Atyrau Province, Inder plateau, karst sinkhole $20 \mathrm{~km}$ E of Inderborskiy (=Inderbor) town, 48³3' N, 5201' E, 29 Sept. 1986, A.V. Ponomarev (ZMMU).

Paratypes $(5 q q)$

KAZAKHSTAN: 2 q $q$, same data as holotype; 3 qq , same data, but 25 May 1987 (ZMMU).

\section{Description}

Female (holotype)

Habitus. See Fig. 22A.

BODY LENGTH. 3.66.

CoLour. Whole spider pale yellowish-grey; eye tubercle brownish; abdomen lacking dorsal pattern.

Carapace (Fig. 42C). 1.34 long, 1.02 wide. 
Eyes. AME 0.07, ALE 0.13, PLE 0.10, PME 0.09, AME-AME 0.04.

ENDOGYNE (Fig. 22B-C, E). Median and lateral receptacles closely spaced and arranged almost in one longitudinal line (median receptacles partly hide lateral ones). Median receptacles very short; lateral receptacles diverging, clublike, with corrugated stems, head of receptacles separated by about 2.5 of their diameter; median receptacles separated by less than 1.5 diameters.

LEG MEASUREMENTS.

\begin{tabular}{lcccccc}
\hline & Femur & Patella & Tibia & Metatarsus & Tarsus & Total \\
\hline Palp & 0.62 & 0.30 & 0.46 & - & 0.51 & 1.89 \\
I & 1.32 & 0.48 & 1.16 & 0.99 & 0.84 & 4.79 \\
II & 1.01 & 0.43 & 0.78 & 0.70 & 0.58 & 3.50 \\
III & 0.87 & 0.41 & 0.63 & 0.79 & 0.55 & 3.25 \\
IV & 1.18 & 0.45 & 0.91 & 0.90 & 0.73 & 4.17 \\
\hline
\end{tabular}

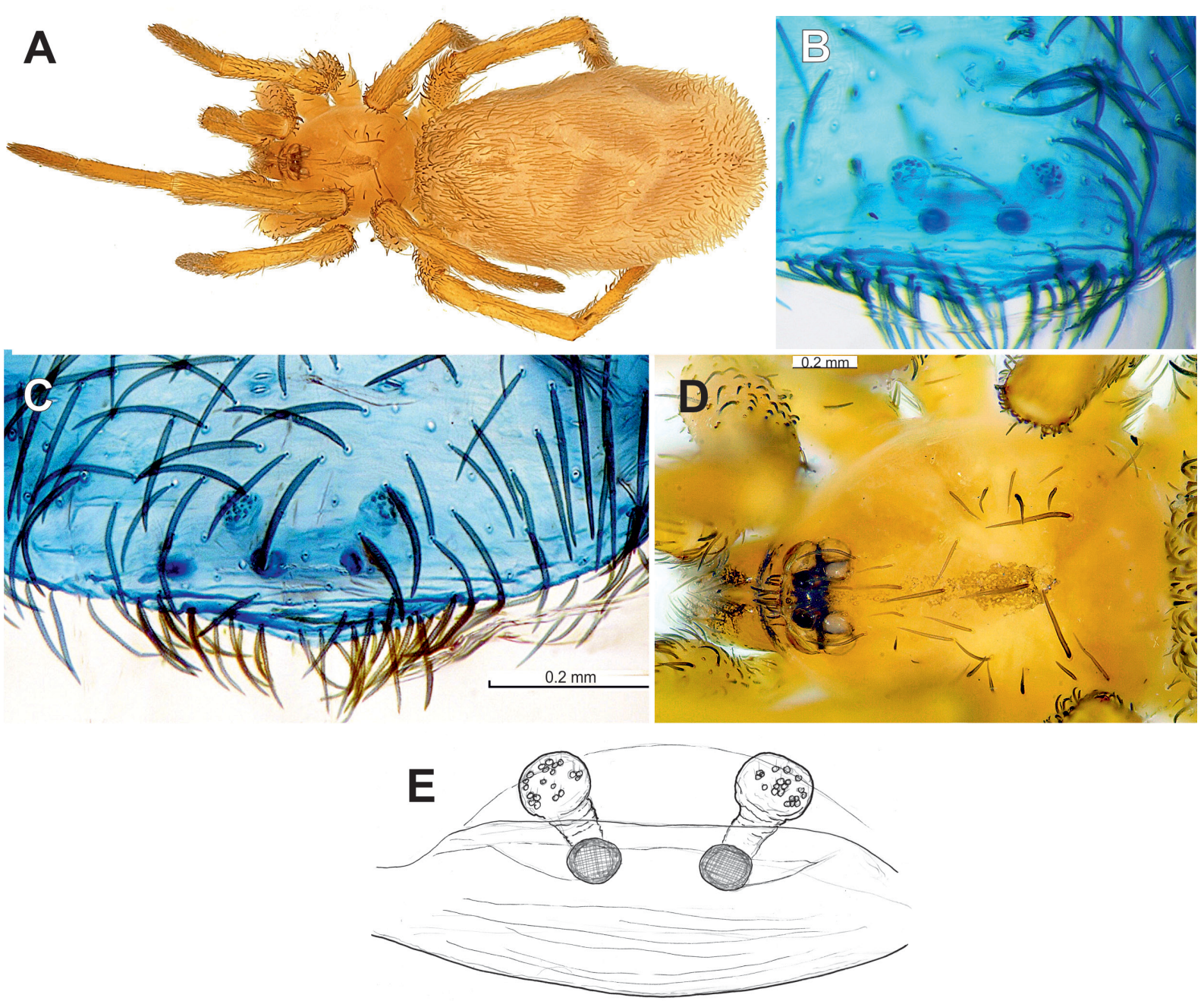

Fig. 22. Somatic characters and endogyne of Zaitunia inderensis Ponomarev, 2005, paratype, $q$. A. Habitus, dorsal. B-C, E. Endogyne, dorsal. D. Prosoma, dorsal. Scale bars: A, C-D = $0.2 \mathrm{~mm}$. 
Male

Unknown.

Variation

Carapace length in female paratypes varies from 1.19 to 1.40 ; no distinction in the colouration is evident.

\section{Ecology}

According to label data and the original description (Ponomarev 2005), the species was found in a low, semi-desert karst plateau.

\section{Distribution}

Known only from the type locality (Fig. 48).

Zaitunia martynovae (Andreeva \& Tyshchenko, 1969)

Figs $23-26,43 \mathrm{~F}, 50 \mathrm{~F}$

Filistata martynovae Andreeva \& Tyshchenko, 1969: 374, fig. 1 (ㅇ).

Filistata martynovae - Andreeva 1976: 19, figs 13-14 ().

Zaitunia martynovae - Zonstein 1990: 50 (transfer from Filistata).

\section{Diagnosis}

By the structure of the bulb, Z. martynovae resembles Z. spinimana sp. nov., but differs from it and all other male congeners by the long and flattened corkscrew-shaped embolus (Figs 25A-D, 43F). Females are easily distinguished from all other congeners due to their large and swollen median receptacles (Fig. 26).

\section{Type material}

\section{Holotype}

TAJIKISTAN: + , Sanglok Mts, Tutkaul Village, 10 Sep. 1966, E. Martynova (depository unknown, not examined).

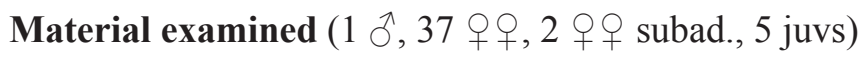

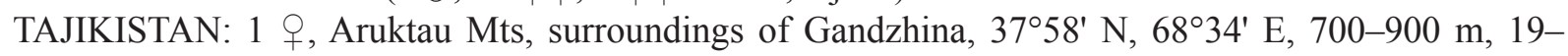
20 Apr. 1986, S. Zonstein (TAU); 1 q subad., same data, but 13 Apr. 1987 (TAU); 3 우, same data, but 11 Apr. 1988 (TAU); 1 \&, same data, but 19 Apr. 1989 (TAU); 1 ภ , 6 q , , same data, but 21 Apr. 2015,

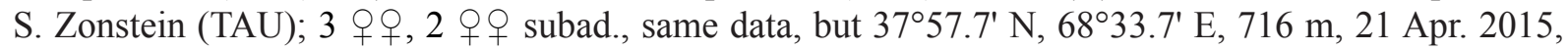
Y.M. Marusik (ZMMU); 2 우, Sanglok Mts, $1 \mathrm{~km} \mathrm{~W}$ of Khodzharki (= Sebiston), 38 ${ }^{\circ} 15^{\prime} \mathrm{N}, 6^{\circ} 15^{\prime} \mathrm{E}$ (10 km SE of Tutkaul village), 1300 m, 18 May 2002, S. Zonstein (TAU); 2 우, Pyandzh Karatau Mts,

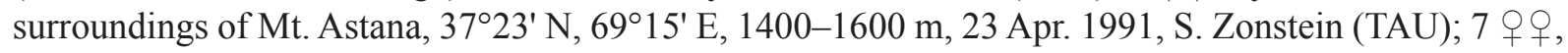
1 juv., same data, but $37^{\circ} 23.2^{\prime} \mathrm{N}, 6^{\circ} 14.8^{\prime} \mathrm{E}, 1674 \mathrm{~m}, 4$ May 2015, Y.M. Marusik (ZMMU); 3 우, same data, but $37^{\circ} 22.8^{\prime} \mathrm{N}, 69^{\circ} 14.7^{\prime} \mathrm{E}, 1600 \mathrm{~m}, 4$ May 2015, S. Zonstein (TAU); 1 \%, 1 juv., foothills $8 \mathrm{~km} \mathrm{E}$ of Pyandzh town, $37^{\circ} 14.7^{\prime}$ N, 69 $9^{\circ} 14.0^{\prime}$ E, 464 m, 5 May 2015, Y.M. Marusik (ZMMU); 2 + + , Khodzha-

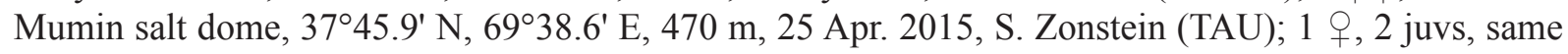
data, but Yu.M. Marusik (ZMMU); 1 q, 1 juv., Rangentau Mts, env. of Khurson, 38 $10.7^{\prime}$ N, 68 $68^{\circ} 39.7^{\prime}$ E, 724 m, clay cliff near road, 4 May 2015, Y.M. Marusik (ZMMU).

TURKMENISTAN: 3 + $q$, Central Kopetdagh Mts, northern slope of Ulydepe Mts, $14 \mathrm{~km} \mathrm{~W}$ of Gektepe, $38^{\circ} 09^{\prime} 45^{\prime \prime}$ N, 5707'05" E, 600 m, 1 Apr. 2002, A.V. Gromov (ZMMU). 


\section{Note}

Tutkaul village, the type locality of Filistata martynovae Andreeva \& Tyshchenko, is now covered by the water of the Nurek Reservoir.

\section{Description}

Male (Gandzhina)

Habitus. See Fig. 24A, C.

BODY LENGTH. 3.47.

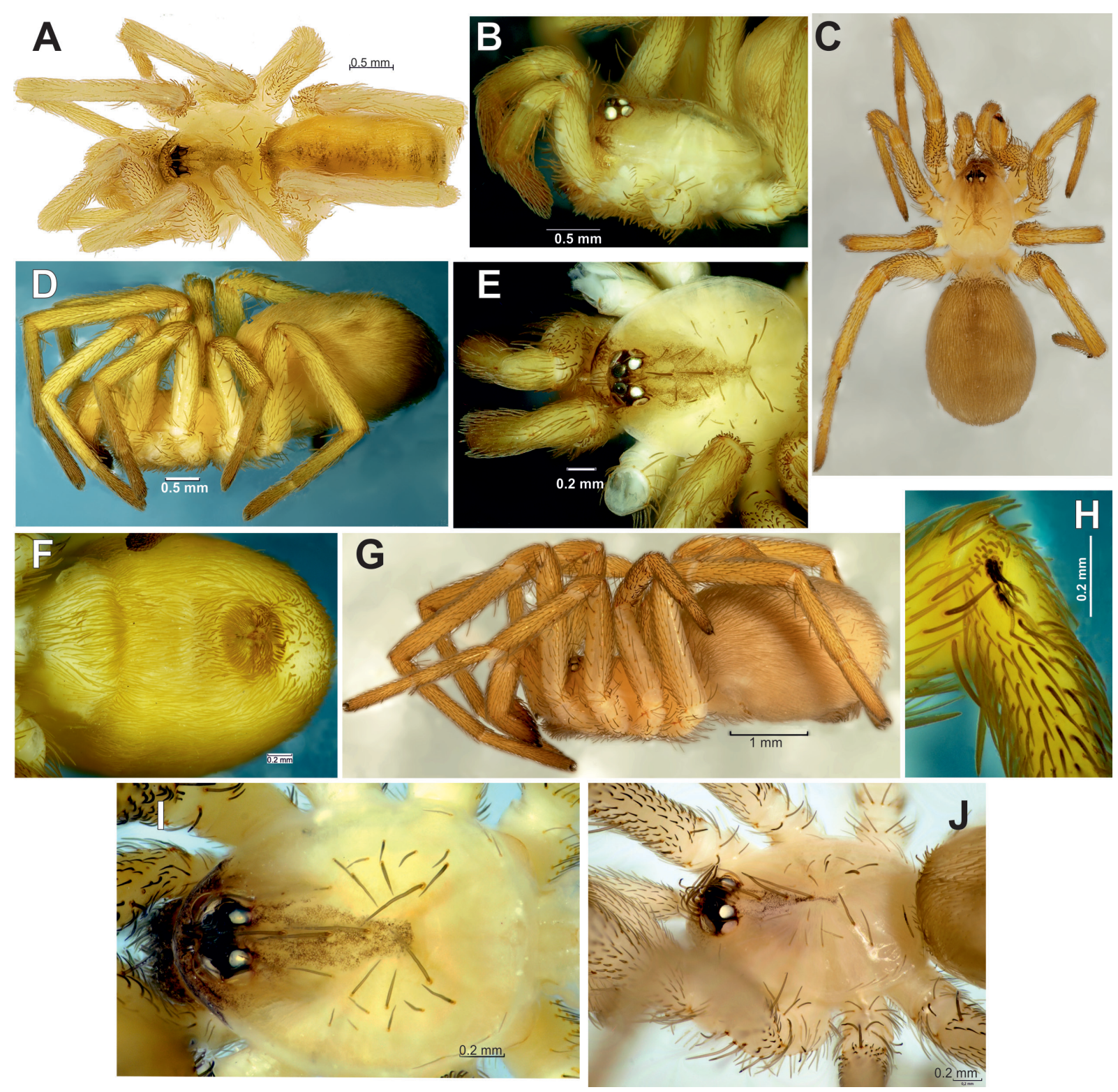

Fig. 23. Somatic characters of Zaitunia martynovae (Andreeva \& Tyshchenko, 1969) from Gandzhina $(\mathbf{A}, \mathbf{C}, \mathbf{G}, \mathbf{I}-\mathbf{J})$ and Kopetdagh $(\mathbf{B}, \mathbf{D}-\mathbf{F}, \mathbf{H}) ;$ lateral. D, G. Habitus, lateral. E, I. Prosoma, dorsal. F. Abdomen, ventral. H. Calamistrum, dorsal. J. Prosoma, dorso-lateral. Scale bars: A-B, D = $0.5 \mathrm{~mm}$; E-F, H-J $=0.2 \mathrm{~mm}$; G $=1.0 \mathrm{~mm}$. 
Colour. Prosoma and legs pale greyish-brownish-yellow; eye tubercle brownish-black; diffuse and narrow median line light brown (but margins of carapace not darkened), abdomen dorsally light brownish with diffuse pattern of slightly darker narrow median line anteriorly and a few transverse fasciae posteriorly.

CARAPACE (Fig. 24B, D). 1.52 long, 1.26 wide.

Eyes (Fig. 25E). AME 0.07, ALE 0.11, PLE 0.09, PME 0.08, AME-AME 0.08.

Palp (Figs 25A-D, 43F). Relatively long and slender, 1.78 times longer than carapace; tibia 1.3 times wider than femur, dorso-distally with brush of strong setae; cymbium shorter than bulb; bulb sinuous in lateral view; spermophore sinuous in embolic neck; embolus longer than neck and equal in length to tegulum + neck, embolus bent twice.
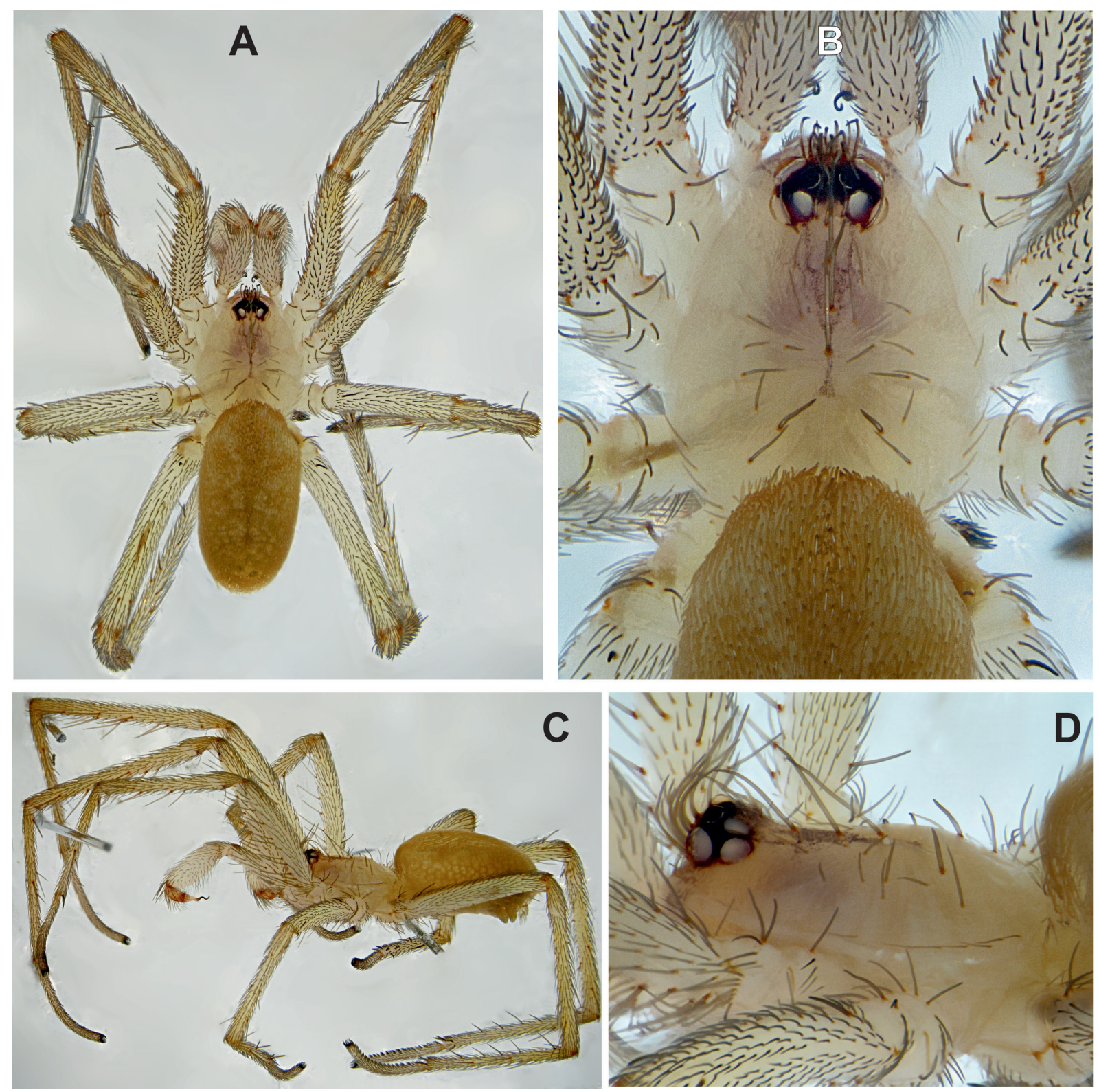

Fig. 24. Somatic characters of Zaitunia martynovae (Andreeva \& Tyshchenko, 1969), ô from Gandzhina. A, C. Habitus, dorsal and lateral. B, D. Prosoma, dorsal and lateral. 
ZONSTEIN S. \& MARUSIK Y.M., Revision of Zaitunia (Araneae, Filistatidae)

LEG MEASUREMENTS. $\sigma^{\top}(q)$

\begin{tabular}{lcccccc}
\hline & Femur & Patella & Tibia & Metatarsus & Tarsus & Total \\
\hline Palp & $1.07(0.93)$ & $0.29(0.36)$ & $1.01(0.55)$ & - & $0.34(0.67)$ & $2.71(2.51)$ \\
I & $2.43(1.95)$ & $0.57(0.57)$ & $2.55(1.89)$ & $2.46(1.57)$ & $1.89(1.18)$ & $9.90(7.16)$ \\
II & $1.94(1.53)$ & $0.49(0.51)$ & $1.76(1.28)$ & $1.94(1.17)$ & $1.28(0.84)$ & $7.41(5.33)$ \\
III & $1.81(1.26)$ & $0.51(0.47)$ & $1.58(0.97)$ & $1.79(0.98)$ & $0.96(0.76)$ & $6.65(4.44)$ \\
IV & $2.34(1.76)$ & $0.48(0.59)$ & $2.17(1.41)$ & $2.43(1.30)$ & $1.54(0.86)$ & $8.96(5.92)$ \\
\hline
\end{tabular}
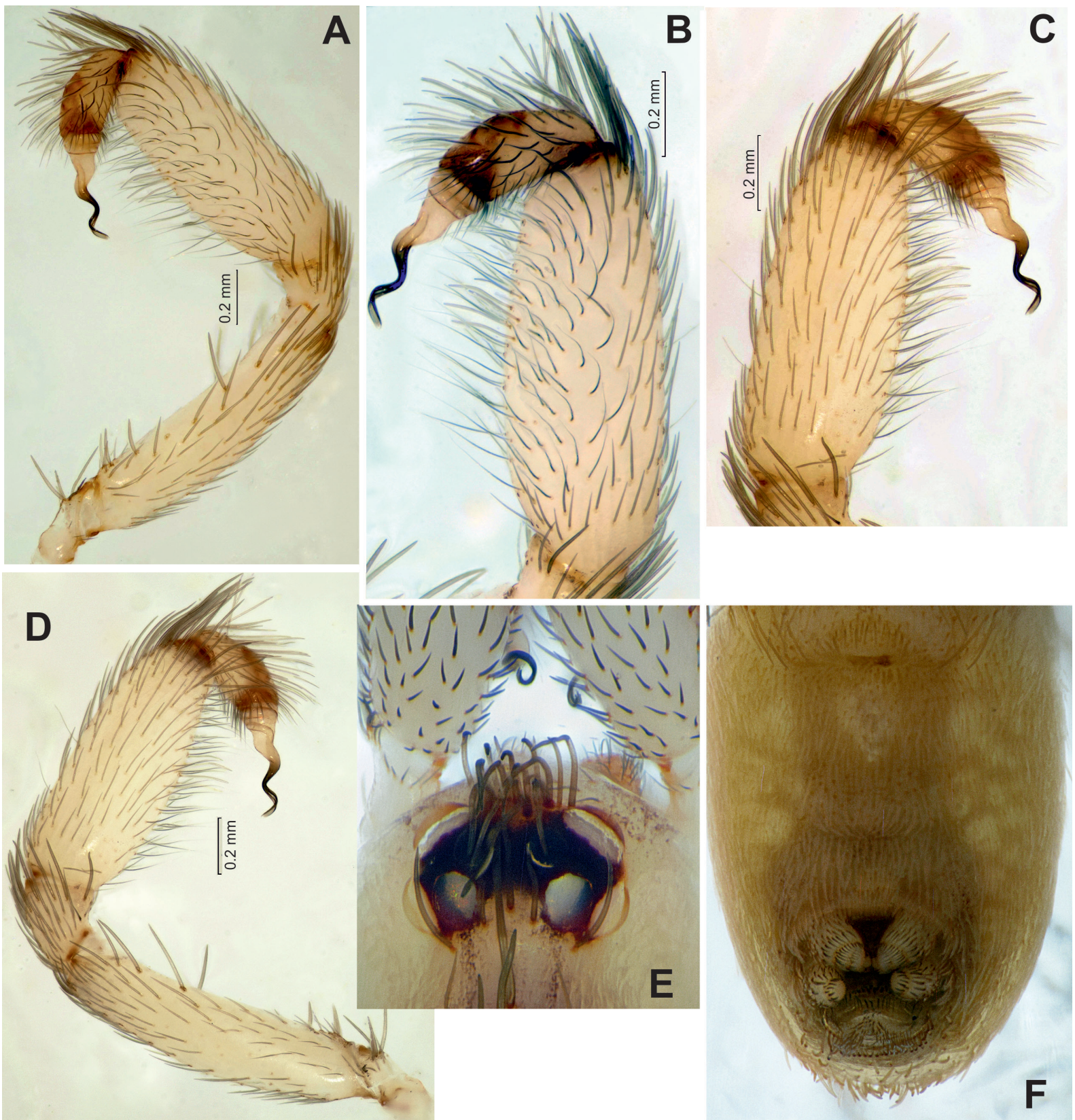

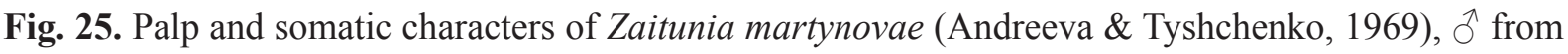
Gandzhina. A, D. Palp, retro- and prolateral. B-C. Terminal part of palp, retro-ventral and prolateral. E. Cephalic part of carapace, dorsal. F. Abdomen, ventral. 
Female (Gandzhina)

Habitus. See Fig. 23C, G.

BODY LENGTH. 4.35 .

CoLour. As in male but abdomen slightly darker dorsally, and ventrally with darker X-shaped spot in genital area.
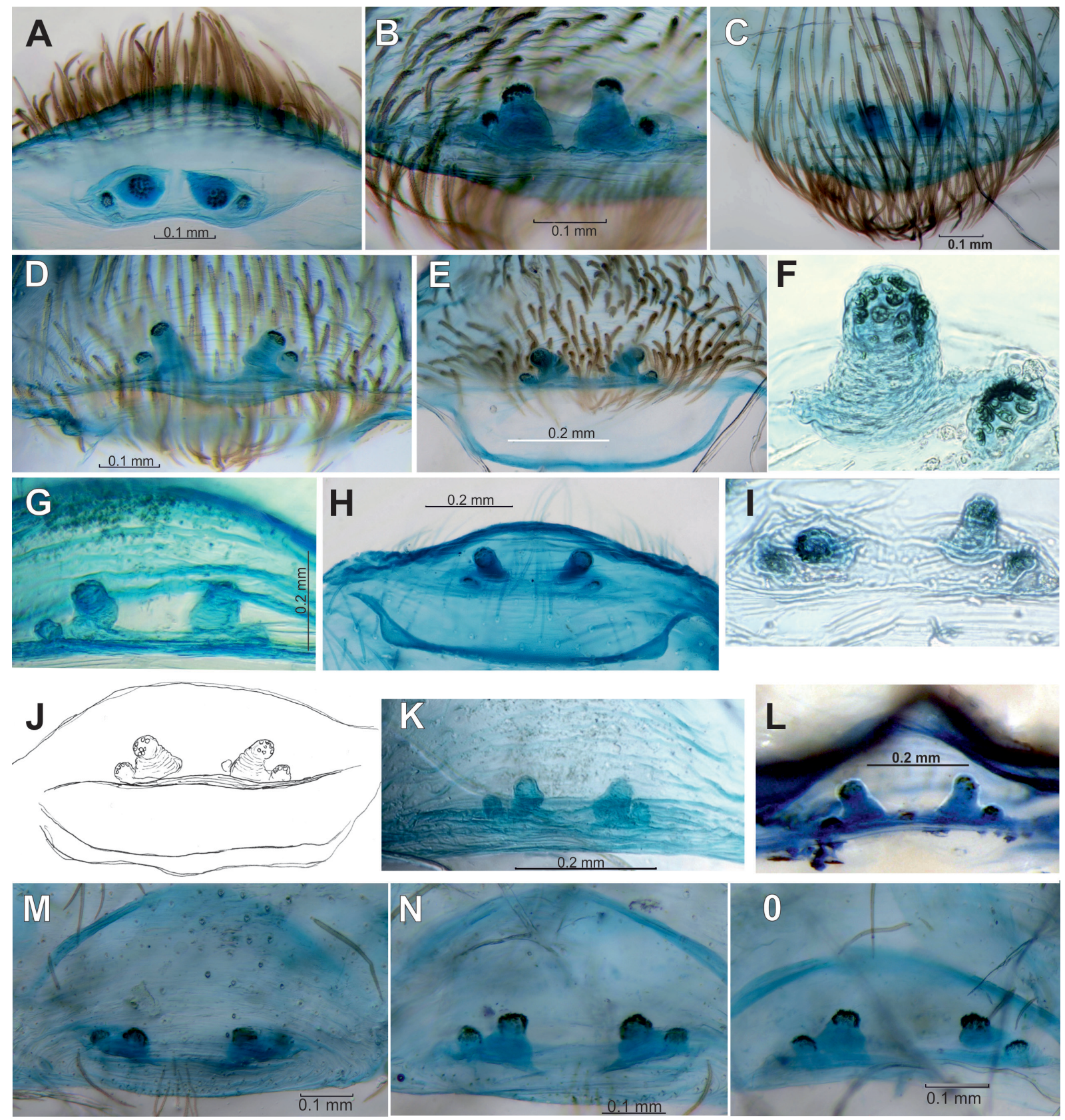

Fig. 26. Zaitunia martynovae (Andreeva \& Tyshchenko, 1969), structure of endogyne in $q$ q from Gandzhina (A-C, J), Kopetdagh (D-E), Babatagh $(\mathbf{F}-\mathbf{I}, \mathbf{K}-\mathbf{L})$ and Pyandzh Karatau $(\mathbf{M}-\mathbf{O})$. - A, I. Endogynal plate from above. B, D, L, N-O. Endogyne, dorsal. C, M. Endogyne, ventral. E, G, H, J-K. Endogyne, dorsal-anterior. F. Right pair of receptacles, dorsal-anterior. 
CARAPACE (Fig. 23I). 1.62 long, 1.29 wide.

Eyes. AME 0.07, ALE 0.13, PLE 0.11, PME 0.09, AME-AME 0.06.

ENDOGYNE (Fig. 26A-C). With large and wide conical median receptacles and small globular lateral receptacles; median receptacles with corrugated stem, their bases separated by less than the diameter of their heads, heads separated by 1.6 of their diameter; heads of both pairs densely covered with gland pores.

\section{Variations}

Carapace length in females varies from 1.50 to 1.75. Variation of coloration and structure of the endogyne in females from Tajikistan and Turkmenistan is shown in Figs 23A-B, D-F, and 26D-O, respectively. The body and leg pattern, including the $\mathrm{X}$-shaped spot in the female genital area, may be well-developed or indistinct.

\section{Ecology}

This species is found in different habitats from foothill steppes and shrubland to open Juniperus forest in the middle mountain belt. The spiders occur under stones (Fig. 50B), and in crevices in clay escarps (Fig. 50C) and rock outcrops (Fig. 50D) where they build small webs below or near the cavity entrance (Fig. 50E, a close-up view of such a web is also shown in Fig. 50F).

\section{Distribution}

Tajikistan and Turkmenistan (Fig. 48).

Zaitunia spinimana sp. nov. urn:lsid:zoobank.org:act:FC2C0EDF-90DD-4D31-B159-45BA263BC9D8

Fig. 27

Zaitunia sp. - Zyuzin \& Tarabaev 1994: 399.

\section{Diagnosis}

By structure of the bulb, Z. spinimana sp. nov. resembles Z. martynovae but differs from the latter by its shorter and narrower corkscrew-shaped embolus (cf. Figs 24A-D, 43F, 27C-E, 44A). Additionally, it differs from $Z$. martynovae and all other congeners by having a femur, tibia and metatarsus I with unusually numerous, long spines (Figs 27A). By structure of the vulva, Z. spinimana sp. nov. is similar to $Z$. inderensis; they differ by the receptacles, which are subequal in size (Fig. 27H-I).

\section{Etymology}

The specific epithet is derived from the Latin spina- (thorn, spine) and -manus (hand, appendage); the proposed name refers to the spiny legs of the male.

\section{Material examined \\ Holotype}

TURKMENISTAN: đ, Ustyurt Plateau (southern part), Kaplankyr Nature Reserve, 29 Apr. 1986, L. Mitroshina (TAU).

\section{Paratype}

KAZAKHSTAN: 1 , Mangystau Province, 40 km S of Aktau, 7 Jun. 2013, G. Abdurrakhmanov (ZMMU). 

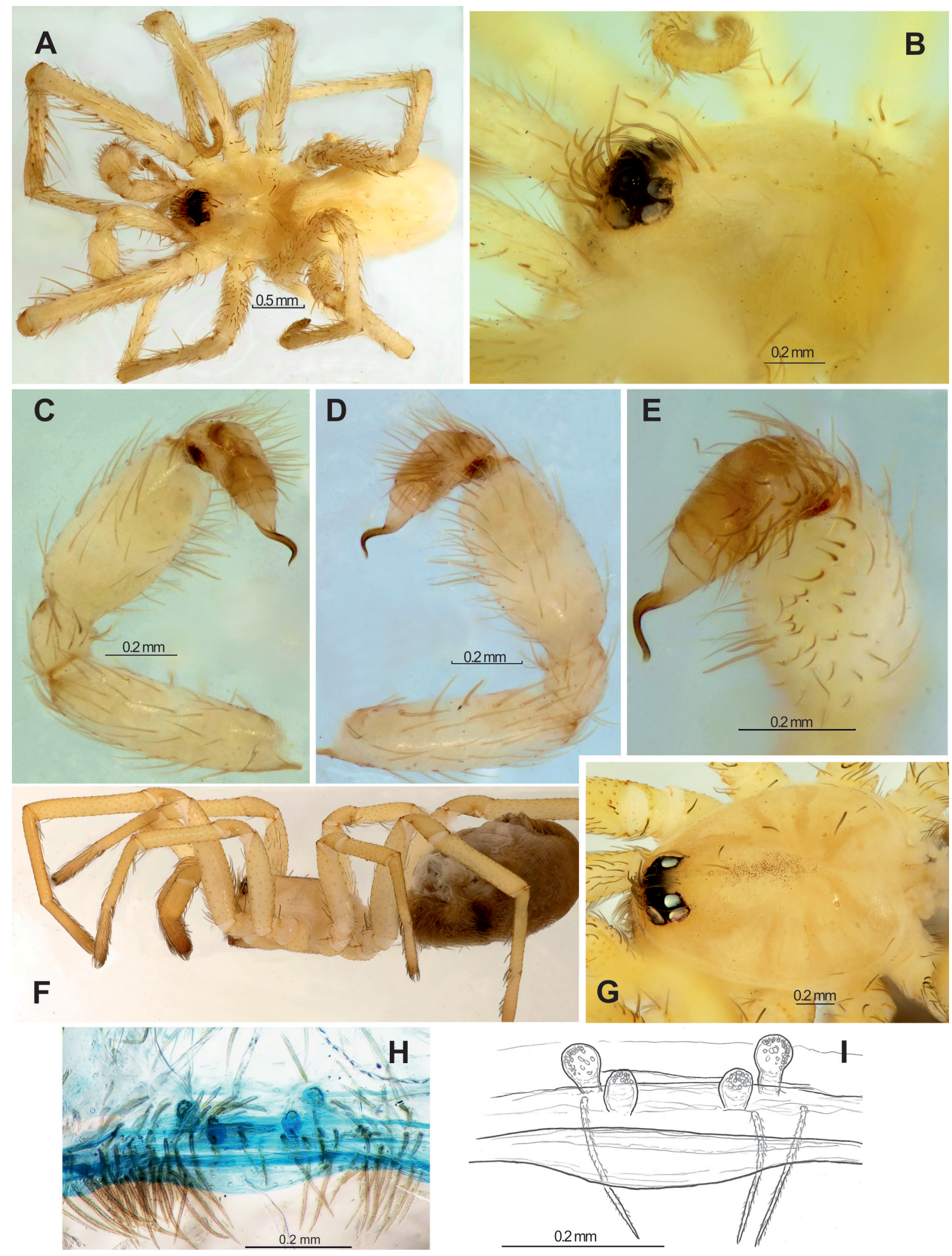

Fig. 27. Somatic characters and copulatory organs of Zaitunia spinimana sp. nov., holotype, $\widehat{\partial}(\mathbf{A}-\mathbf{E})$ and paratype, $q(\mathbf{F}-\mathbf{I})$. - A, F. Habitus, dorsal and lateral. B, G. Prosoma, dorso-lateral. C-D. Palp, pro- and retrolateral. E. Cymbium and bulb, anterior-retrolateral. H-I. Endogyne, dorsal. 


\section{Note}

The holotype male and the only collected paratype female are very similar in possessing a very similar shape of the carapace (flattened more than usual) and a similar conformation of the eye group. Although the distance between the localities listed above is about $500 \mathrm{~km}$, these slightly hilly and extremely uniform desert landscapes have no significant natural barriers. We prefer currently to treat these specimens as the same species (with no serious objectives against this assumption) rather than consider them representatives of two very close but distinct species.

\section{Description}

\section{Male}

Habitus. See Fig. 27A.

BODY LENGTH. 2.60.

CoLour. Whole body and legs pale yellowish-white; clypeus with weak pale orange area; eye tubercle marked with medium to dark brown; abdomen dorsally with slightly darker and almost indistinct narrow median stripe.

CARAPace. 1.12 long, 0.96 wide.

Eyes (Fig. 27B). AME 0.08, ALE 0.13, PLE 0.11, PME 0.08, AME-AME 0.06.

Palp (Figs 27C-E, 44A). Femur and tibia subequal in length; tibia 1.4 times wider than femur; cymbium slightly shorter than bulb; spermophore relatively wide; neck of embolus shorter than embolus proper; embolus long and arched, slightly screw-shaped.

SPeCiAl CHARACTERs. Leg I with numerous long spines, located proapically on femur, prolaterally and ventrally on tibia and metatarsus (Fig. 27A).

LEG MEASUREMENTS. $\partial^{\lambda}(+)$

\begin{tabular}{lcccccc}
\hline & Femur & Patella & Tibia & Metatarsus & Tarsus & Total \\
\hline Palp & $0.63(0.73)$ & $0.22(0.29)$ & $0.58(0.48)$ & - & $0.28(0.57)$ & $1.71(2.08)$ \\
I & $1.61(1.54)$ & $0.46(0.51)$ & $1.47(1.48)$ & $1.35(1.27)$ & $1.09(0.88)$ & $5.98(5.68)$ \\
II & $1.33(1.23)$ & $0.43(0.46)$ & $1.15(1.06)$ & $1.08(0.95)$ & $0.84(0.70)$ & $4.83(4.40)$ \\
III & $1.14(1.03)$ & $0.36(0.44)$ & $1.04(0.84)$ & $1.03(0.84)$ & $0.58(0.59)$ & $4.15(3.74)$ \\
IV & $1.52(1.49)$ & $0.44(0.53)$ & $1.43(1.17)$ & $1.48(1.15)$ & $0.64(0.75)$ & $5.51(5.09)$ \\
\hline
\end{tabular}

Female

Habitus. See Fig. 27F.

Body LENGTH. 3.87.

Colour. As in male except for darker brownish abdomen.

CARAPace (Fig. 27G). 1.62 long, 1.23 wide.

Eyes. AME 0.07, ALE 0.13, PLE 0.10, PME 0.08, AME-AME 0.06.

ENDOGYNE (Fig. 27H-I). Both pairs of receptacles club-like, lateral receptacles longer than median, with distinct corrugated stem; median receptacles separated by more than 2.5 diameters; gland pores cover entire head of lateral receptacles and only top of median ones. 


\section{Ecology}

According to Zyuzin \& Tarabaev (1994) and the label data, this species occurs in upland desert area; no more details are known.

\section{Distribution}

Northwestern Turkmenistan, southwestern Kazakhstan (Cis-Caspian area) (Fig. 48).

\section{Zaitunia beshkentica species group}

\section{Remarks}

This group includes pale-coloured species. The clypeus, post-ocular area, dorsal abdominal pattern and sometimes lateral margins of the carapace are slightly darker than the pale background colour. Legs I-IV, mostly lacking darker fasciae, are concolorous with the prosoma. The conical tegulum is much shorter than the cymbium. The relatively long embolus is provided with a well-developed raised keel. The vulva has two pairs of receptacles. Four species are included: $Z$. beshkentica (Andreeva \& Tyshchenko, 1969) from Tajikistan, Turkmenistan and Uzbekistan, Z. psammodroma sp. nov. from Turkmenistan, Z. wunderlichi sp. nov. from Kyrgyzstan, and (tentatively, because the male is unknown) Z. huberi sp. nov. from Afghanistan.

\section{Key to species of the Zaitunia beshkentica-group}

(Male of $Z$. huberi sp. nov. and female of $Z$. psammodroma sp. nov. are unknown.)

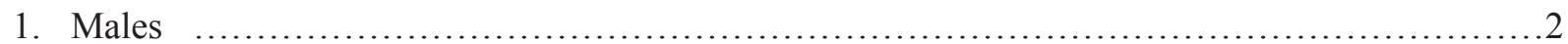

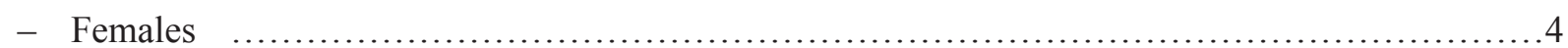

2. Metatarsus IV shortened and thickened with distal comb of short spines (Fig. 30G, K); palpal tibia and embolic keel shorter (Figs 30H-J, 44C); Turkmenistan ......Z. psammodroma sp. nov.

- Metatarsus IV unmodified (as in Figs 28A, D-F, 31E); palpal tibia and embolic keel longer (Figs 28G-I, 32A-G, 44B, D)

3. Embolic keel lower and longer, and rounded at median part of terminal hook (Figs 32D-F, 44D); Kyrgyzstan ................................................... wunderlichi sp. nov.

- Embolic keel higher and shorter, and ends abruptly at basal part of terminal hook (Figs 28G-I, 44B); Tajikistan, Uzbekistan .............................. beshkentica (Andreeva \& Tyshchenko, 1969)

4. Receptacles short, globular and subequal in size (Fig. 30C-E); Afghanistan ....... huberi sp. nov.

- Receptacles more elongate and noticeably differing by size (Figs 29I-K, 32H-I) ................5

5. Median receptacles smaller than lateral pair (Fig. 33A-B) ................. wunderlichi sp. nov.

- Median receptacles larger than lateral pair (Fig. 29I-K)

Zaitunia beshkentica (Andreeva \& Tyshchenko, 1969)

Figs 28-29, 33C, 42D-E, 44B

Filistata beshkentica Andreeva \& Tyshchenko, 1969: 376, fig. 2 (†).

Filistata beshkentica - Andreeva 1976: 18, figs 10-12 (ㅇ).

Zaitunia beshkentica - Zonstein 1990: 50 (transfer from Filistata). 

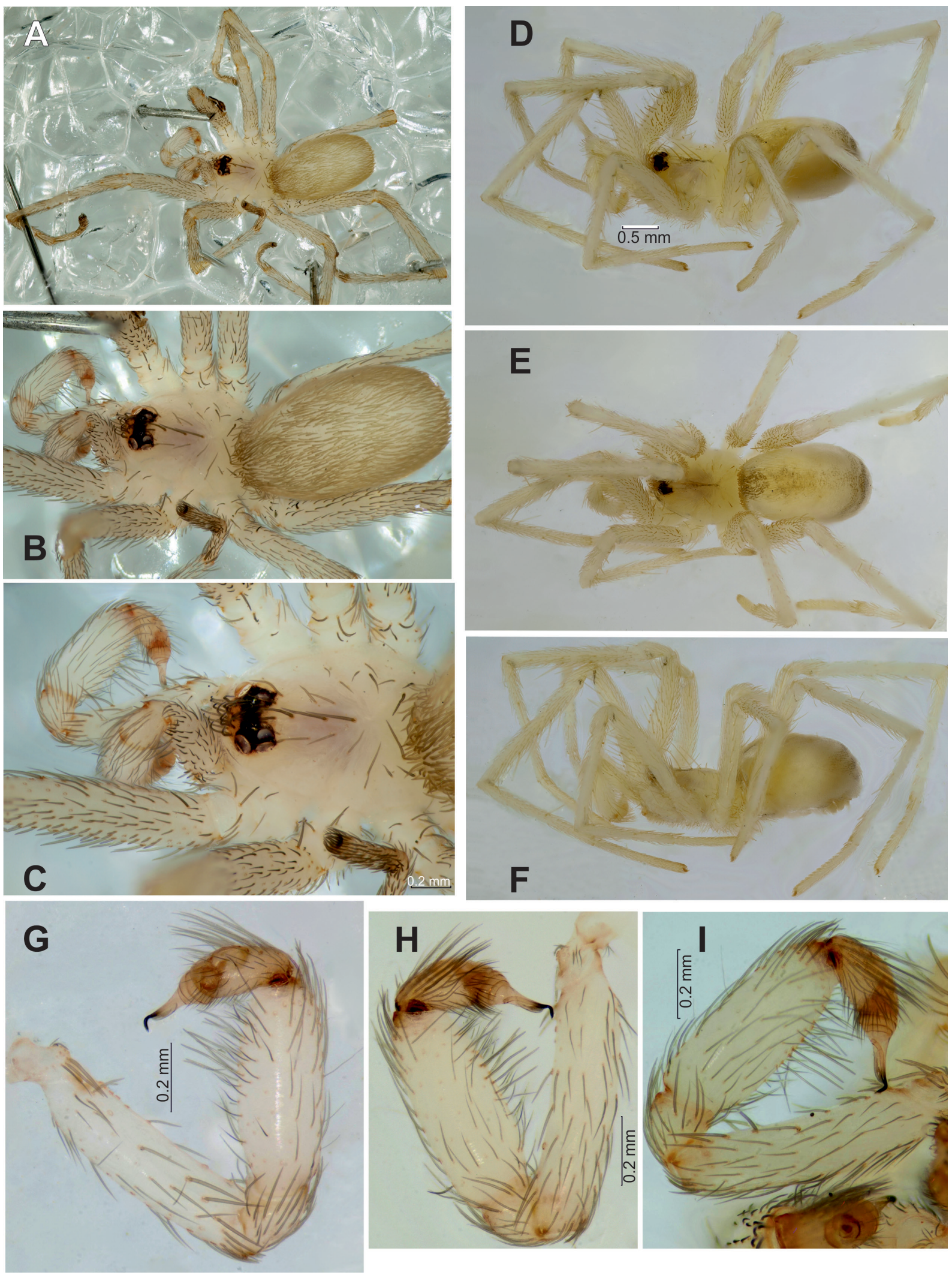

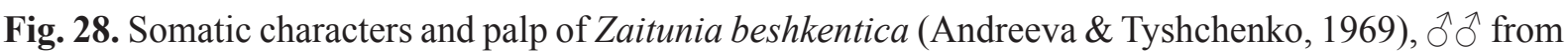
Khurshedi (A-C, G-I) and Babatagh (D-F). - A, E. Habitus, dorsal. B. Body, dorsal. C. Prosoma, dorsal. D, F. Habitus, doro-lateral and lateral. G. Palp, retrolateral. H-I. Same, prolateral. 


\section{Diagnosis}

Males of $Z$. beshkentica are similar to those of $Z$. wunderlichi sp. nov. but differ from them by the shape of the raised embolic keel, which terminates more abruptly (cf. Figs 28G-I and 32D-F), whereas females rather resemble $Z$. huberi sp. nov. in vulval structure but differ from the latter species by the shape of the median receptacles, which are longer and tubiform (vs shorter and rounded in Z. huberi sp. nov., cf. Figs 29I-K, 30C-E).

\section{Type material}

\section{Holotype}

TAJIKISTAN: + , Beshkent Valley, Chiluchor-Chashma, 8 May 1965, E. Martynova (depository unknown, not examined).

Material examined $(4 \hat{\jmath} \widehat{\partial}, 20 \stackrel{+}{q}, 8$ juvs)

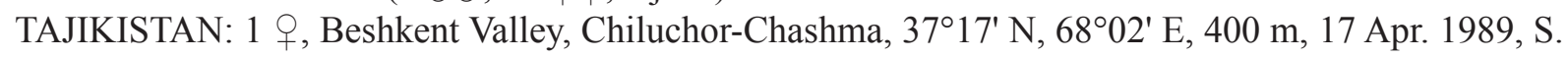
Zonstein (TAU); 1 , same locality, but 19 Apr. 2015, S. Zonstein (TAU); 2 우, Tigrovaya Balka (Tiger
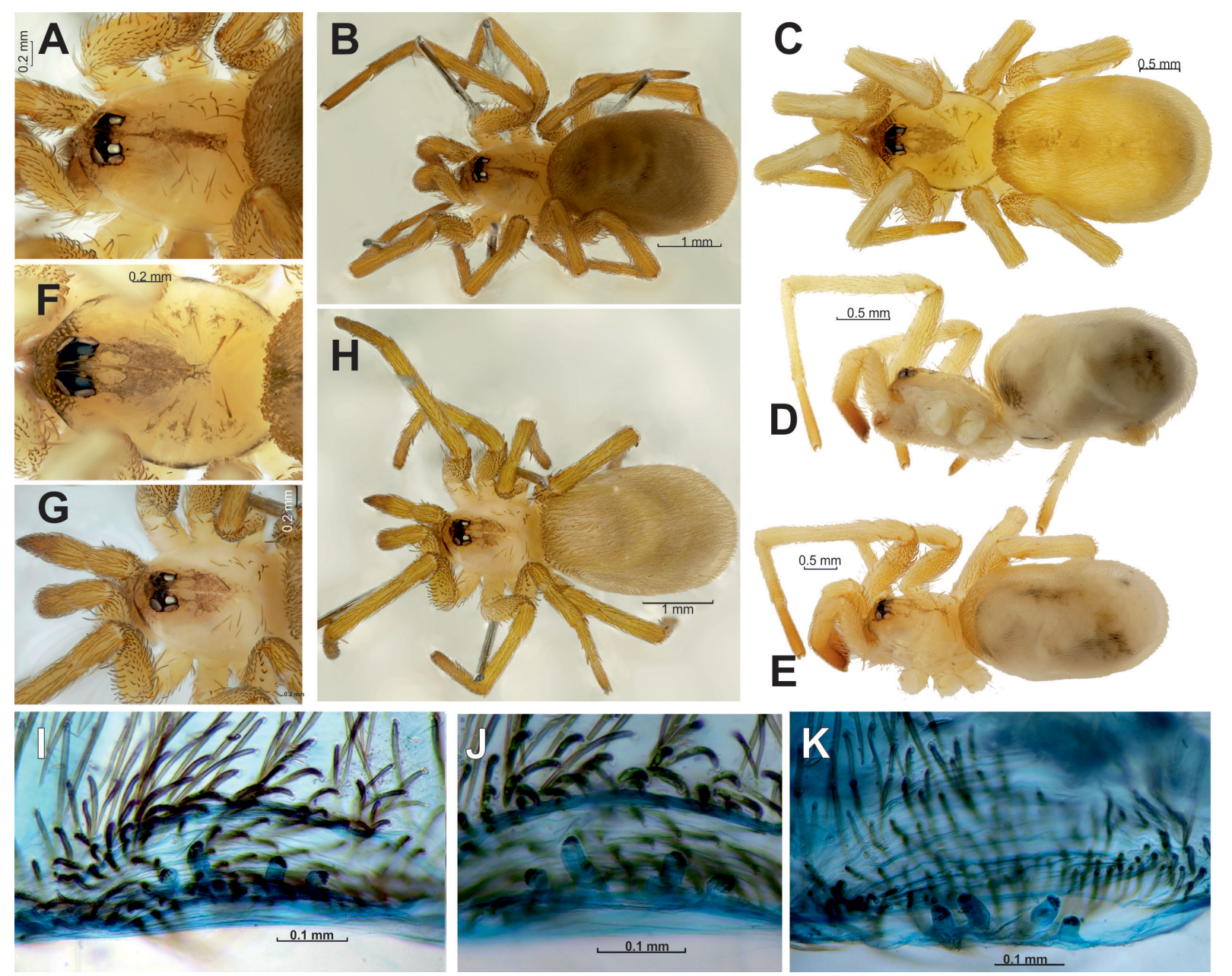

Fig. 29. Somatic characters and endogyne of Zaitunia beshkentica (Andreeva \& Tyshchenko, 1969),, $ᄋ$ from Chiluchor-Chashma (A-B), Babatagh $(\mathbf{C}-\mathbf{F})$ and Khurshedi $(\mathbf{G}-\mathbf{K})$. - A, F-G. Prosoma, dorsal. B-C, H. Habitus, dorsal. D-E. Same, lateral and dorso-lateral. I-K. Endogyne, dorsal. 


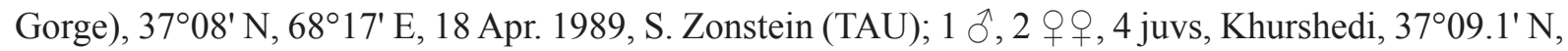
$68^{\circ} 04.2^{\prime}$ E, $342 \mathrm{~m}$, stony desert, chiefly under shrubs, 19 Apr. 2015, Y.M. Marusik (ZMMU); 1 juv., foothills of Hissar Mts, Varzob valley, $10 \mathrm{~km} \mathrm{~N}$ of Dushanbe, surroundings of Varzob Lake, $38^{\circ} 40.6^{\prime} \mathrm{N}$, 6847.4' E, 985 m, 3 May 2015, Y.M. Marusik (ZMMU); 1 ð’, Hissar Mts, Takob Gorge, near Dehmalik Village, $38^{\circ} 50.8^{\prime}$ N, 6854.6' E, 805 m, 8 May 2015, Y.M. Marusik \& M. Saidov (TAU).

UZBEKISTAN: $1 \partial^{\lambda}$, Babatagh Mts, $2.5 \mathrm{~km}$ ESE of Mt. Zarkassa, $1800 \mathrm{~m}, 37^{\circ} 58^{\prime} \mathrm{N}, 68^{\circ} 11^{\prime} \mathrm{E}, 1$ May

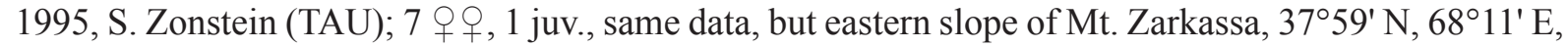

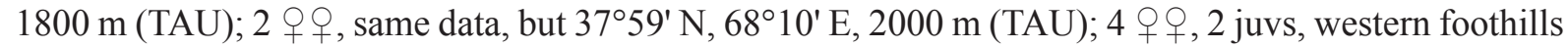

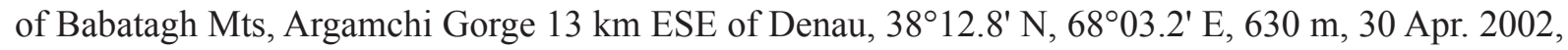
A.V. Gromov (ZMMU); 1 ○, 1 q, same, eastern foothills, Uzu,n $6.5 \mathrm{~km} \mathrm{~W}$ of Akmechet, $38^{\circ} 03.2^{\prime} \mathrm{N}$, 68¹4.3' E, 1123 m, 25 May 2003, L. Prendini \& A.V. Gromov (AMNH).

\section{Description}

Male (Zarkassa)

Habitus. See Fig. 28D-F.

BODY LENGTH. 2.95.

COLOR. Whole spider pale greyish-brownish-yellow; eye tubercle brownish-black; diffuse and narrow median line and margins of carapace light brown, as well as a weak and diffuse dorsal abdominal pattern consisting of interrupted median line anteriorly and a few transverse fasciae posteriorly.

CARapace (Fig. 42D). 1.28 long, 1.02 wide.

Eyes. AME 0.07, ALE 0.11, PLE 0.09, PME 0.08, AME-AME 0.08.

PaLP (Fig. 44B; also Fig. 28G-I, $\widehat{O}$ from Khurshedi). Femur distinctly longer than tibia; tibia less than 1.5 times wider than femur; cymbium longer than bulb; keel of embolic neck with rounded terminal end; embolus bent at right angle.

LEG MEASUREMENTS. $\widehat{\partial}(+)$

\begin{tabular}{lcccccc}
\hline & Femur & Patella & Tibia & Metatarsus & Tarsus & Total \\
\hline Palp & $0.87(0.72)$ & $0.28(0.29)$ & $0.74(0.44)$ & - & $0.32(0.53)$ & $2.21(1.98)$ \\
I & $1.95(1.09)$ & $0.54(0.48)$ & $1.90(1.14)$ & $1.88(1.07)$ & $1.33(0.82)$ & $7.60(4.60)$ \\
II & $1.79(0.98)$ & $0.48(0.36)$ & $1.49(0.84)$ & $1.42(0.79)$ & $1.00(0.61)$ & $6.18(3.58)$ \\
III & $1.58(0.84)$ & $0.47(0.33)$ & $1.11(0.57)$ & $1.36(0.71)$ & $0.78(0.52)$ & $5.30(2.97)$ \\
IV & $1.97(1.22)$ & $0.53(0.41)$ & $1.69(0.98)$ & $1.92(0.97)$ & $1.09(0.60)$ & $7.20(4.18)$ \\
\hline
\end{tabular}

Female (Chiluchor-Chashma)

Habitus. See Fig. 29B.

BODY LENGTH. 4.05.

Colour. As in male.

CARapace (Fig. 29A). 1.36 long, 0.94 wide.

Eyes. AME 0.05, ALE 0.11, PLE 0.09, PME 0.07, AME-AME 0.04. 
ENDOGYNE (Figs 29I-K, 33C). Median receptacles diverging; both pairs with corrugated stems; lateral receptacles globular, and median receptacles subconical (wide base and thinner head); heads of median receptacles separated by 3 diameters, and bases separated by one diameter; gland pores cover tops of heads only.

\section{Variations}

Carapace length in females varies from 1.30 to 1.95 . Specimens inhabiting lowland desert areas are almost uniformly pale-yellowish, with darker pattern on the body and legs very weak to absent (sometimes only metatarsi and tarsi are slightly dark, but the eye tubercle is still black). By contrast, specimens collected in foothills have typical though somewhat paler coloration, with darker median lanceolate spots on carapace and abdomen combined with weak and diffuse transverse fasciae on legs and in the posterior part of the abdomen (cf. Fig. 29A-H).

\section{Ecology}

Spiders were collected in desert, semi-desert and dry steppe biotopes in piedmont plains and low foothills and in the middle mountain zone with open park woods composed of Juniperus spp. and Acer spp.

\section{Distribution}

Known from western Tajikistan and southern Uzbekistan (Fig. 49).

Zaitunia huberi sp. nov. urn:1sid:zoobank.org:act:F999D3D3-7D62-44BD-9297-AB022AEA817E

Fig. 30A-F

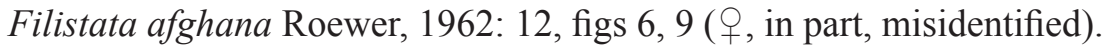

Zaitunia afghana - Zonstein et al. 2013: 69, figs 13, 21-27 (+, misidentified).

\section{Diagnosis}

By structure of the vulva, Z. huberi sp. nov. resemble $Z$. beshkentica but differ from them by the shape of the median receptacles, which are shorter and round ( $v s$ longer and tube-shaped in Z. beshkentica, cf. Figs 29I-K, 30C-E).

\section{Etymology}

The specific epithet is given after the prominent German arachnologist Bernhard Huber, who has transferred some misplaced Asian genera from Pholcidae to Filistatidae.

\section{Material examined}

\section{Holotype}

AFGHANISTAN: +, surroundings of Pol-e Khumri city, 35 $57^{\prime}$ N, 68 $42^{\prime}$ E, 700 m, 9 Nov. 1957, K. Lindberg (SMF).

\section{Paratype}

AFGHANISTAN: 1 juv., collected and deposited together with holotype.

\section{Description}

Female

Habitus. See Fig. 30A-B.

BODY LENGTH. 5.35. 

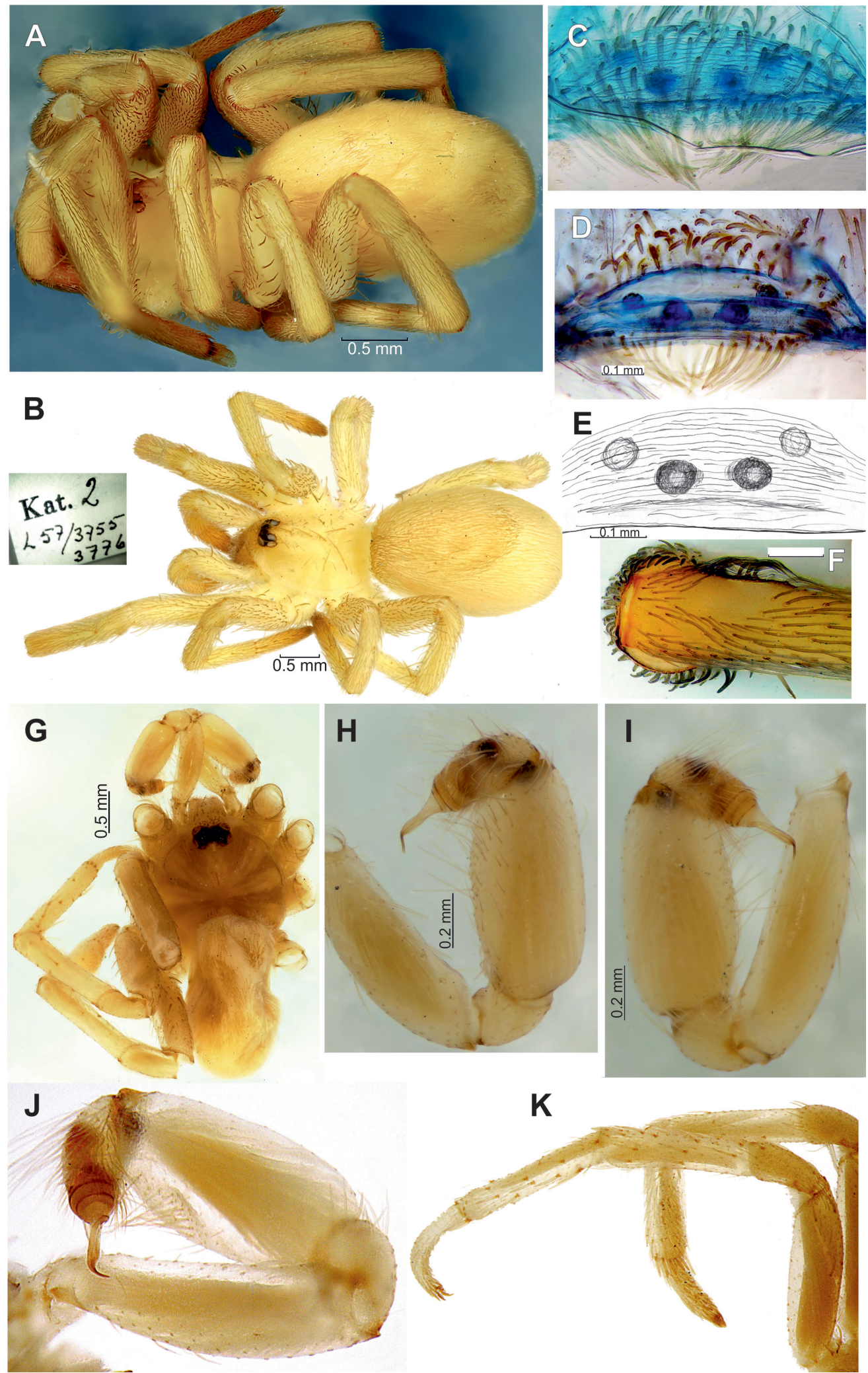

Fig. 30. Somatic characters and copulatory organs of Zaitunia huberi sp. nov., holotype, $q(\mathbf{A}-\mathbf{F})$ and Z. psammodroma sp. nov., holotype, $\widehat{\partial}(\mathbf{G}-\mathbf{K})$. - A. Habitus, dorso-lateral. B, G. Habitus, dorsal. C, E. Endogyne, ventral. D. Endogyne, dorsal. F. Calamistrum, lateral. H, J. Palp, retrolateral. I. Palp, prolateral. K. Legs III and IV, prolateral. 
CoLour. Whole body and legs light brownish-yellow, abdomen without dorsal pattern, tarsi of palp and legs I-IV darkened, eye tubercle blackish-brown.

Carapace. 2.13 long, 1.77 wide.

Eyes. AME 0.09, ALE 0.23, PLE 0.20, PME 0.20, AME-AME 0.11.

Endogyne (Fig. 30C-E). Both pairs of receptacles globular, median receptacles separated from each other by the same distance as lateral and median receptacles; median receptacles larger, separated by less than one diameter.

LEG MEASUREMENTS.

\begin{tabular}{lcccccc}
\hline & Femur & Patella & Tibia & Metatarsus & Tarsus & Total \\
\hline Palp & 1.17 & 0.65 & 0.87 & - & 0.97 & 3.66 \\
I & 2.33 & 0.87 & 2.23 & 1.97 & 1.30 & 8.70 \\
II & 1.97 & 0.83 & 1.65 & 1.63 & 1.05 & 7.13 \\
III & 1.75 & 0.75 & 1.33 & 1.38 & 0.97 & 6.18 \\
IV & 2.37 & 0.80 & 1.85 & 1.83 & 1.03 & 7.88 \\
\hline
\end{tabular}

\section{Male}

Unknown.

\section{Note}

See comments in the redescription of the holotype of Z. afghana. Both of these species are very similar in somatic characters, which probably misled Roewer (1962). Nevertheless, they differ so drastically in the structure of the endogyne (cf. Figs 14G-K, 30C-E) that they are assigned here to different species groups.

\section{Distribution}

Known only from the type locality (Fig. 49).

Zaitunia psammodroma sp. nov. urn:1sid:zoobank.org:act:C4E7DB83-2472-4BCF-85B6-B1CF85CA5714

Fig. 30G-K

\section{Diagnosis}

The species differs from all other congeners in having modified metatarsi IV - shortened, distally dilated and flattened, with ventrodistal spines (Fig. 30G, K).

\section{Etymology}

The specific epithet is derived from psammo- (a combining form of the Greek psámmos, "sand") + -droma (a combining form of the Greek drómos meaning "running"), indicating the ability of these spiders to run on a loose, sandy substrate.

\section{Material examined}

\section{Holotype}

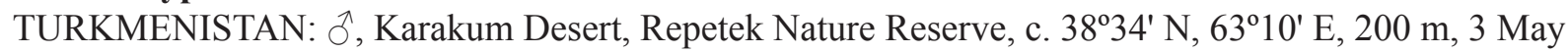
1972, V.I. Kuznetzov (TAU).

\section{Paratype}

TURKMENISTAN: $1 \hat{\jmath}$, same data as holotype (ZMMU). 


\section{Description}

Male (holotype)

Habitus. See Fig. 30G.

BODY LENGTH. 3.37 .

CoLour. Carapace light yellowish-orange, other parts of body and legs uniformly pale greyish-yellow.

CARAPACE. Subcircular, 1.47 long, 1.42 wide.

Eyes. AME 0.09, ALE 0.14, PLE 0.12, PME 0.10, AME-AME 0.09.

Palp (Figs 30H-J, 44C). Femur in prolateral view $1 / 3$ longer than tibia and 1.5 times thinner; cymbium slightly shorter than bulb; embolic neck straight, with thin, straight keel, its width equal to spermophore diameter; embolus relatively long and thin, bent ventrally.

LEG MEASUREMENTS.

\begin{tabular}{lcccccc}
\hline & Femur & Patella & Tibia & Metatarsus & Tarsus & Total \\
\hline Palp & 0.97 & 0.42 & 0.78 & - & 0.32 & 2.49 \\
I & 2.23 & 0.72 & 1.54 & 1.65 & 0.90 & 7.04 \\
II & 1.86 & 0.65 & 1.32 & 1.51 & 0.68 & 6.02 \\
III & 1.78 & 0.67 & 1.32 & 1.30 & 0.53 & 5.60 \\
IV & 2.13 & 0.75 & 1.29 & 1.53 & 0.61 & 6.31 \\
\hline
\end{tabular}

Special CHARACTERS. Tibia and metatarsus III with c. 20 short spines each; metatarsus IV short and flattened, with 7-8 short and stout ventroapical spines (Fig. 30K).

\section{Female}

Unknown.

\section{Variation}

Carapace length in males varies from 1.42 to 1.45 ; no differences in coloration are evident.

\section{Ecology}

The species occurs in an extra-arid sandy desert with Haloxylon shrubs; the males were collected in pitfall traps in rodent colonies. Most likely the spiders inhabit abandoned gerbil burrows.

\section{Distribution}

Known only from the type locality (Fig. 49).

Zaitunia wunderlichi sp. nov. urn:1sid:zoobank.org:act:E06085D0-2BB4-435E-91F8-F7C25685B36A

Figs 31-32, 33A-B, D, 42F, 44D

\section{Diagnosis}

By the structure of the bulb, Z. wunderlichi sp. nov. is similar to Z. beshkentica, but differs by the shape of the raised embolic keel, which terminates more gently (cf. Figs 28G-I, 32D-F), whereas females differ by the structure of the vulva, which is more similar to those of $Z$. maracandica and $Z$. ferghanensis sp. nov.; they differ from both these species by the shorter median receptacles (cf. Figs 33A-B, D, 35E-J, 38E-I). 


\section{Etymology}

This species is named after the famous German arachnologist, our friend and colleague Jörg Wunderlich.

\section{Material examined}

\section{Holotype}

KYRGYZSTAN: $\widehat{\jmath}$, Ferghana Mts, Baubashata Range, Yarodar, $2.5 \mathrm{~km}$ E of Arslanbob, 41 ${ }^{\circ} 20^{\prime} 12^{\prime \prime} \mathrm{N}$, 7258'23" E, 1450 m, 12 Aug. 1981, S. Zonstein (TAU).
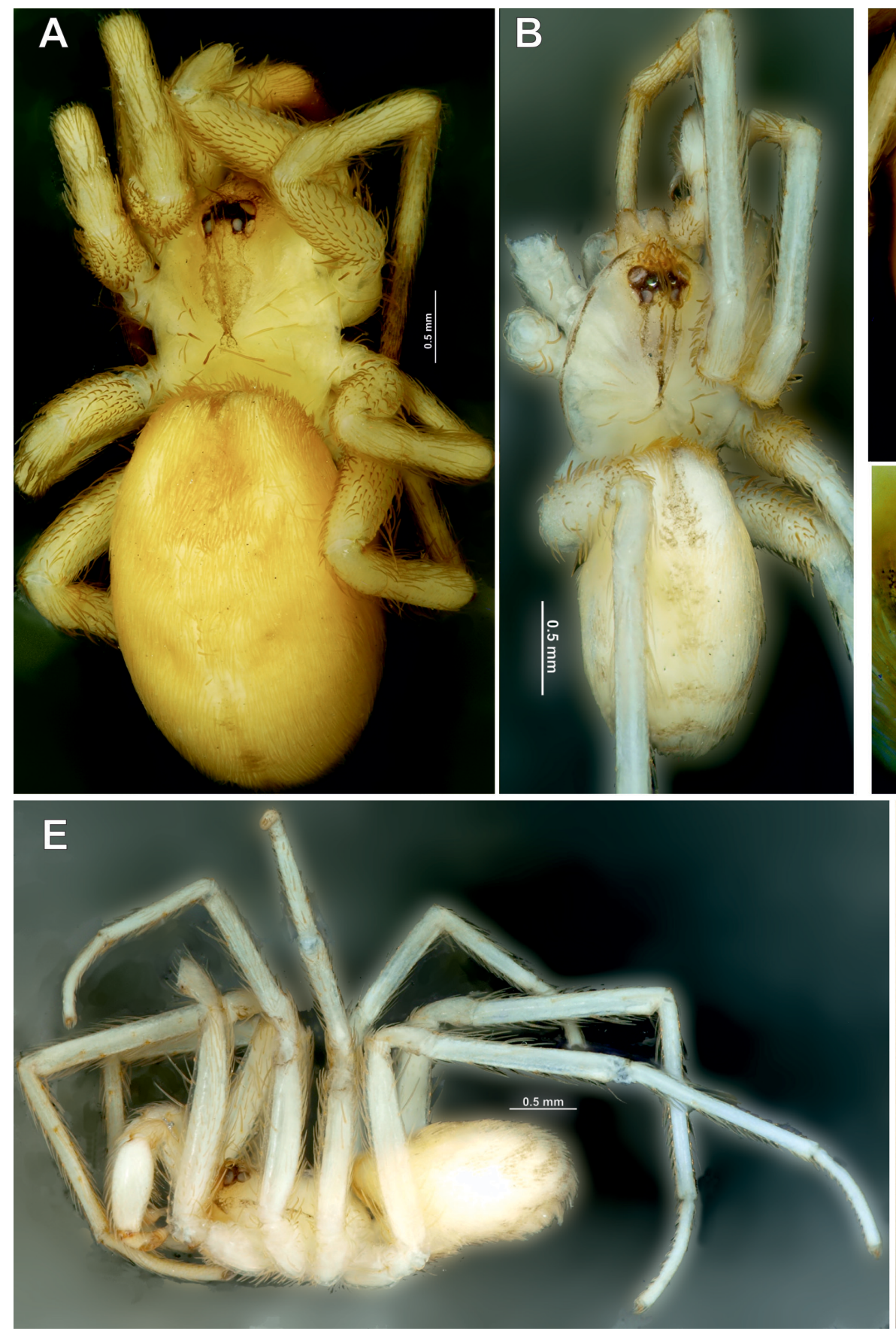
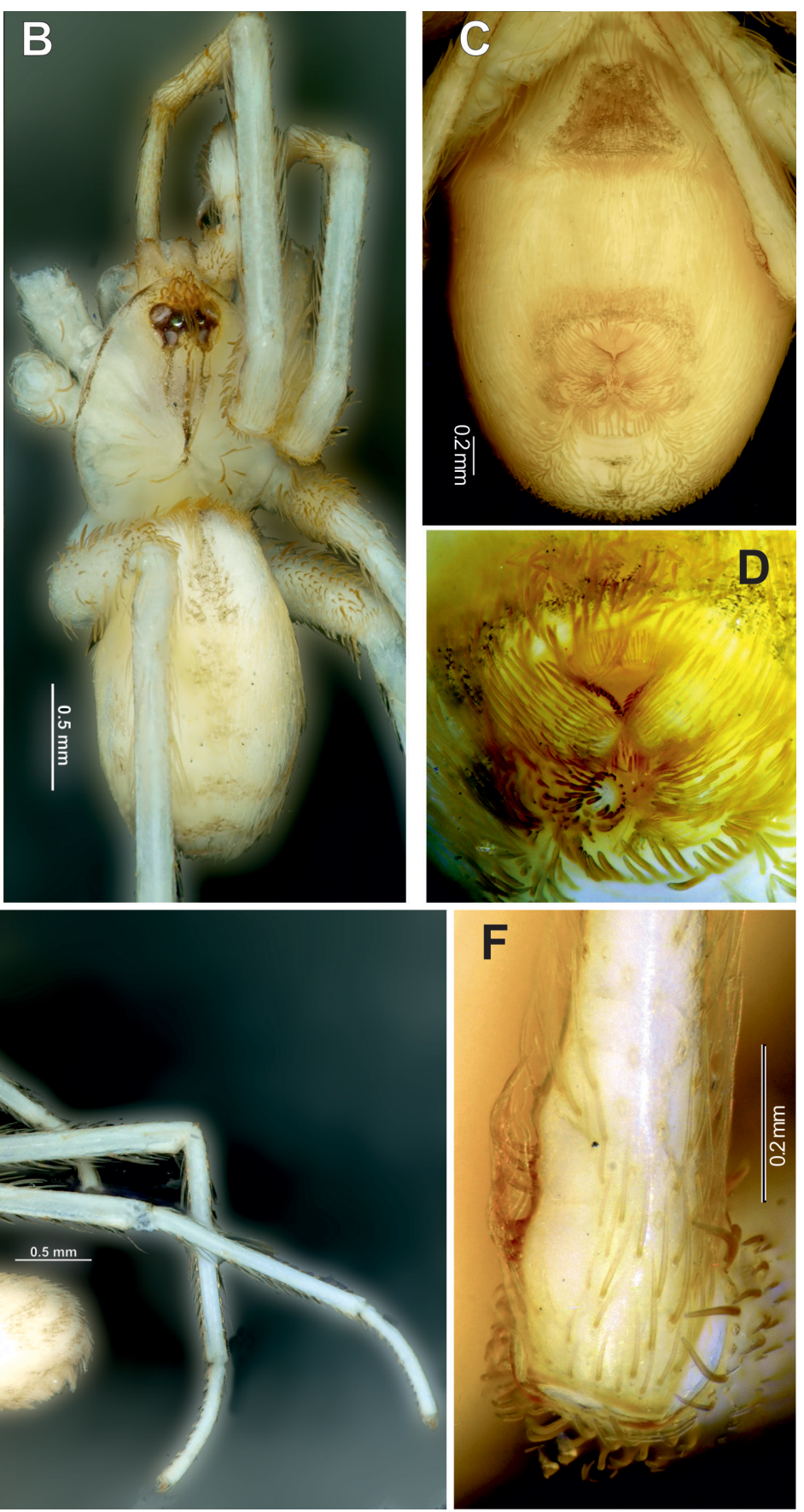

Fig. 31. Somatic characters of Zaitunia wunderlichi sp. nov., paratype, $q$ (A, C-D, F), paratype (B), § and holotype (E), ô. - A-B. Habitus, dorsal. C. Abdomen, ventral. D. Spinnerets, ventral. E. Habitus, lateral. F. Calamistrum, lateral. 

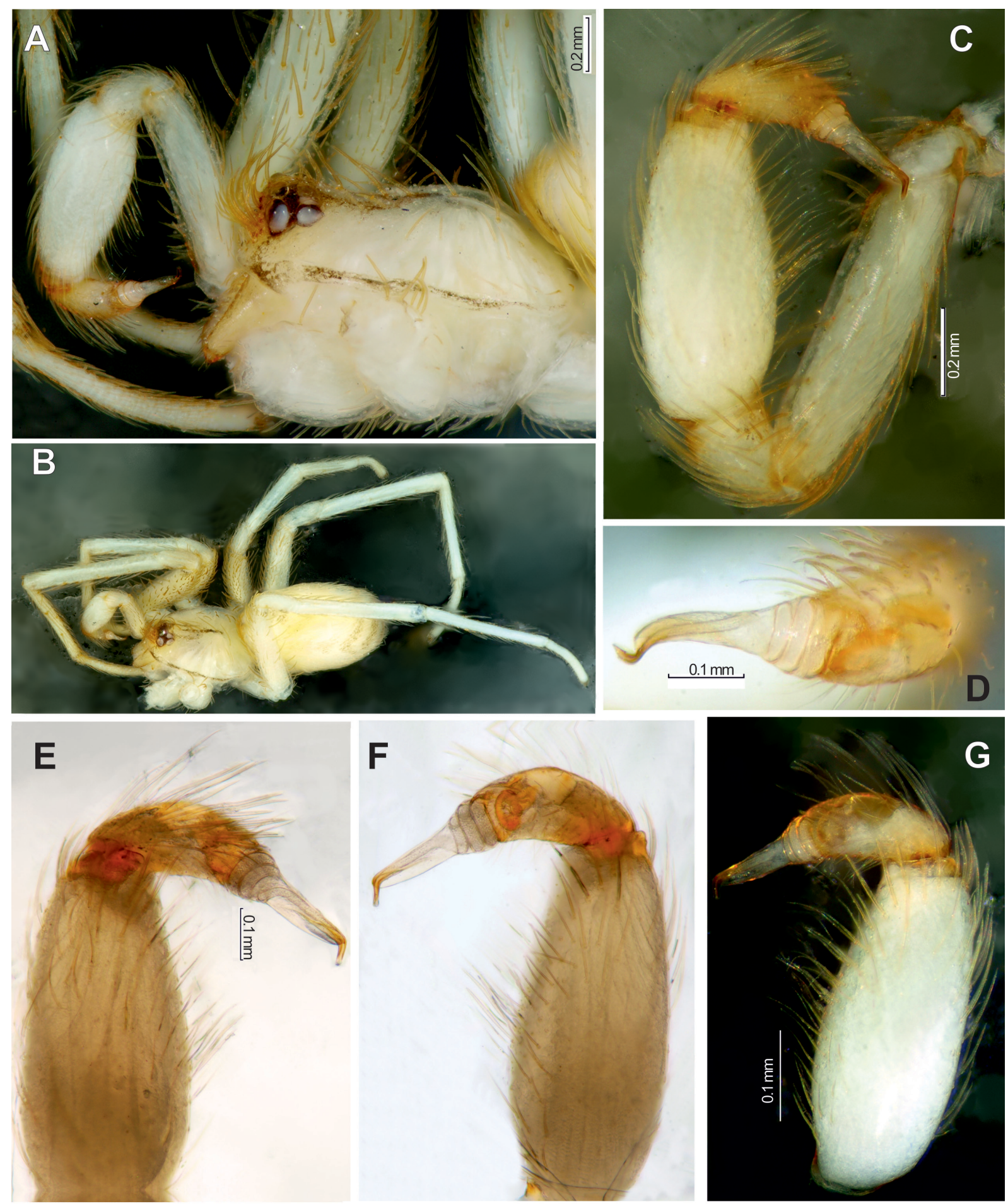

Fig. 32. Somatic characters and copulatory organs of Zaitunia wunderlichi sp. nov., paratype, $\hat{o}$. A. Prosoma, lateral. B. Habitus, dorso-lateral. C. Palp, prolateral. D. Cymbium and bulb, dorsal. E. Terminal part of palp, prolateral. F-G. Same, retrolateral. 

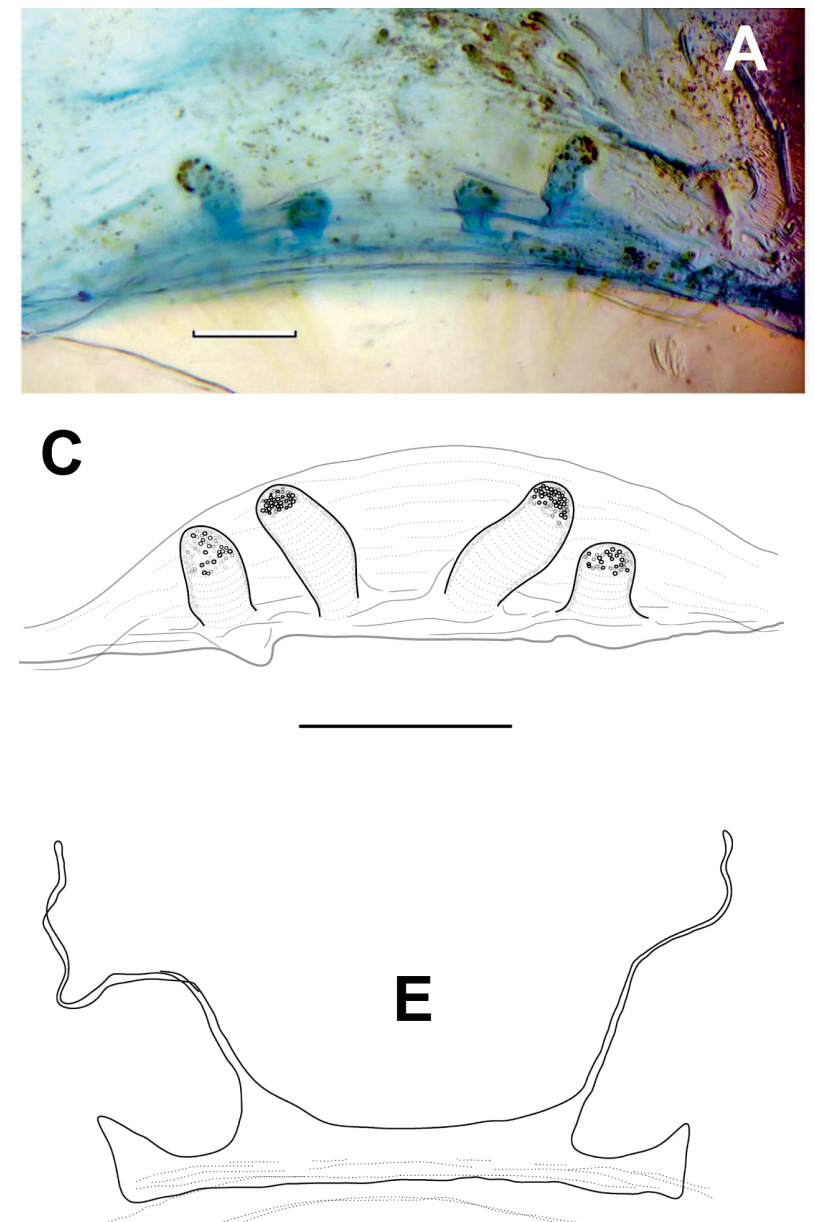
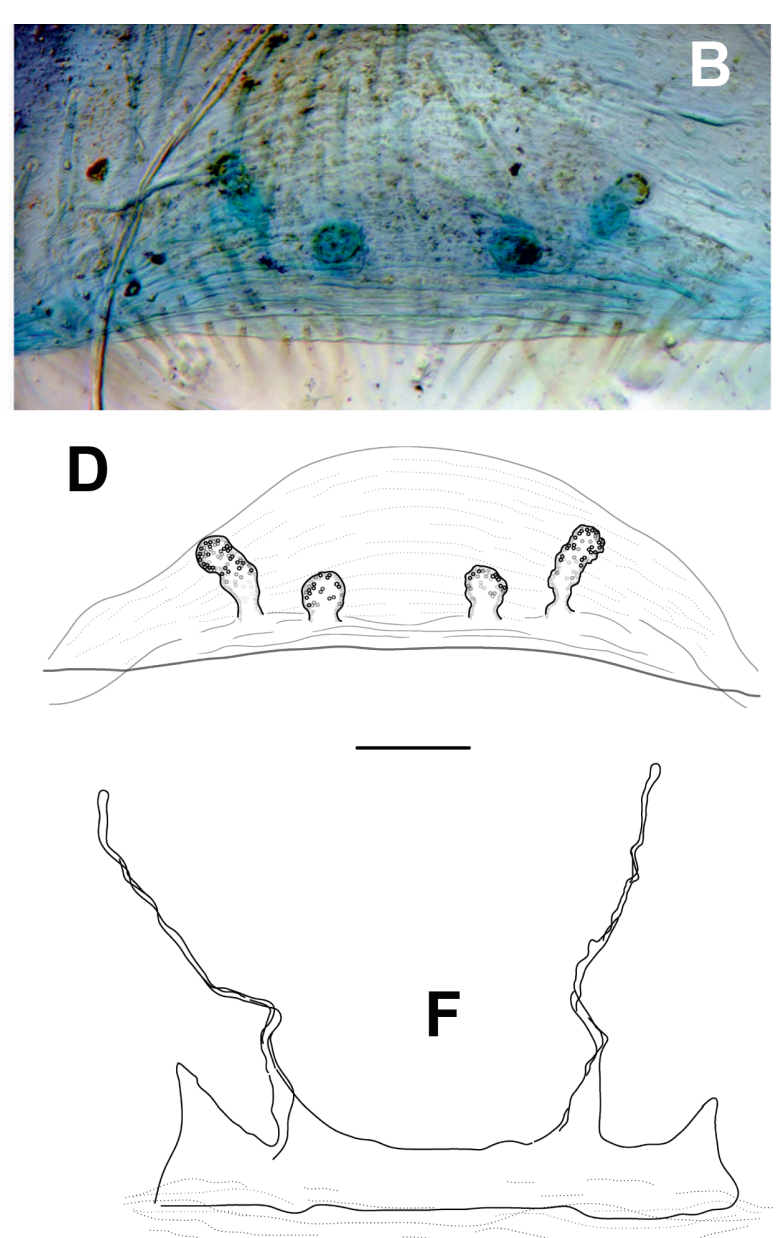

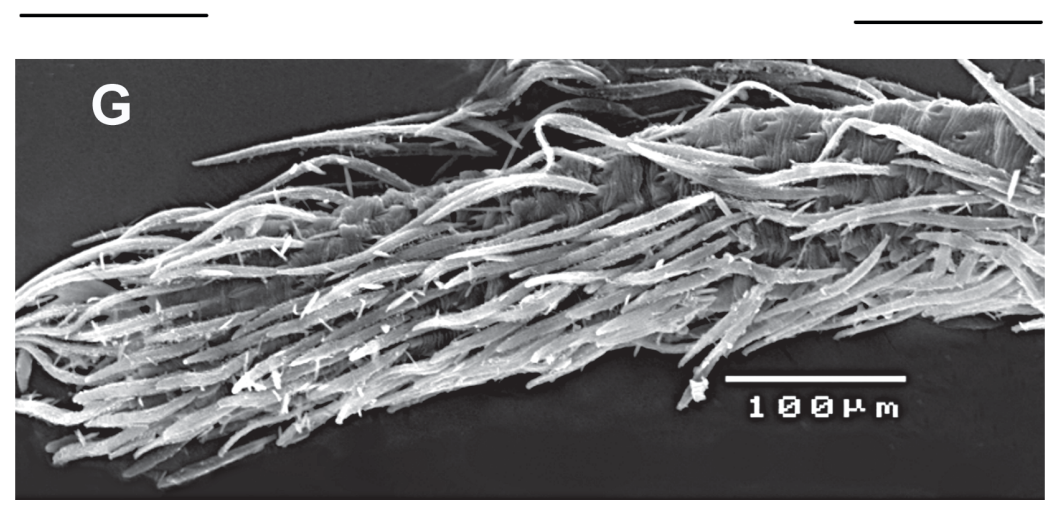

Fig. 33. Somatic characters and copulatory organs of Zaitunia wunderlichi sp. nov., paratype, $q$ (A-B, D), Z. beshkentica (Andreeva \& Tyshchenko, 1969), ㅇ from Babatagh Mts (C), Z. logunovi sp. nov., paratype, $\hat{o}$ (E, G) and $Z$. schmitzi (Kulczyński, 1911), $q$ from Jerusalem area (F). - A-D. Endogyne, dorsal (A, C-D) and ventral (B). E-F. Posterior respiratory system, dorsal. G. Close-up view of male tarsus IV, prolateral, showing pseudosegmentation. Scale bars: $A-B, D-G=0.1 \mathrm{~mm} ; C=0.2 \mathrm{~mm}$. 
Paratypes $(2 \hat{\jmath}, 1 \phi)$

KYRGYZSTAN: $2 \hat{\delta} \hat{o}^{\circ}$, same data as holotype (TAU, ZMMU); 1 , , Chatkal Mts, Arkit, $41^{\circ} 48^{\prime} \mathrm{N}$, 71'57' E, 1300 m, 2 May 1983, S. Zonstein (ZMMU).

\section{Note}

Although males and the only collected female listed above were found in two separate areas distant from each other by about $100 \mathrm{~km}$, they are very similar in having the same type of body and legs colouration, as well as in possessing a very similar carapace setation and a similar conformation of the eye group. Additionally, they all occurred in almost identical humid biotopes. Thus, we have no doubt that in both these situations, we are dealing with representatives of the same species.

\section{Description}

Male (holotype)

Habitus. See Fig. 31E.

BODY LENGTH. 2.78.

Colour. Whole spider pale greyish-yellow; eye tubercle dark brown; Y-shaped median spot occupying cephalic portion and extending to clypeus, and margins of carapace light brown; weak and diffuse dorsal abdominal pattern consisting of lancet-shape median spot anteriorly and a few transverse fasciae posteriorly pale brown.

CARAPACE (Fig. 42F). 1.18 long, 1.00 wide.

Eyes. AME 0.06, ALE 0.10, PLE 0.10, PME 0.10, AME-AME 0.06.

PaLP (Figs 32C-G, 44D). Femur slightly longer than tibia (in prolateral view); tibia 1.5 times wider that femur; cymbium as long as bulb; keel of embolic neck with straight margin (not curved in terminal part); tip of embolus bent downward.

LEG MEASUREMENTS. $\widehat{\jmath}($ ( $)$

\begin{tabular}{lcccccc}
\hline & Femur & Patella & Tibia & Metatarsus & Tarsus & Total \\
\hline Palp & $0.76(0.84)$ & $0.24(0.35)$ & $0.76(0.57)$ & - & $0.23(0.62)$ & $1.99(2.38)$ \\
I & $1.61(1.69)$ & $0.51(0.56)$ & $1.60(1.63)$ & $1.47(1.44)$ & $1.08(1.14)$ & $6.27(6.46)$ \\
II & $1.26(1.41)$ & $0.46(0.52)$ & $1.13(1.12)$ & $1.12(0.97)$ & $0.83(0.71)$ & $4.80(4.73)$ \\
III & $1.19(1.15)$ & $0.43(0.52)$ & $0.97(0.91)$ & $1.13(0.86)$ & $0.77(0.63)$ & $4.49(4.07)$ \\
IV & $1.68(1.55)$ & $0.56(0.56)$ & $1.48(1.24)$ & $1.61(1.25)$ & $1.01(0.80)$ & $6.34(5.40)$ \\
\hline
\end{tabular}

Female

Habitus. See Fig. 31A.

Body LENGTH. 4.11.

CoLour. As in male, except without darkened carapace margins.

Carapace. 1.59 long, 1.27 wide.

Eyes. AME 0.08, ALE 0.15, PLE 0.12, PME 0.10, AME-AME 0.05. 
ENDOGYNe (Fig. 33A-B, D). Both pairs of receptacles long (especially lateral pair), cylindrical with somewhat dilated heads; lateral and median receptacles separated by about one diameter; lateral receptacles longer than median; median receptacles separated by 3 diameters; pores cover the entire receptacle.

\section{Variation}

Length of the carapace in males varies from 1.15 to 1.23 , the body and leg colouration does not vary significantly.

\section{Ecology}

The species inhabits humid habitats including walnut forest of Juglans regia L. in the middle mountain belt, where it certainly prefers more open slopes, occurring under stones in low forest and shrubs.

\section{Distribution}

Southern Kyrgyzstan (Western Tian-Shan Mts) (Fig. 49).

\section{Zaitunia maracandica-group}

\section{Remarks}

This group includes pale-coloured species. The clypeus, post-ocular area, dorsal abdominal pattern and often also lateral margins of the carapace are slightly darker than the pale background colour. Legs I-IV with or without darker fasciae. The conical tegulum is much shorter than the cymbium. The relatively long embolus is provided with a low, more or less reduced keel. The vulva has two pairs of receptacles. Five species are included: Z. ferghanensis sp. nov. from Kyrgyzstan and Uzbekistan, Z. maracandica (Charitonov, 1946) from Uzbekistan and Kazakhstan and (tentatively, because of unknown male characters) Z. feti sp. nov. from Turkmenistan, Z. minuta sp. nov. from Uzbekistan and Z. zonsteini Fomichev \& Marusik, 2013 from Kazakhstan.

\section{Key to species of the Zaitunia maracandica-group}

(Males of Z. feti sp. nov., Z. minuta sp. nov. and Z. zonsteini are unknown.)

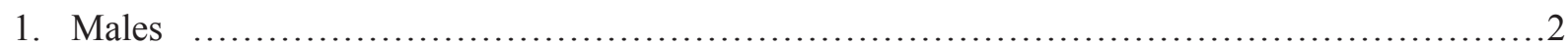

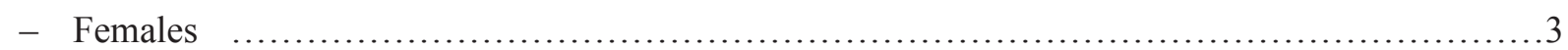

2. Palpal tibia considerably swollen, vestigial embolic keel terminates more gently (Figs 37D-E, 44F); Uzbekistan, southern Kazakhstan ....................... maracandica (Charitonov, 1946)

- Palpal tibia only slightly swollen, vestigial embolic keel terminates more steeply (Figs 35A-C, 44E); Kyrgyzstan, Uzbekistan .... .Z. ferghanensis sp. nov.

3. Receptacles short, globulate or stump-shaped, subequal in size; lateral and median receptacles located near each other (Figs 40, 41I-M)

- Receptacles more elongate and noticeably differ by size, lateral and median receptacles more distant from each other (Figs 35E-J, 36D-E, 38E-I) .

4. Receptacles stump-shaped, with only few gland-pores apically (Fig. 40); Uzbekistan

- Receptacles globulate, with more numerous gland-pores spread evenly (Fig. 41I-M); Kazakhstan

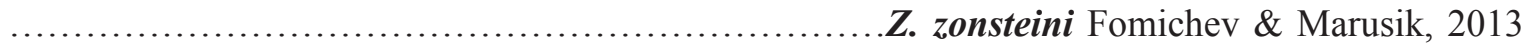

5. Distance between lateral and median receptacles is shorter; lateral pair of receptacles longer than median pair (Fig. 35E-J) 
- Distance between lateral and median receptacles is longer; lateral pair of receptacles subequal to

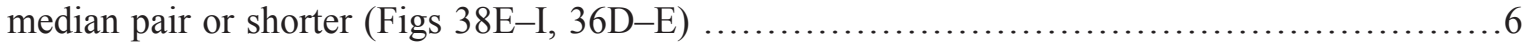

6. Receptacles are subequal in size (Fig. 38E-I) ................ maracandica (Charitonov, 1946)

- Median receptacles considerably longer than lateral pair (Fig. 36D-E); Turkmenistan Z. feti sp. nov.

\section{Zaitunia ferghanensis sp. nov. urn:1sid:zoobank.org:act:71E3378A-5770-4E84-B96F-6E1662074823}

Figs 34-35, 44E

\section{Diagnosis}

By structure of the bulb, males of Z. ferghanensis sp. nov. resemble those of $Z$. maracandica but differ by the shape of the palpal tibia, which is considerably less swollen and lacks thickened setae, as well as by the shape of the vestigial embolic keel, which terminates more sharply than in the latter species (cf. Figs 35A-D, 37A-C). Females are similar by the structure of the vulva to Z. maracandica and $Z$. wunderlichi sp. nov.; they differ from the former species by the relative size of the median receptacles, which are larger than the lateral pair (in Z. maracandica, all receptacles are subequal in size, cf. Fig. 38I), and from the latter by the longer median and lateral receptacles (which are shorter in $Z$. wunderlichi sp. nov., cf. Fig. 33A-B, D). Unlike Z. maracandica and Z. wunderlichi sp. nov., the lateral receptacles in Z. ferghanensis sp. nov. are dilated basally (Fig. 35E-J).

\section{Etymology}

Named after the distribution area, Ferghana Valley.

\section{Material examined}

Holotype

KYRGYZSTAN: $\widehat{\jmath}$, eastern border of Ferghana Valley, foothills of Alai Mts, Mt. Taht-i-Suleiman in Osh city, 40³2' N, 72²7' E, 1100 m, 7 Jun. 1985, A.A. Zyuzin (TAU).

Paratypes $(2 \hat{\jmath}, 5$ 우, 4 우 subad.)

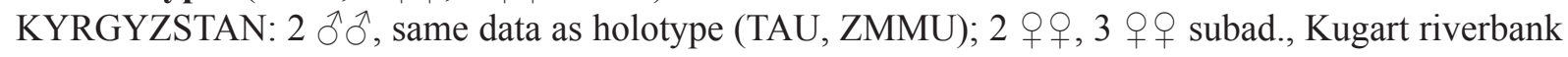

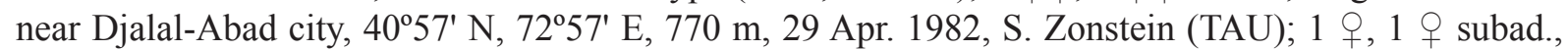
same locality, but 29 Aug. 1982 (TAU); 1 q, Kurshab River valley 16 km E of Osh city, 40 30' N, 7302' E, 1200-1400 m, 1 Jun. 1988, S.N. Rybin (ZMMU).

UZBEKISTAN: 1 q, surroundings of Ferghana city, 40²3' N, 71²47' E, 14 May 1981, D.M. Schwetz (TAU).

\section{Description}

Male (holotype)

Habitus. See Fig. 34B.

Body LENGTH. 3.14.

CoLour. Whole spider medium brownish-yellow; eye tubercle dark brown to brownish-black; cephalic part, clypeus and margins of carapace not darkened; abdomen with almost indistinct and slightly interrupted darkened spot dorso-medially.

CARAPACE (Fig. 34F; paratype from the type locality). 1.44 long, 1.09 wide. 
Eyes. AME 0.09, ALE 0.14, PLE 0.13, PME 0.11, AME-AME 0.05.

Palp (Figs 35A-D, 44E). Femur and tibia subequal in length; tibia about 1.5 times wider than femur, wider in basal part than terminally; cymbium and bulb subequal in length; bulb conical, embolus gently curved and roundly bent subapically.
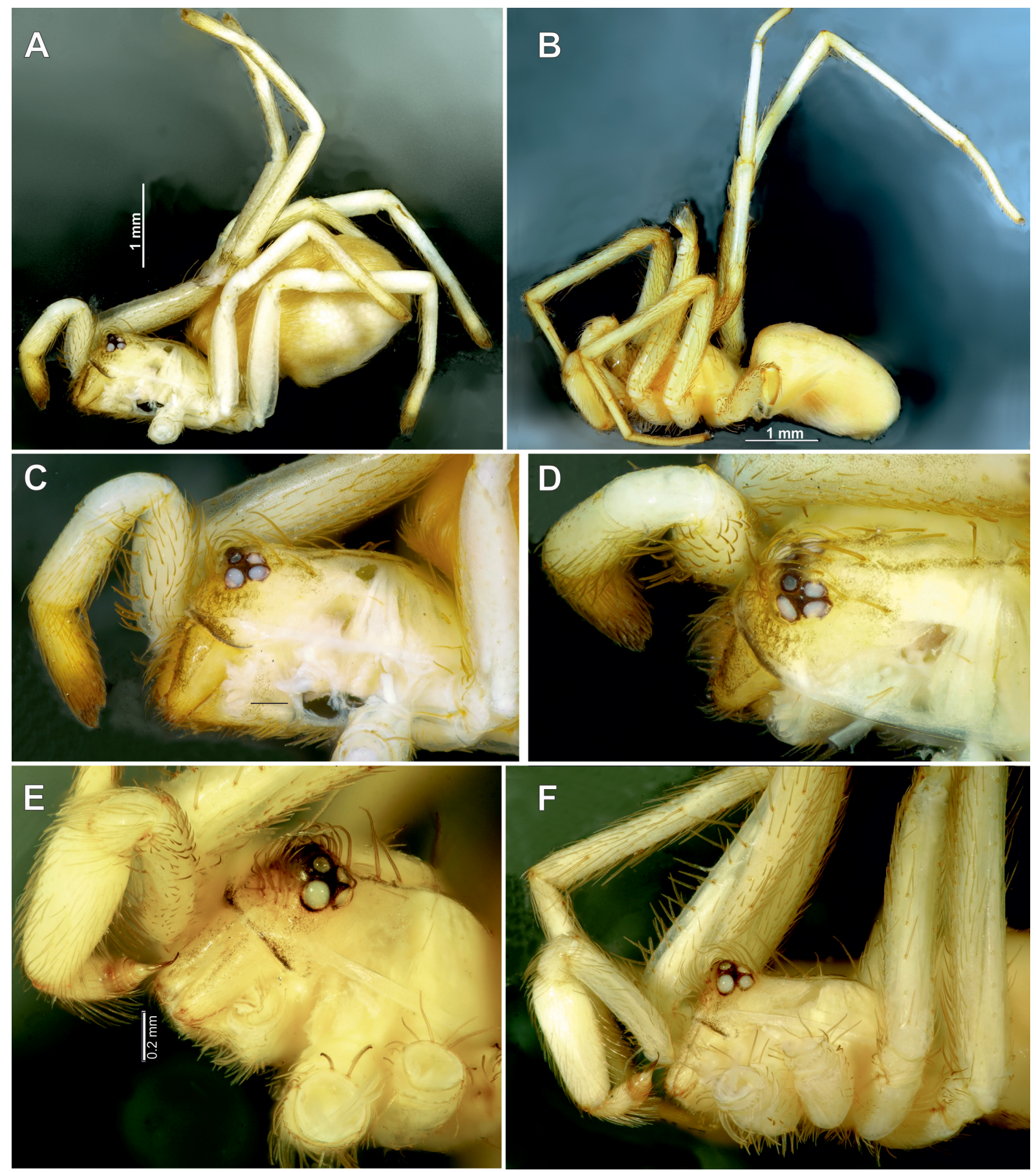

Fig. 34. Somatic characters of Zaitunia ferghanensis sp. nov., paratype, $\circ$ from Kurshab (A, C-D) and paratype, $\widehat{\jmath}$ from Osh $(\mathbf{B}, \mathbf{E}-\mathbf{F})$. - A-B. Habitus, lateral. C, F. Prosoma, lateral. D. Same, dorso-lateral. E. Same, fronto-lateral. 

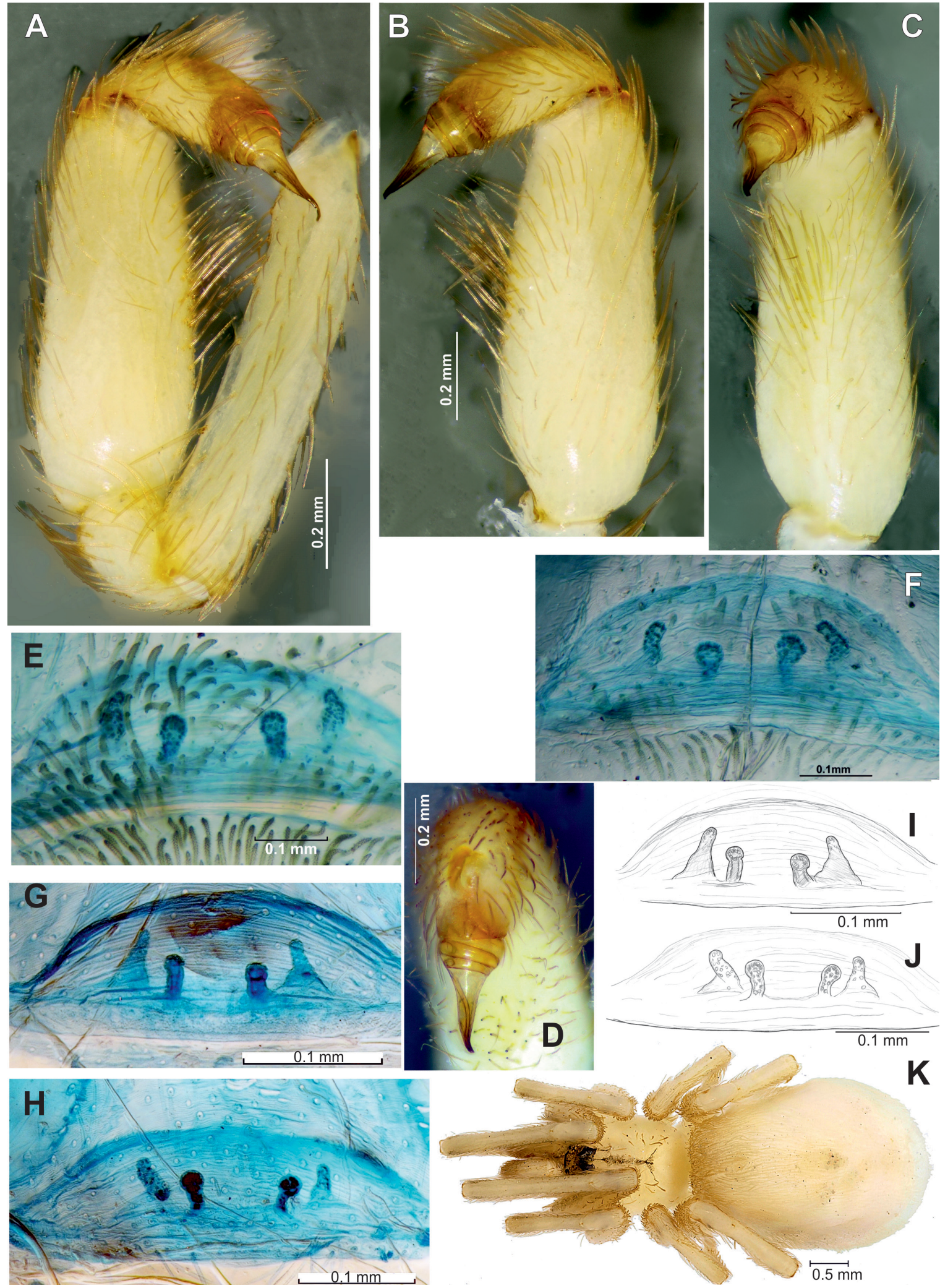

Fig. 35. Copulatory organs and somatic characters of Zaitunia ferghanensis sp. nov., paratype, $\widehat{\partial}$ from Osh (A-D) and paratypes, $q$ + 9 from Djalal-Abad $(\mathbf{E}-\mathbf{J})$ and Ferghana $(\mathbf{K})$. - A. Palp, prolateral. B-D. Terminal part of palp, retrolateral, ventral and dorsal. E-J. Endogyne (variants), dorsal. K. Habitus, dorsal. 
LEG MEASUREMENTS. $\overbrace{}^{\lambda}(+)$

\begin{tabular}{lcccccc}
\hline & Femur & Patella & Tibia & Metatarsus & Tarsus & Total \\
\hline Palp & $1.09(0.87)$ & $0.27(0.39)$ & $0.91(0.54)$ & - & $0.36(0.74)$ & $2.63(2.54)$ \\
I & $2.12(1.85)$ & $0.59(0.62)$ & $2.07(1.73)$ & $2.04(1.44)$ & $1.37(1.00)$ & $8.19(6.64)$ \\
II & $1.95(1.37)$ & $0.55(0.53)$ & $1.64(1.11)$ & $1.60(0.97)$ & $1.17(0.72)$ & $6.91(4.70)$ \\
III & $1.59(1.26)$ & $0.53(0.54)$ & $1.43(0.94)$ & $1.69(1.03)$ & $0.94(0.68)$ & $6.18(4.45)$ \\
IV & $2.35(1.78)$ & $0.61(0.67)$ & $2.19(1.37)$ & $2.43(1.39)$ & $1.44(0.86)$ & $9.02(6.07)$ \\
\hline
\end{tabular}

Female (Kurshab)

Habitus. See Fig. 34A.

BODY LENGTH 4.11.

CoLour. As in male but darker brownish pattern on carapace (narrow median longitudinal stripe, two shorter stripes located sideward and reticulated area covering clypeus) better developed; abdomen also a little darker, with almost indistinct brownish median spot.

Carapace (Fig. 34C-D). 1.53 long, 1.19 wide.

Eyes. AME 0.09, ALE 0.14, PLE 0.13, PME 0.10, AME-AME 0.05.

Endogyne (Fig. 35E-J). Receptacles separated; median receptacles club-like, and lateral receptacles subconical; both pairs with corrugated stems; head of median receptacles separated by 3 diameters; pores present on stem and heads.

\section{Variation}

Carapace length in males varies from 1.35 to 1.47 , in females from 1.40 to 1.65 . Carapace with clypeus and margins slightly or noticeably pigmented; abdomen with or without weak dorsal pattern, consisting of a narrow interrupted median stripe and several pairs of short lateral chevrons (Figs 34, 35K).

\section{Ecology}

This species inhabits semi-desert habitats in piedmont plains and foothills.

\section{Distribution}

Kyrgyzstan, Uzbekistan (Fig. 49).

Zaitunia feti sp. nov.

urn:Isid:zoobank.org:act:01F422A2-5DE8-42F9-AB10-246EA623877B

Fig. 36

\section{Diagnosis}

By the structure of the endogyne, Z. feti sp. nov. resembles Z. maracandica but differs by the extended median receptacles, which are considerably longer than the lateral pair (vs similarly long in the latter species, cf. Figs 36D-E, 38E-I).

\section{Etymology}

The specific epithet is given after our good friend and colleague Victor Fet (Marshall University, USA), the author of many works devoted to the spiders of Turkmenistan. 


\section{Material examined}

\section{Holotype}

TURKMENISTAN: 1 , western foothills of Kughitang Mts (also known as Koytendagh Mts), near

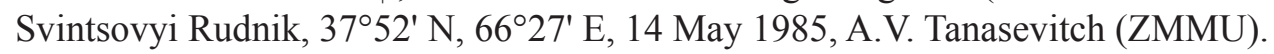

\section{Description}

Female (holotype)

Habitus. See Fig. 36A-B.

\section{Body LENGTH. 4.37.}

CoLour. Body and legs pale brownish-yellow, carapace with contrasting median brown spot and narrow margins; eye tubercle blackish-brown; legs with distinct brown marks and fasciae; abdomen with brown dorsal pattern consisting of contrasting narrow median band combined in posterior third with a few pairs of weak and diffuse lateral chevrons.

CARAPACE. 1.38 long, 1.12 wide.

Eyes. AME 0.07, ALE 0.14, PLE 0.12, PME 0.10, AME-AME 0.07.
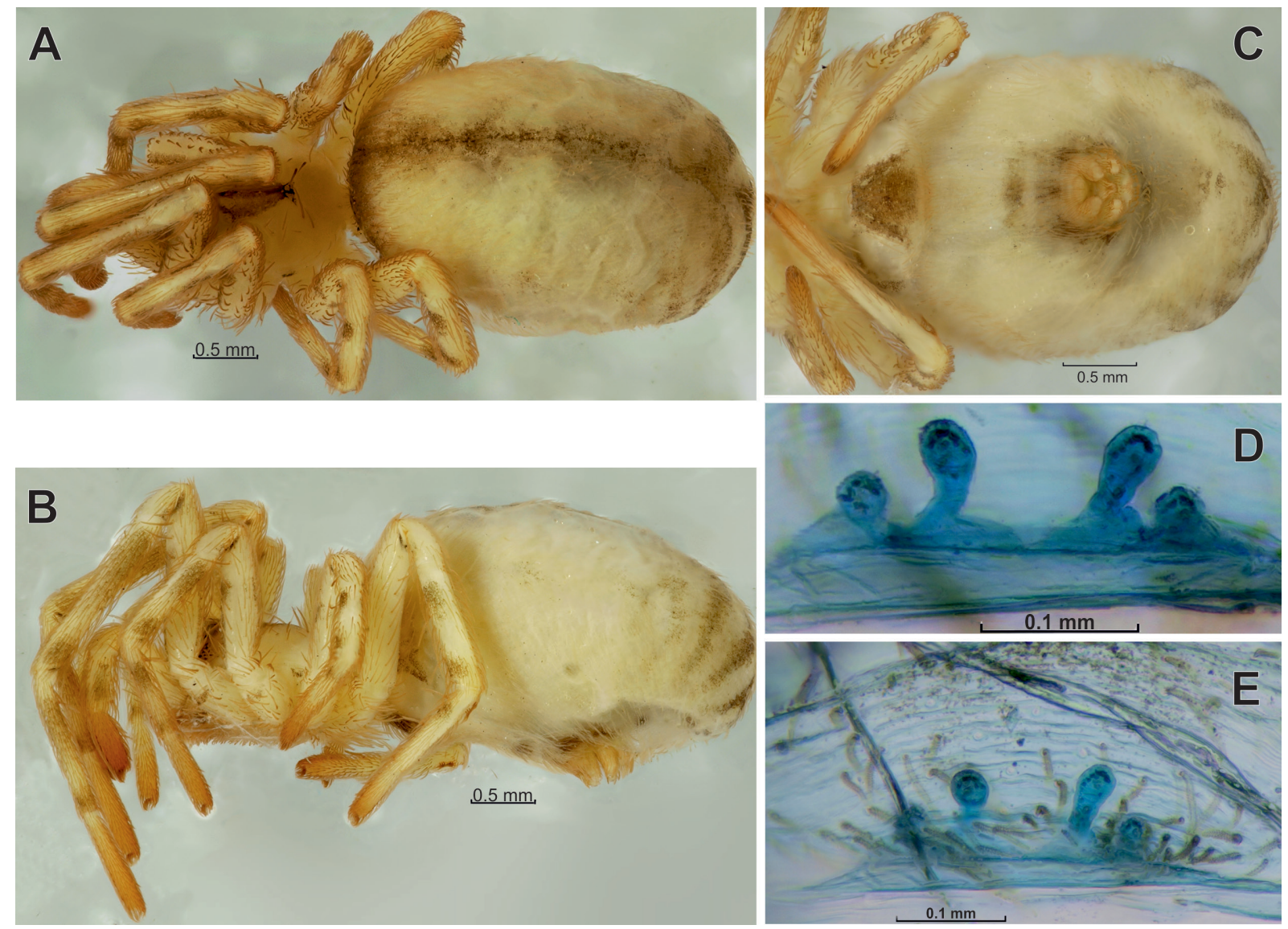

Fig. 36. Somatic characters and endogyne of Zaitunia feti sp. nov., holotype, $q$. A-B. Habitus, dorsolateral and lateral. C. Abdomen, ventral. D-E. Endogyne, dorsal. 
Endogyne (Fig. 36D-E). Median receptacles club-like, wide at the base, with heads wider than stems, pore glands cover whole receptacle, receptacles separated by almost 3 diameters of heads. Lateral receptacles globular, with short stems; heads of median and lateral receptacles separated by one diameter.

LEG MEASUREMENTS.

\begin{tabular}{lcccccc}
\hline & Femur & Patella & Tibia & Metatarsus & Tarsus & Total \\
\hline Palp & 0.67 & 0.34 & 0.42 & - & 0.52 & 1.95 \\
I & 1.39 & 0.52 & 1.31 & 1.21 & 1.13 & 5.56 \\
II & 1.13 & 0.47 & 0.92 & 0.84 & 0.63 & 3.99 \\
III & 0.92 & 0.46 & 0.67 & 0.78 & 0.56 & 3.39 \\
IV & 1.38 & 0.49 & 1.05 & 0.98 & 0.66 & 4.56 \\
\hline
\end{tabular}

Male

Unknown.

\section{Ecology}

The holotype was collected in the desert foothill area; other details are unknown.

\section{Distribution}

Known only from the type locality (Fig. 49).

Zaitunia maracandica (Charitonov, 1946)

Figs $37-38,42 \mathrm{G}-\mathrm{H}, 44 \mathrm{~F}$

Filistata maracandica Charitonov, 1946: 20, fig. 3 (subad. ๆ).

Filistata maracandica - Charitonov 1969: 66 (subad. P).

Zaitunia maracandica - Zonstein 1990: 50 (transfer from Filistata).

\section{Diagnosis}

In the structure of the bulb, males of $Z$. maracandica resemble $Z$. ferghanensis sp. nov. but differ by the shape of the palpal tibia, which is considerably more swollen, with thickened setae, as well as by the shape of the vestigial embolic keel, which terminates more gently than in Z. ferghanensis sp. nov. (cf. Figs $35 \mathrm{~A}-\mathrm{D}, 37 \mathrm{~A}-\mathrm{C}$ ). In the structure of the endogyne, $Z$. maracandica is similar to $Z$. ferghanensis sp. nov. and $Z$. wunderlichi sp. nov., but differs from these species by the shape of the median receptacles, which are subequal to the lateral pair (by contrast, in $Z$. ferghanensis sp. nov. the lateral receptacles are largest, cf. Fig. 38E-J) and from Z. wunderlichi sp. nov. by the longer median receptacles (which are shorter in the latter species; cf. Fig. 33A-B, D).

\section{Type material}

Lectotype (designated here)

UZBEKISTAN: + subad., southern foothills of Zaravshan Mts, 9-12 km north of Kitab, 21 Mar. 1942, D.M. Fedotov (ZMPU; examined).

\section{Paralectotypes}

UZBEKISTAN: 2 juvs, same data as holotype.

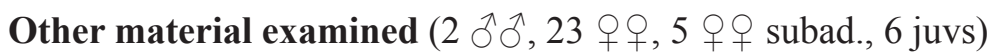
UZBEKISTAN: 2 우, $10 \mathrm{~km} \mathrm{~N}$ of Kitab, 39 ${ }^{\circ} 12^{\prime} \mathrm{N}, 66^{\circ} 54^{\prime} \mathrm{E}, 800-850 \mathrm{~m}, 9$ Apr. 1990, S. Zonstein \& S.V. Ovchinnikov (TAU); 1 ㅇ, surroundings of Bakhmal, 4004' N, 67³9' E, 5 May 1990, A.A. Zyuzin 
\& A.A. Feodorov (TAU); 1 \% , north-western slope of Hissar Mts, Ishkent, 38 $51^{\prime} \mathrm{N}, 66^{\circ} 58^{\prime} \mathrm{E}, 1200 \mathrm{~m}$,

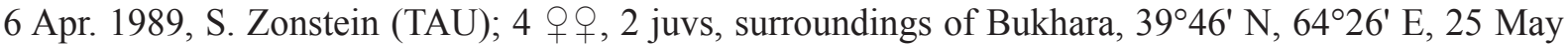

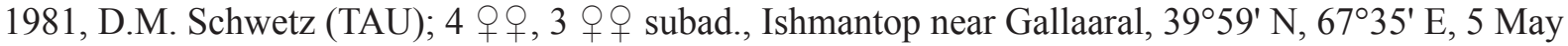
1990, A.A. Feodorov \& A.A. Zyuzin (TAU); 1 गै, Ulus, 53 km W of Samarkand, 39³4' N, 66²3' E, 550 m, 7 May 1990, A.A. Feodorov \& A.A. Zyuzin (TAU); 3 qㅜ, same data, but 8 May 1990 (TAU); 3 우, 3 juvs, western tip of Zeravshan Mts, foothills, Beshbarmak (now Djam), $47 \mathrm{~km}$ SW of Samarkand, $39^{\circ} 24^{\prime}$ N, 66²7' E, 700-800 m, 8 May 1990, A.A. Feodorov \& A.A. Zyuzin (TAU).

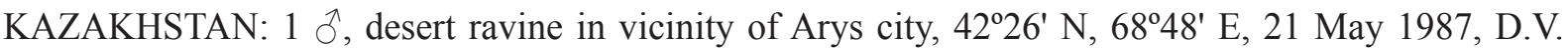

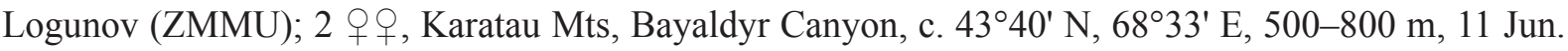
1989, A.A. Zyuzin (TAU); 2 + $ᄋ$ subad., 1 juv., same mountain ridge, surroundings of Zhunusata town,

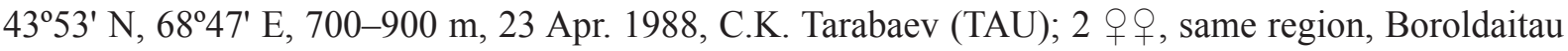
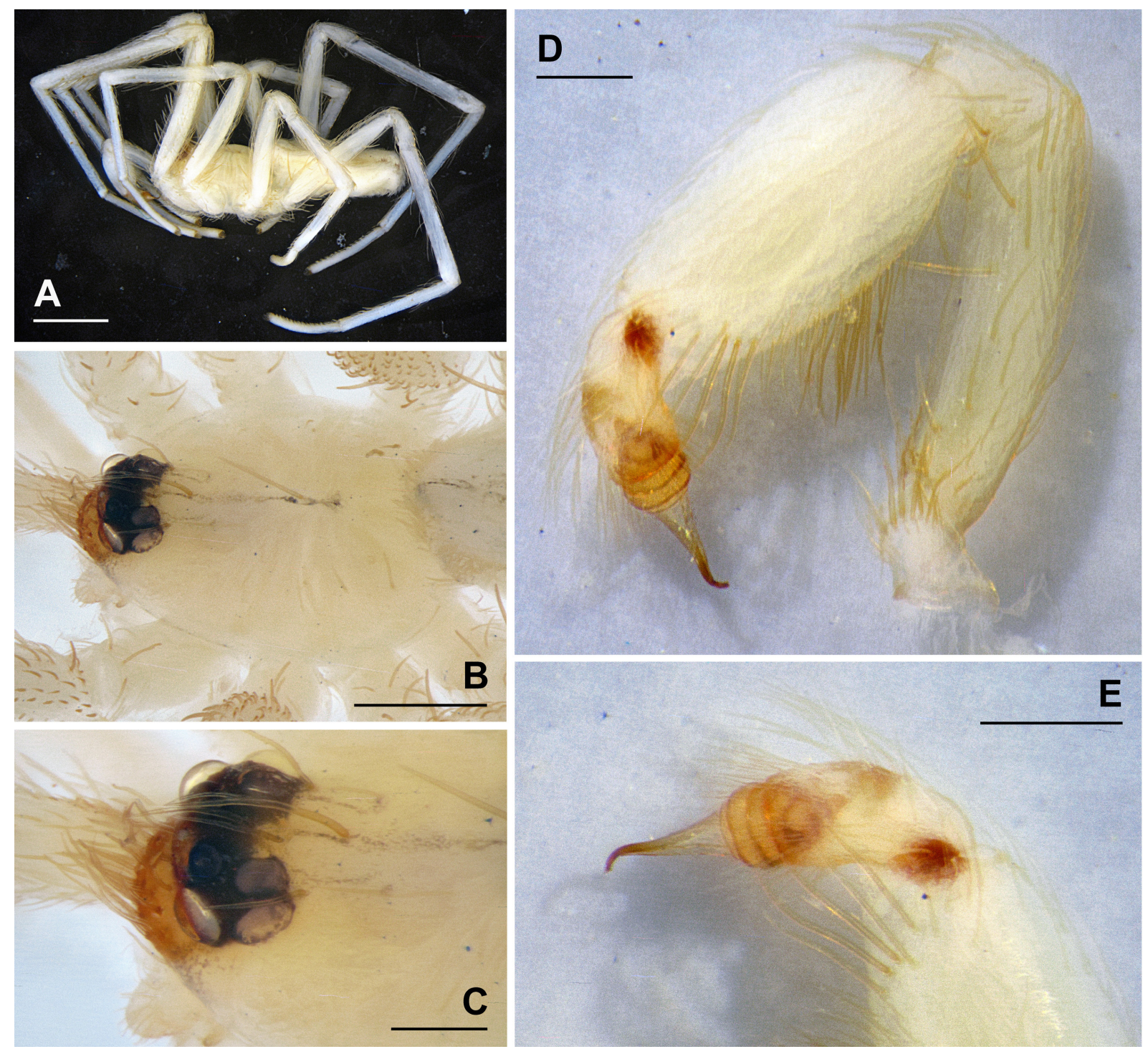

Fig. 37. Somatic characters and palp of Zaitunia maracandica (Charitonov, 1946), đ̂ from Ulus. A. Habitus, lateral. B-C. Prosoma, laterodorsal. D-E. Palp, retro- and prolateral. Scale bars: A=1.0 mm; $\mathrm{B}=0.5 \mathrm{~mm} ; \mathrm{C}-\mathrm{E}=0.2 \mathrm{~mm}$. 
Mts, Boroldai river canyon, c. 42 $52^{\prime}$ N, 6956' E, 600-800 m, 16 Apr. 1988, C.K. Tarabaev (TAU); 1 , Kyzylkum Desert, Zhautkan well, 43 km W of Bairkum town, 11 May 1995, A.A. Zyuzin (ZMMU).

\section{Description}

Male (Ulus)

Habitus. See Fig. 37A.

BODY LENGTH. 3.27.

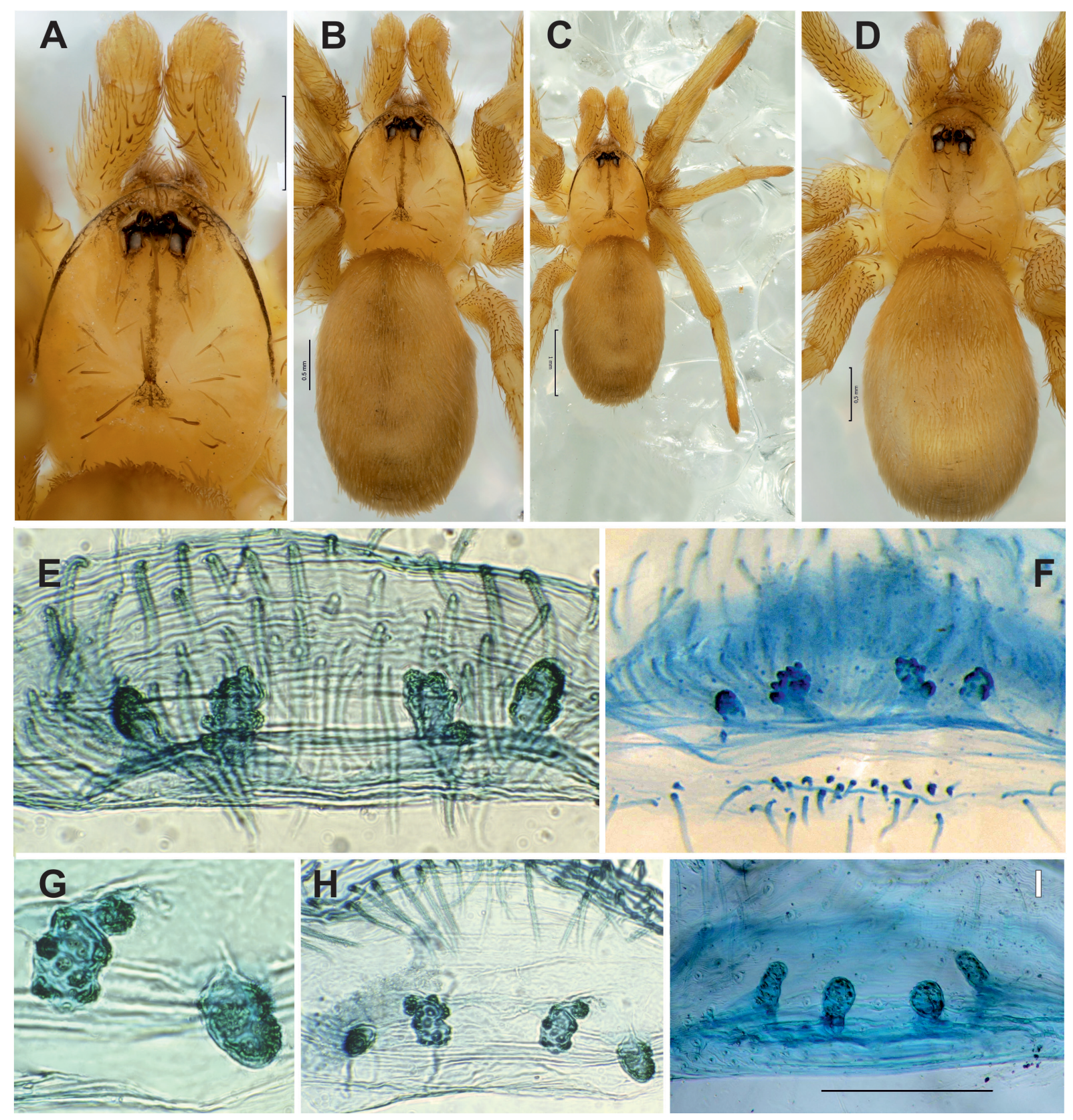

Fig. 38. Somatic characters and endogyne of Zaitunia maracandica (Charitonov, 1946), $q q$ from Bukhara (A-D), Kitab (E-H) and Ulus (I). A. Prosoma, dorsal. B, D. Body, dorsal. C. Habitus, dorsal. E-F, I. Endogyne, dorsal. G. Right pair of receptacles, anterior. H. Endogyne, anterior. Scale bars: B, D $=0.5 \mathrm{~mm} ; \mathrm{C}=1.0 \mathrm{~mm} ; \mathrm{I}=0.2 \mathrm{~mm}$. 
CoLour. Body and legs pale greyish-yellow; clypeus reddish-brown; eye tubercle blackish-brown; carapace with weak and narrow darker median line spreading from central area to eye tubercle; carapace margins not darkened; abdomen dorsally with narrow diffuse, interrupted and almost indistinct pale brown median line.

CARAPace (Figs 37B, 42G). 1.49 long, 1.14 wide.

Eyes (Fig. 37C). AME 0.09, ALE 0.14, PLE 0.13, PME 0.11, AME-AME 0.05.

Palp (Figs 37D-E, 44F). Femur longer than tibia and almost 2 times thinner; tibia with a few strong ventro-retrolateral setae in terminal part; cymbium subequal in length to bulb; bulb conical; embolic part long and straight; ventral keel of embolic neck gradually tapering; tip of embolus bent downward.

LEG MEASUREMENTS. $\hat{\jmath}(+9)$

\begin{tabular}{lcccccc}
\hline & Femur & Patella & Tibia & Metatarsus & Tarsus & Total \\
\hline Palp & $1.05(0.92)$ & $0.36(0.46)$ & $0.78(0.61)$ & - & $0.28(0.84)$ & $2.47(2.83)$ \\
I & $2.18(1.94)$ & $0.63(0.63)$ & $1.98(1.80)$ & $1.89(1.53)$ & $1.38(1.18)$ & $8.06(7.08)$ \\
II & $1.77(1.50)$ & $0.55(0.60)$ & $1.54(1.23)$ & $1.56(1.15)$ & $1.12(0.91)$ & $6.54(5.39)$ \\
III & $1.62(1.39)$ & $0.55(0.58)$ & $1.36(1.06)$ & $1.60(1.12)$ & $0.83(0.86)$ & $5.96(5.01)$ \\
IV & $2.13(1.94)$ & $0.57(0.63)$ & $2.01(1.42)$ & $1.72(1.42)$ & $1.13(0.89)$ & $7.56(6.30)$ \\
\hline
\end{tabular}

Female (Kitab)

Habitus. See Fig. 38C.

Body LENGTH. 4.33 .

CoLour. As in male, but abdomen dorsally and carapace margins are somewhat darker.

CARAPace (Fig. 42H). 1.62 long, 1.34 wide.

Eyes. AME 0.07, ALE 0.13, PLE 0.11, PME 0.08, AME-AME 0.08.

ENDOGYNE (Fig. 38E-I). All receptacles with corrugated stems, equally spaced; median receptacles clublike, heads separated by 1.6 diameters, shorter than lateral; lateral receptacles conical, with wide bases, slightly bent mesally in the middle part, converging; gland pores evenly distributed on both pairs of receptacles.

\section{Variation}

Carapace length in females varies from 1.53 to 2.05; spiders may have darker marks and fasciae on the carapace, legs and abdomen, or these marks may be almost completely absent on the pale background (cf. Fig. 38A-D).

\section{Ecology}

This species occurs in various habitats from foothill deserts, steppes and shrubs to open Juniperus forest in the middle mountain belt.

\section{Distribution}

Uzbekistan and southern Kazakhstan (Fig. 49). 

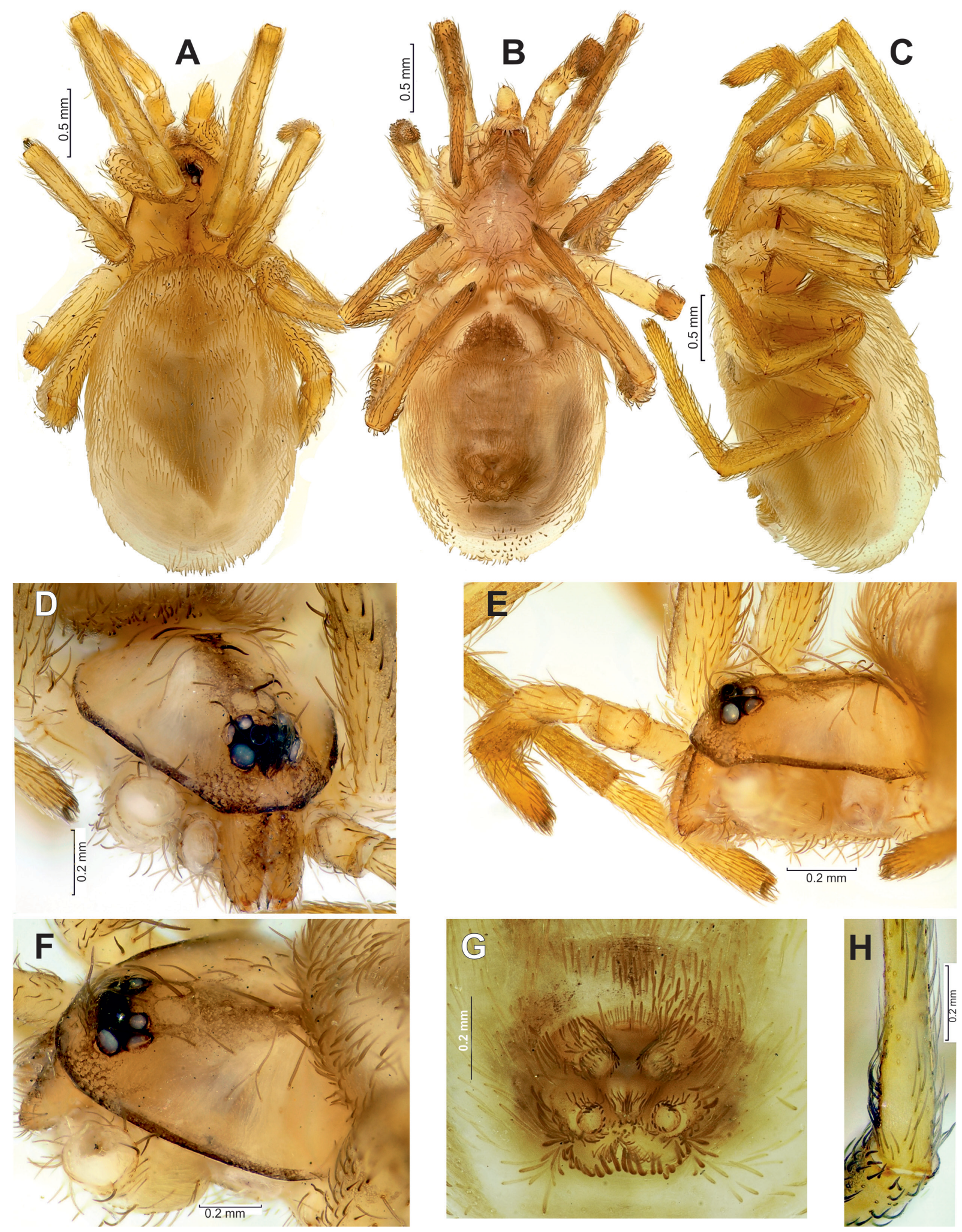

Fig. 39. Somatic characters of Zaitunia minuta sp. nov., holotype, $\subsetneq$. A-C. Habitus, dorsal, ventral and lateral. D-F. Prosoma, fronto-lateral, lateral, and dorso-lateral. G. Spinnerets, ventral. H. Metatarsus IV, dorsal. 


\section{Zaitunia minuta sp. nov. urn:Isid:zoobank.org:act:EE0EBF91-FD5E-4C35-A86B-4C63CA53E0BE}

Figs $39-40$

\section{Diagnosis}

Females of $Z$. minuta sp. nov., with their very short and small receptacles, resemble females of $Z$. zonsteini, but differ by having a relatively larger eye group (cf. the eye measurements in both measured representatives of these species are almost identical, although the former species is considerably smaller than the latter), as well as by the longer and narrower calamistral setae (cf. Figs $39 \mathrm{H}$ and 41E, H), relatively smaller cribellum (cf. Figs 39G, 41F) and somewhat different lateral receptacles, which have triangular heads (vs rounded in Z. zonsteini, cf. Figs 40, 41I-M).

\section{Etymology}

The specific epithet is derived from the Latin minutus ("little, small, minute").

\section{Material examined}

\section{Holotype}

UZBEKISTAN: + , Namangan Province, Pap District, southeastern foothills of Kurama Mts, about $5.5 \mathrm{~km} \mathrm{NW}$ of Khanabad, 4054.1' N, 70²45.7' E, 850 m, 16 May 2002, A.V. Gromov (ZMMU).

\section{Paratype}

UZBEKISTAN: 1 q, same area, Rizaksai River valley, 14 km NW of Khanabad, 1274 m, 13 Jun. 2003, L. Prendini \& A.V. Gromov (AMNH).
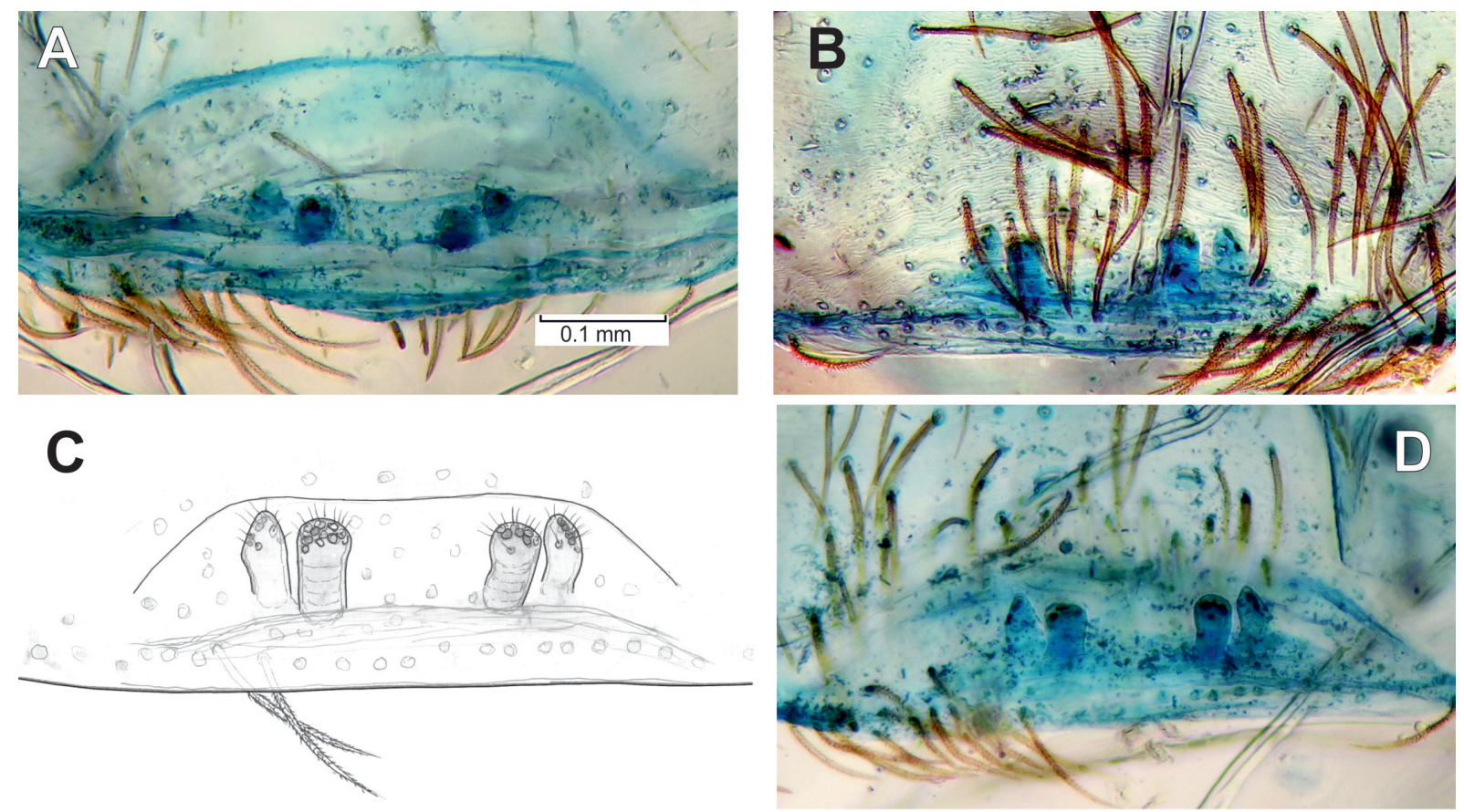

Fig. 40. Endogyne of Zaitunia minuta sp. nov., holotype, ․ . A. Anterior. B. Ventral. C- D. Dorsal. 


\section{Description}

Female (holotype)

Habitus. See Fig. 39A-C.

BODY LENGTH. 3.23.

Colour. Body and legs pale sandy-brown, carapace with slightly darker median spot and noticeably darker narrow margins; eye tubercle blackish-brown; abdomen uniformly colored, without dorsal pattern.

Carapace (Fig. 39E). 1.27 long, 0.82 wide.

Eyes (Fig. 39D, F). AME 0.06, ALE 0.11, PLE 0.09, PME 0.08, AME-AME 0.05.

Endogyne (Fig. 39). Both pairs of receptacles subequal in length and width; median receptacles with head slightly wider than stem, heads separated by about 2.5 diameters; lateral receptacles with triangular heads; only heads covered by pores.

LEG MEASUREMENTS.

\begin{tabular}{lcccccc}
\hline & Femur & Patella & Tibia & Metatarsus & Tarsus & Total \\
\hline Palp & 0.52 & 0.27 & 0.38 & - & 0.45 & 1.62 \\
I & 1.33 & 0.42 & 1.25 & 1.07 & 0.77 & 4.84 \\
II & 0.97 & 0.35 & 0.83 & 0.75 & 0.57 & 3.47 \\
III & 0.87 & 0.30 & 0.63 & 0.70 & 0.43 & 2.93 \\
IV & 1.23 & 0.37 & 0.95 & 0.93 & 0.48 & 3.96 \\
\hline
\end{tabular}

Male

Unknown.

\section{Distribution}

Known only from the type locality (Fig. 49) which appears to be entirely separate from the area occupied by the closest congener, Z. zonsteini, by biotopes inhabited by Z. maracandica, Z. ferghanensis sp. nov., $Z$. wunderlichi sp. nov. and Z. logunovi sp. nov. (see Figs 48 and 49).

Zaitunia zonsteini Fomichev \& Marusik, 2013

Fig. 41

Zaitunia zonsteini Fomichev \& Marusik, 2013: 85, figs 1-9, 12-14 (†).

\section{Diagnosis}

Females of Z. zonsteini, with their very short and small receptacles, resemble those of Z. minuta sp. nov., but differ by having smaller eyes, broader calamistral setae, a larger cribellum and more globular receptacles (both pairs) (cf. Figs 39D-H, 40, 41D-M).

\section{Type material}

\section{Holotype}

KAZAKHSTAN: $q$ East Kazakhstan Province, Urdzhar District, Kyzylbel'tau Mountains, near Terekty

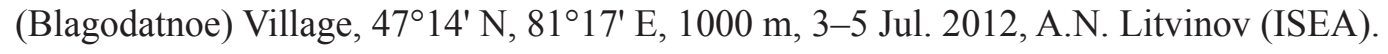



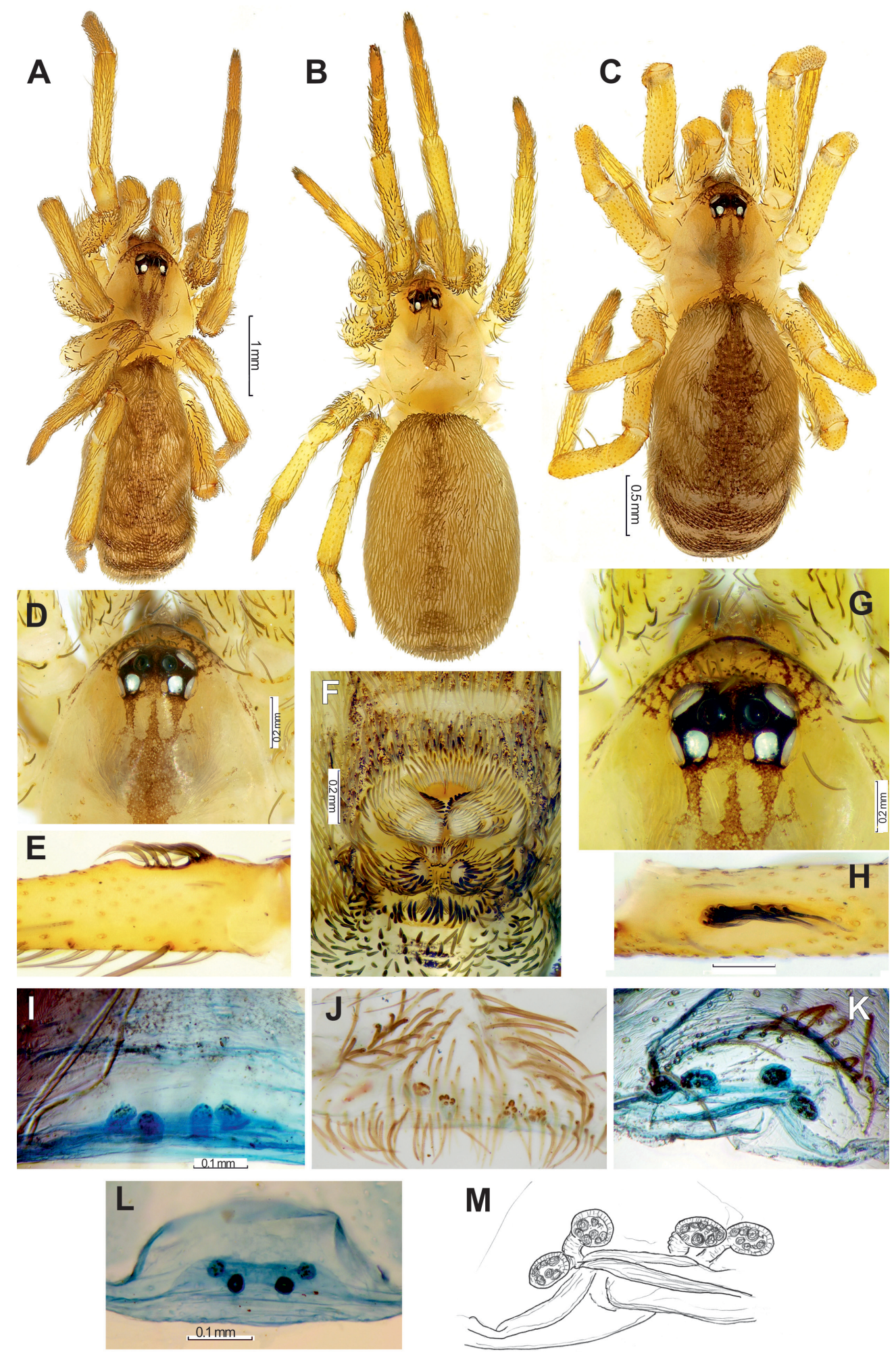

Fig. 41. Somatic characters and endogyne of Zaitunia zonsteini Fomichev \& Marusik, 2012 (A-H, $\mathbf{J}-\mathbf{K}, \mathbf{M}$ ), and $q$ ㅇ from Taldykorgon $(\mathbf{I}, \mathbf{L}) .-\mathbf{A}-\mathbf{C}$. Habitus, dorsal, showing variations of pattern. D, G. Cephalic part of prosoma, dorsal. E, H. Calamistrum, lateral and dorsal. F. Posterior part of abdomen, ventral. I-J. Endogyne, dorsal. K, M. Same, anterior. L. Same, subcaudal (receptacles visible from below). Scale bars: A $=1.0 \mathrm{~mm}$; B-C $=0.5 \mathrm{~mm}$; D, F-H $=0.2 \mathrm{~mm}$; I, L $=0.1 \mathrm{~mm}$. 
Paratypes $(12 q q$, all in ISEA)

KAZAKHSTAN: 1 , same data as holotype; 8 우 , same locality, 3-5 Jul. 2011, A.A. Fomichev \&

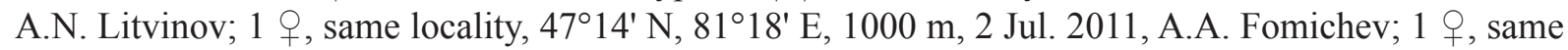
locality, 900 m, 15 Jul. 2011, A.A. Fomichev; 1 , SW part of West Tarbagatai Mountains, $47^{\circ} 18^{\prime} \mathrm{N}$, 81 $19^{\prime}$ E, near Terekty (Blagodatnoe) Village, 1200 m, 3 Jul. 2011, A.A. Fomichev \& A.N. Litvinov.

Other material examined $(6 q q)$

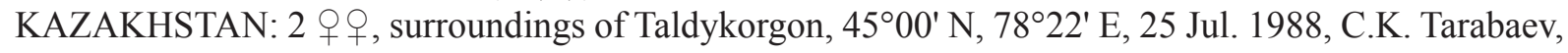
A.A. Zyuzin \& M. Zharko (TAU); 2 우, Syugaty Valley, $5 \mathrm{~km} \mathrm{~W}$ of Charyn canyon, $43^{\circ} 22^{\prime} \mathrm{N}, 79^{\circ} 01^{\prime} \mathrm{E}$, 1200 m, 2 Jun. 1989, C.K. Tarabaev, A.A. Zyuzin \& M. Zharko (TAU); 2 우, 1 juv., Ketmen Mts, 11

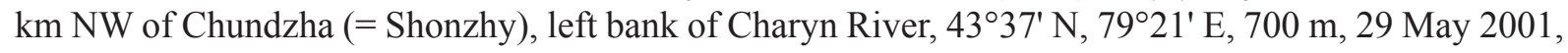
A.V. Gromov (ZMMU).

\section{Description}

Female (Taldykorgon)

Habitus. See Fig. 41C, refers to the paratype.

BODY LENGTH. 4.70.

CoLor. Carapace brownish-yellow, with darkened brown clypeus and triangular median band; eye tubercle blackish-brown; light oval postocular spots well-developed; chelicerae brownish-yellow; labium, sternum and maxillae greyish-yellow; palps and legs light yellow, gradually darkened to apices; abdomen dorsally light yellow with diffuse brownish pattern consisting of narrow dashed median band and few pairs of transverse chevrons, ventrally pale yellow with darker brownish area surrounding spinnerets.

Carapace. 1.75 long, 1.20 wide.

Eyes (Fig. 41D, G). AME 0.06, ALE 0.13, PLE 0.09, PME 0.08, AME-AME 0.04.

LEG MEASUREMENTS.

\begin{tabular}{lcccccc}
\hline & Femur & Patella & Tibia & Metatarsus & Tarsus & Total \\
\hline Palp & 1.07 & 0.65 & 0.87 & - & 0.97 & 3.56 \\
I & 2.33 & 0.87 & 2.23 & 1.97 & 1.30 & 8.70 \\
II & 1.97 & 0.83 & 1.65 & 1.63 & 1.05 & 7.13 \\
III & 1.75 & 0.75 & 1.33 & 1.38 & 0.97 & 6.18 \\
IV & 2.37 & 0.80 & 1.85 & 1.83 & 1.03 & 7.88 \\
\hline
\end{tabular}

EndogYNe (Fig. 41I-M). Both pairs of receptacles subequal in width and length; median receptacles separated by one diameter, with round heads; lateral receptacles with angled heads, slightly converging; pores present on heads only.

\section{Male \\ Unknown. \\ Variation}

Carapace length in females varies from 1.20 to 1.75. Darker median band on the carapace and lateral chevrons on the abdomen may be less distinct in paler specimens (cf. Fig. 41A-C). 

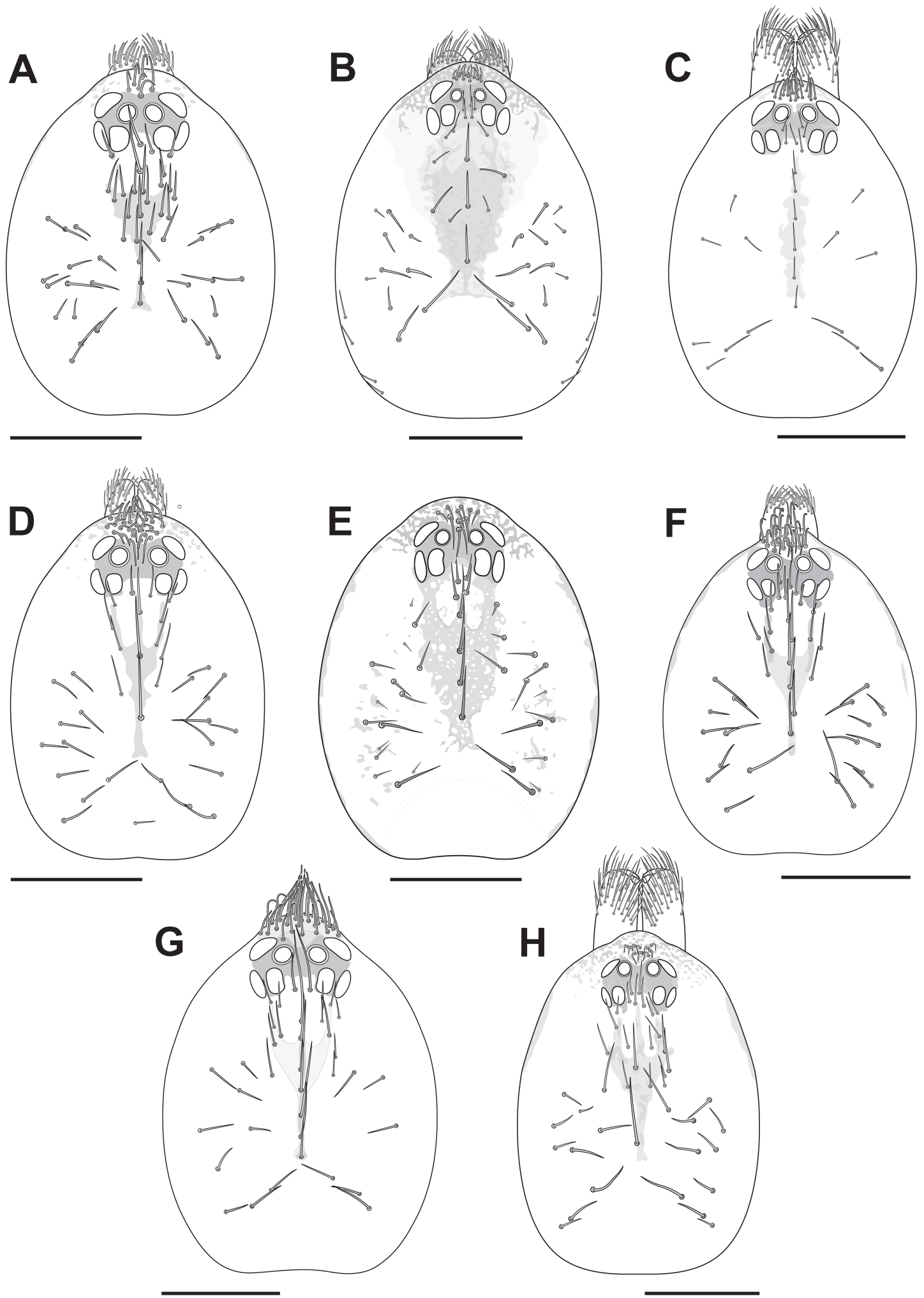

Fig. 42. Variations of coloration and setation of carapace in ${ }^{\lambda} \widehat{\jmath}(\mathbf{A}, \mathbf{D}, \mathbf{F}-\mathbf{G})$ and $q q q(\mathbf{B}-\mathbf{C}, \mathbf{E}, \mathbf{H})$ of some Zaitunia species. - A-B. Z. logunovi sp. nov. C. Z. inderensis Ponomarev, 2005. D-E. Z. beshkentica (Andreeva \& Tyshchenko, 1969). F. Zaitunia wunderlichi sp. nov. G-H. Z. maracandica (Charitonov, 1946). Scale bars $=0.5 \mathrm{~mm}$. 


\section{Ecology}

This species has been collected in steppe and semi-desert biotopes.

\section{Distribution}

Eastern Kazakhstan (Fig. 49).
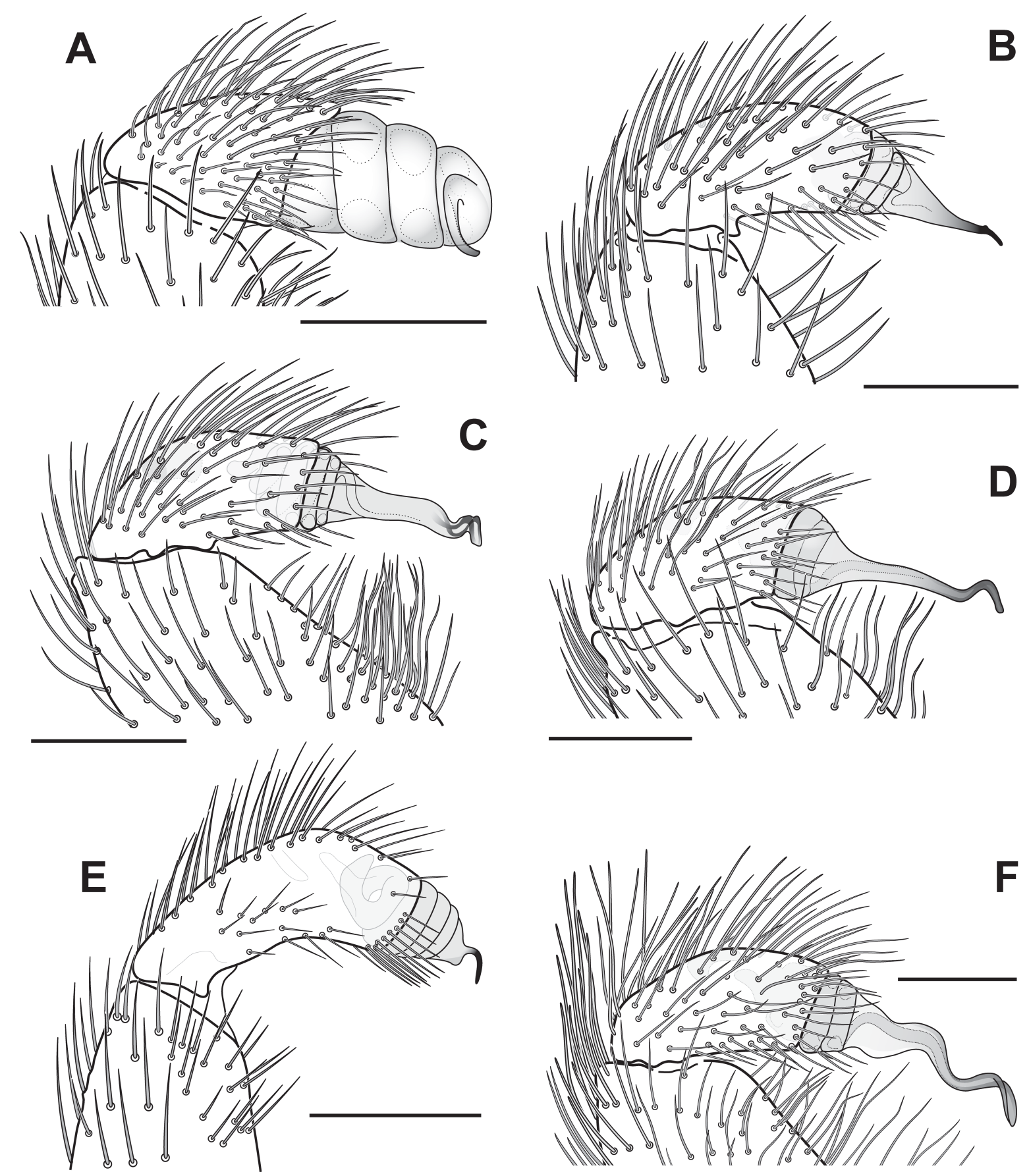

Fig. 43. Male copulatory organs of Zaitunia species, retrolateral. A. Z. schmitzi (Kulczyński, 1911) (Jerusalem area). B. Z. annulipes (Kulczyński, 1908) (Paramali). C. Z. kunti sp. nov. (holotype). D. Z. minoica sp. nov. (paratype). E. Z. logunovi sp. nov. (paratype). F. Z. martynovae (Andreeva \& Tyshchenko, 1969) (Gandzhina). Scale bars $=0.2 \mathrm{~mm}$. 

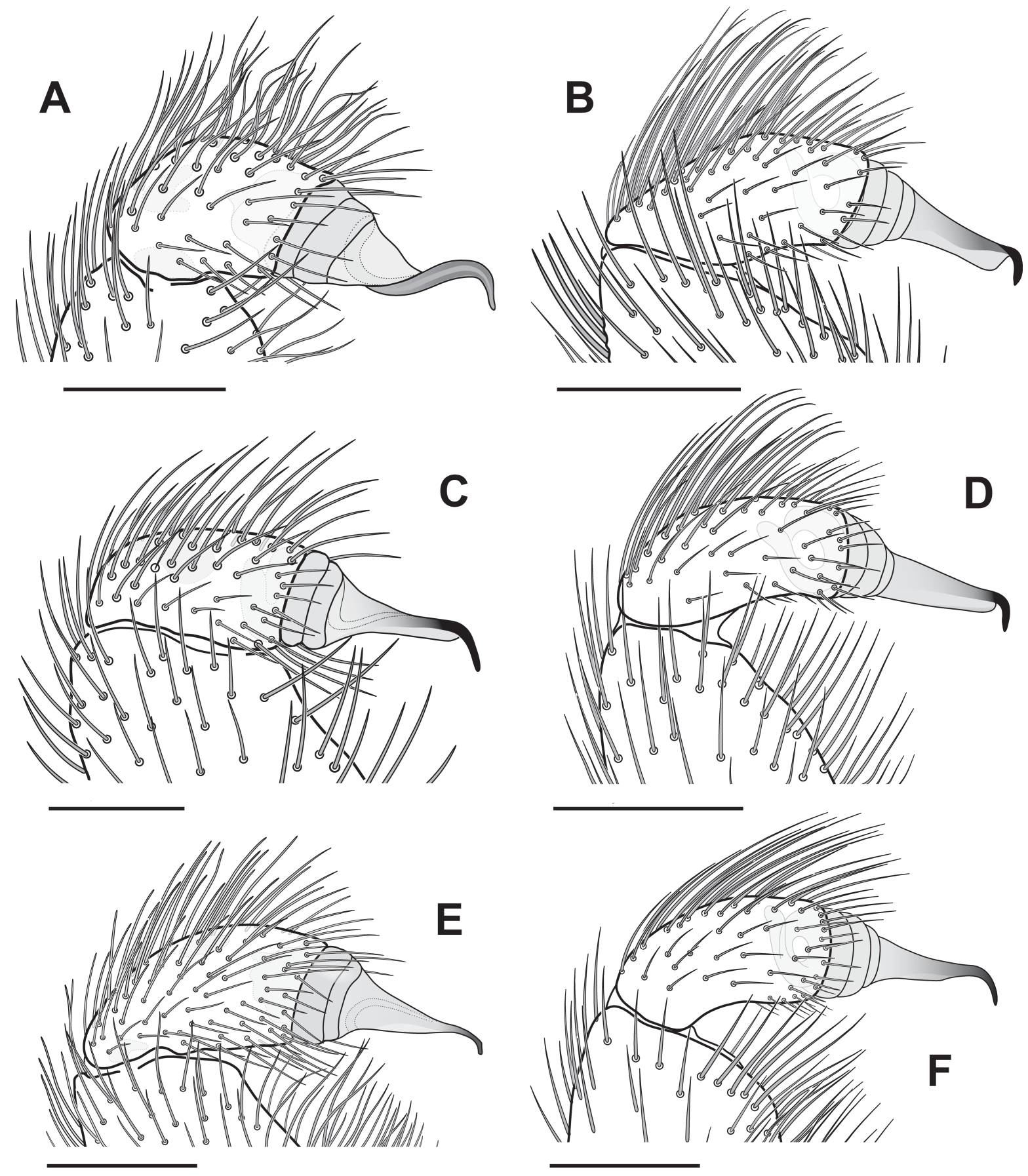

Fig. 44. Male copulatory organs of Zaitunia species, retrolateral. A. Z. spinimana sp. nov. (holotype). B. Z. beshkentica (Andreeva \& Tyshchenko, 1969) (Babatagh). C. Z. psammodroma sp. nov. (holotype). D. Z. wunderlichi sp. nov. (holotype). E. Z. ferghanensis sp. nov. (paratype). F. Z. maracandica (Charitonov, 1946) (Ulus). Scale bars $=0.2 \mathrm{~mm}$. 


\section{Misplaced species}

\section{Genus Pholcoides Roewer, 1962}

Pholcoides Roewer, 1962: 40 (type species by monotypy: P. afghana Roewer, 1960).

Pholcoides - Huber 2009: 68. - Zonstein et al. 2013: 65.

\section{Note}

Originally described by Roewer (1962) in the Pholcidae, this monotypic genus was later transferred to the Filistatidae (Huber 2009). Zonstein et al. (2013) assigned Pholcoides to the Prithinae Gray, 1995.

Pholcoides monticola (Spassky, 1941) comb. nov.

Fig. 45

Filistata monticola Spassky, 1941: 12 (q).

Filistata monticola - Spassky 1952: 194.

Zaitunia monticola - Zonstein 1990: 50 (transfer from Filistata).

\section{Material examined}

Lectotype (designated here)

TAJIKISTAN: +, Western Pamir, “Kalaj-Chumb”, Kalaikhum: $38^{\circ} 28^{\prime}$ N, 7047’ E, 1340 m, 30 Jul. 1935, S. Nenjukov (ZISP).

\section{Paralectotypes}

TAJIKISTAN: 1 juv., "Kalaj-Vamar", Rushan: 3757' N, 71³4' E, 2000 m, 2 Sept. 1937, E. Luppova (ZISP); 1 juv., "Pamir occidentalis", 11 Aug. 1937, E. Luppova (ZISP). All specimens are in a poor condition, dried and damaged.

\section{Additional material examined}

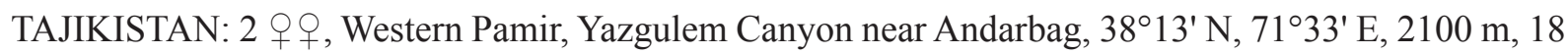
Jul. 1988, S. Zonstein (TAU).

\section{Remarks}

Unlike Zaitunia, females of Pholcoides monticola lack the metatarsal crest on leg IV (Fig. 45C), typical for the Filistatinae. However, this species shares relatively long legs, a rounded carapace and sternum (cf. Fig. 45A and Zonstein et al. 2013: figs 1-2, respectively), spinnerets located closer to the posterior tip of the abdomen (Fig. 45B and Zonstein et al. 2013: fig. 3) and a characteristic calamistrum with two posteriorly convergent rows of setae with P. afghana (Fig. 45C and Zonstein et al. 2013: fig. 6). The structure of the endogyne in these two species is also similar, although not identical (cf. Figs 45D-E and Zonstein et al. 2013: figs 11-12), and differs drastically from that in Zaitunia. Based on these reasons, the aforementioned species is transferred from Zaitunia to Pholcoides. Its relationship to P. afghana and other congeners (some of which are still undescribed) will be considered in detail in a taxonomic revision of Pholcoides (Zonstein \& Marusik, in prep.). 


\section{Discussion}

\section{Taxonomic placement of Zaitunia}

When Lehtinen (1967) described Zaitunia, he allocated it to a group of three genera along with Filistata Latreille, 1810 and Kukulcania Lehtinen, 1967. He stated that, unlike other family members, all three genera share the presence of spines on leg femora, tarsi and metatarsi, and the ejaculatory duct (spermophore) is tightly coiled. Concurrently, he considered Zaitunia as lacking tarsal spines and possessing the calamistrum composed of " 2 rows of 2 strong bristles" (Lehtinen 1967: 300, table 3). Contrary to that statement, during the present revision, we found that all Zaitunia species have few to numerous short tarsal spines on the legs. The calamistrum in Zaitunia was found to be uniseriate,

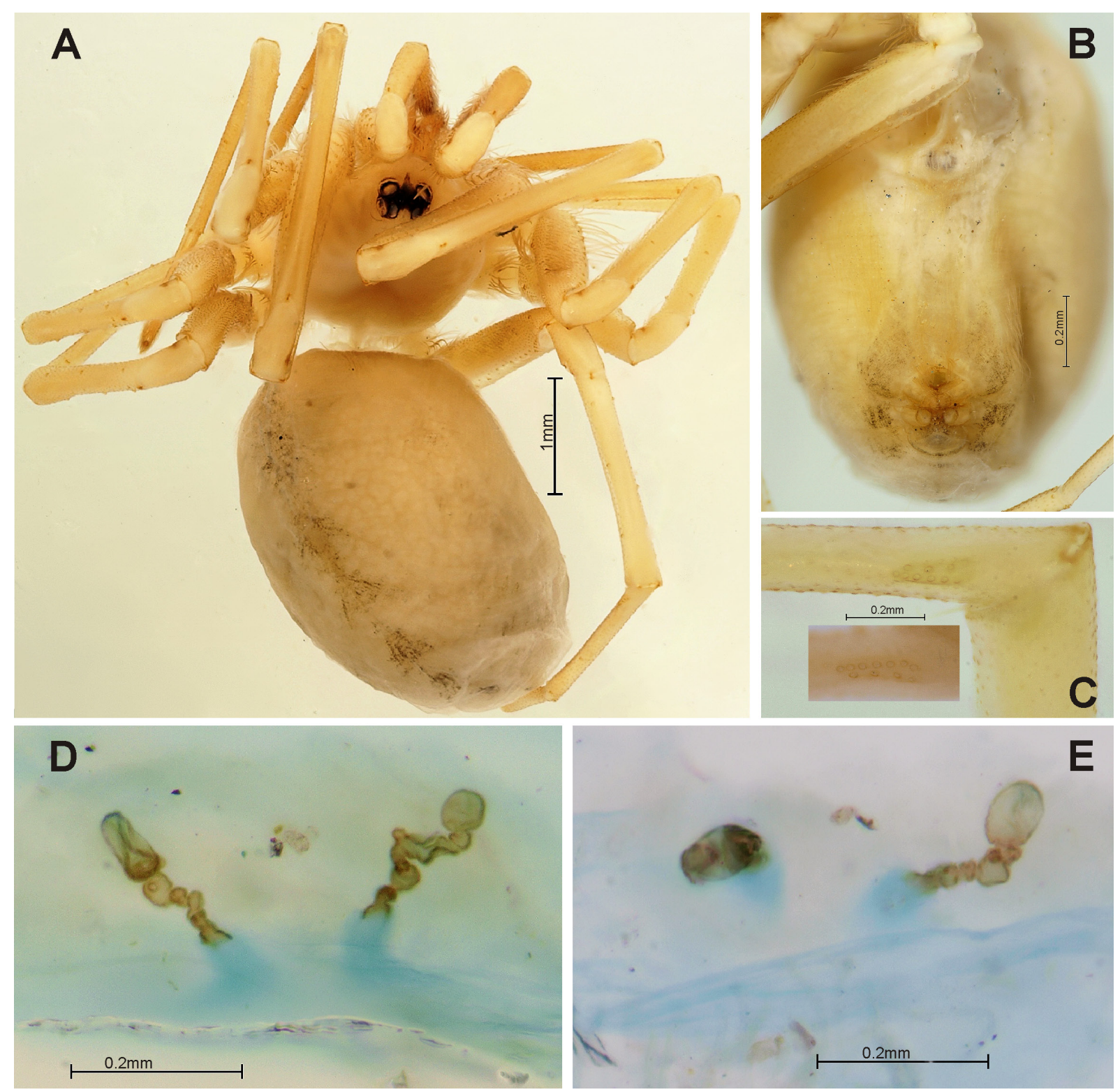

Fig. 45. Somatic characters and endogyne of Pholcoides monticola comb. nov., $q$ from Andarbag. A. Habitus, dorsal. B. Abdomen, ventral. C. Calamistrum of both metatarsi IV, all setae lost. D. Endogyne, dorsal. E. Same, anterior. Scale bars: $A=1.0 \mathrm{~mm}$; $\mathrm{B}-\mathrm{E}=0.2 \mathrm{~mm}$. 


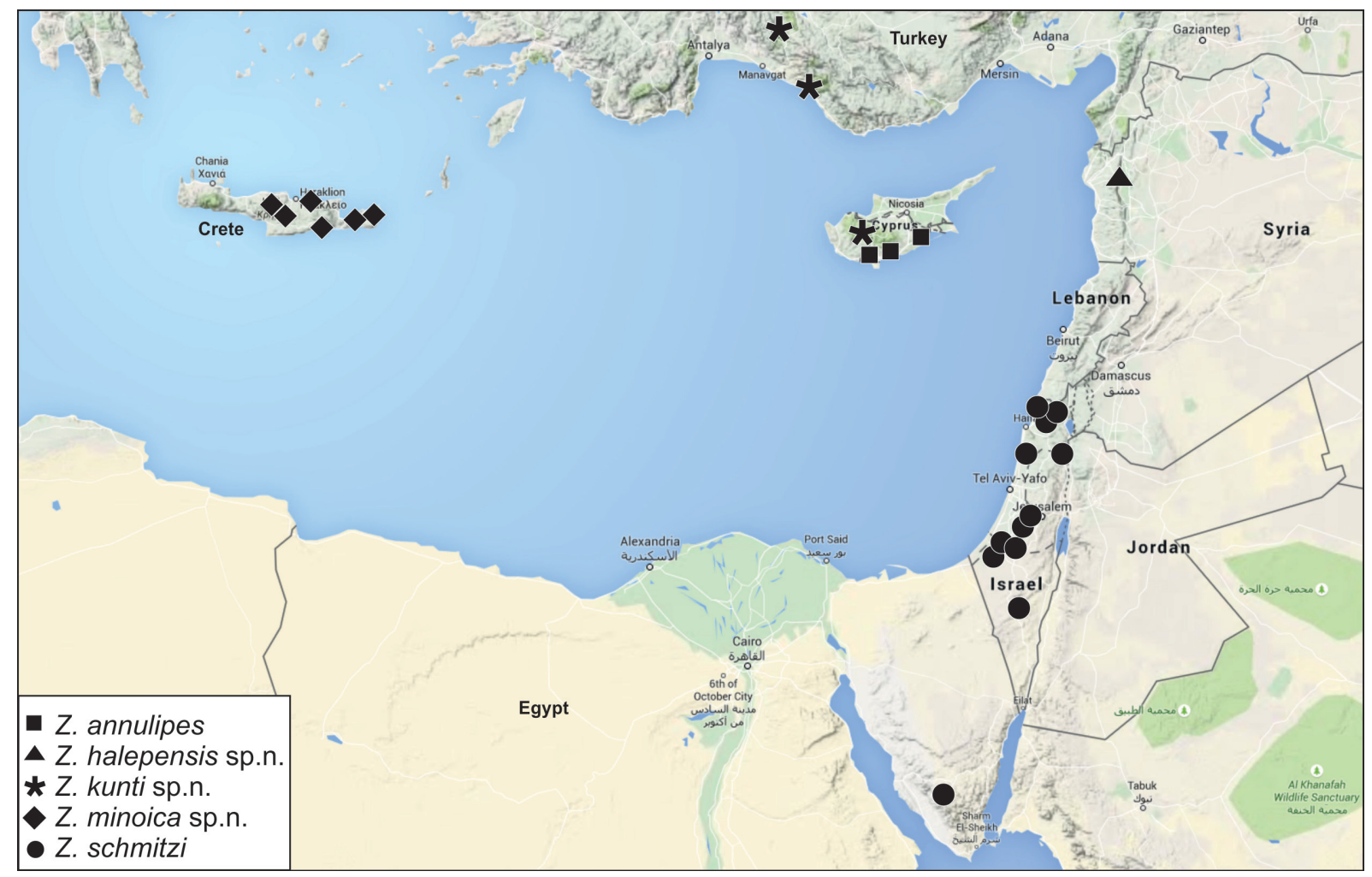

Fig. 46. Distribution of Zaitunia schmitzi and Zaitunia annulipes species groups.

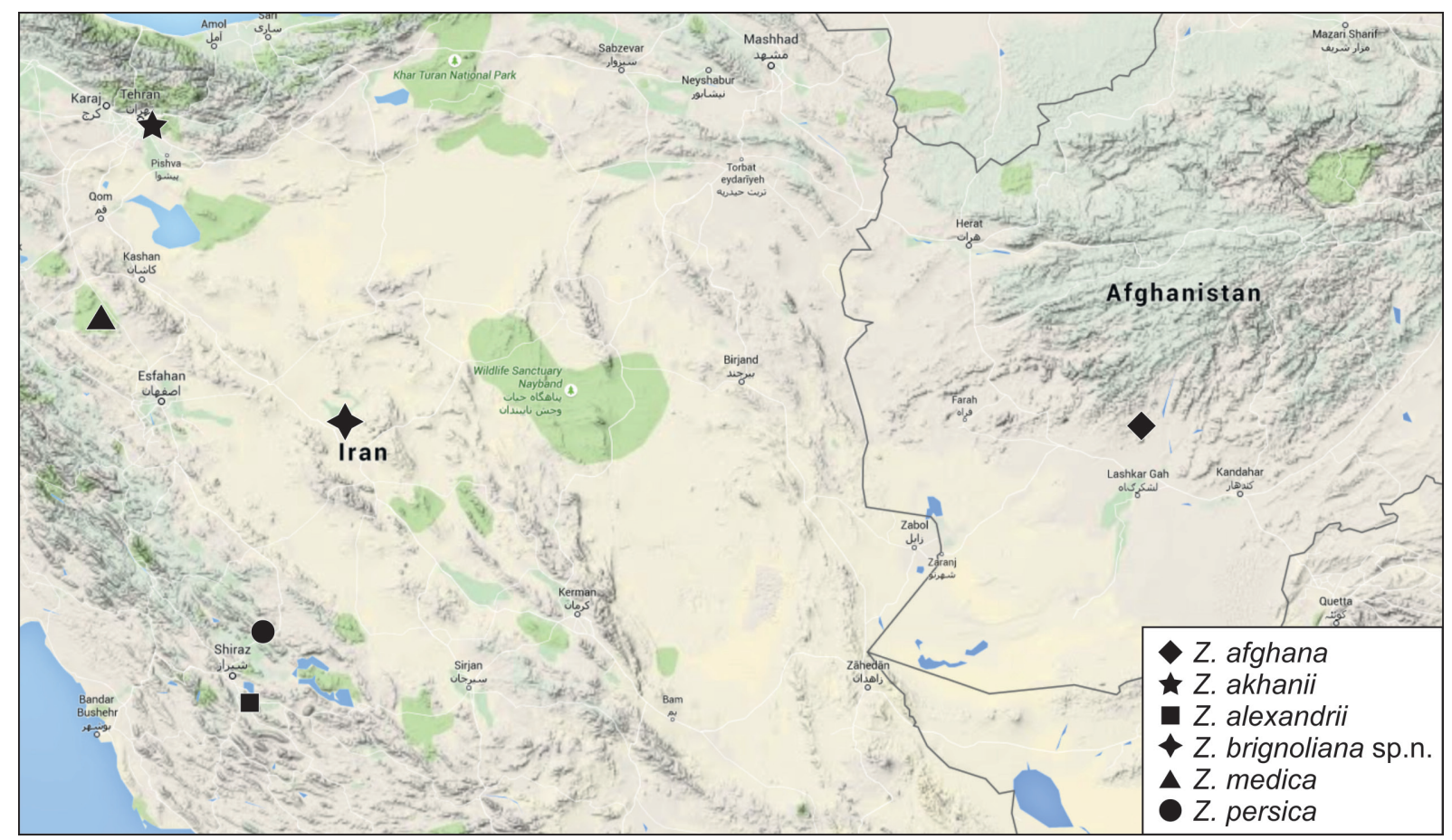

Fig. 47. Distribution of Zaitunia persica species group. 


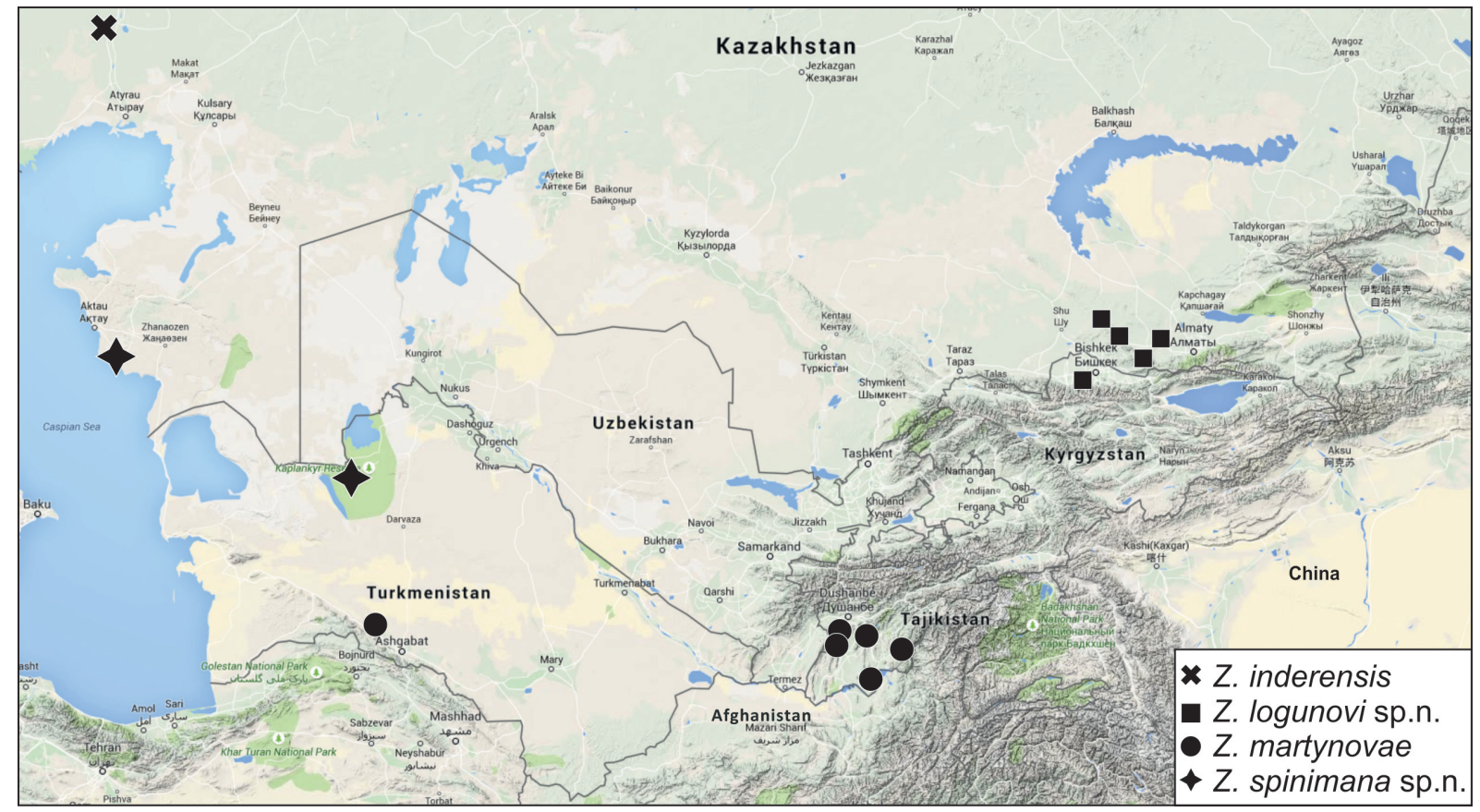

Fig. 48. Distribution of Zaitunia logunovi and Zaitunia martynovae species groups.

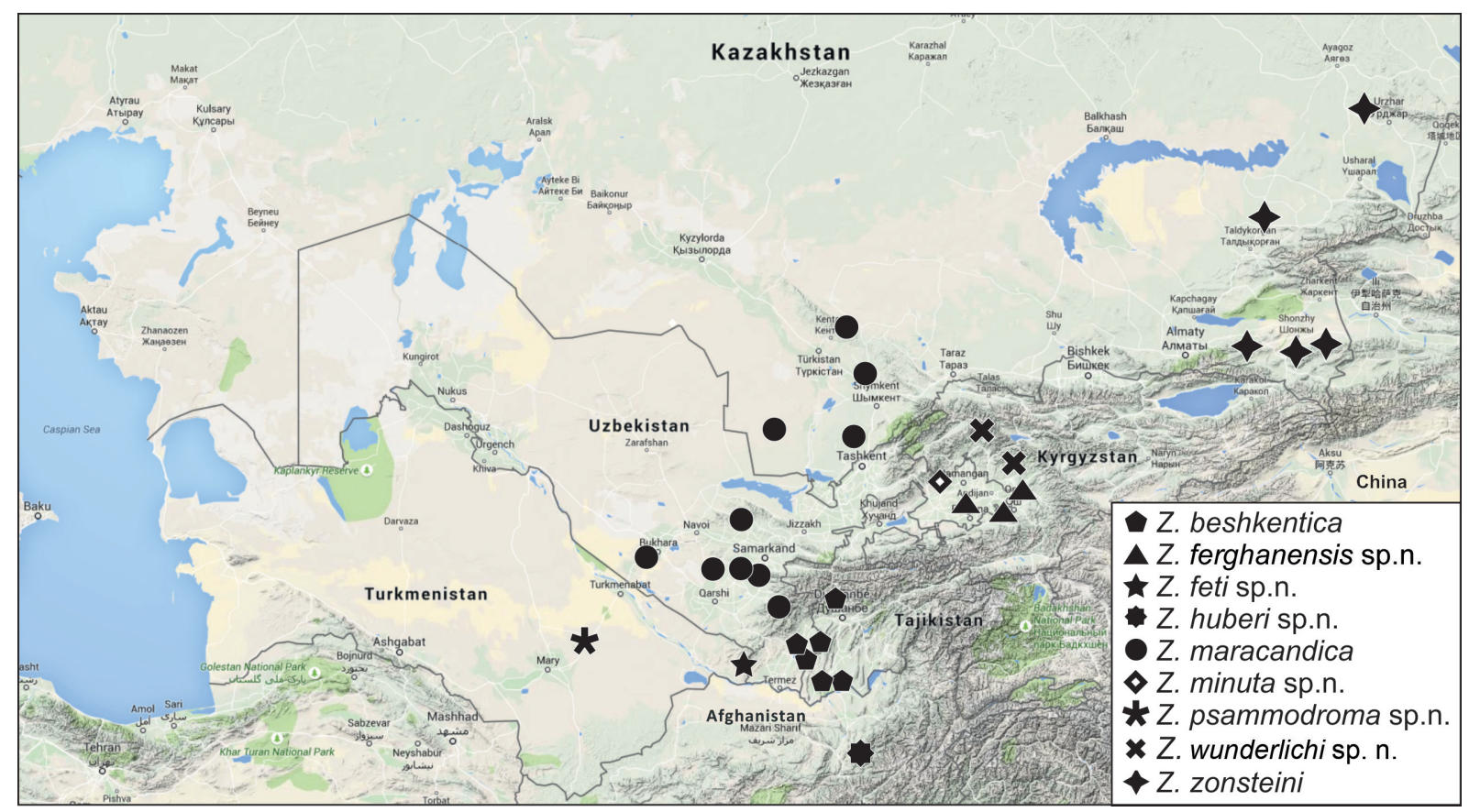

Fig. 49. Distribution of Zaitunia beshkentica and Zaitunia maracandica species groups. 

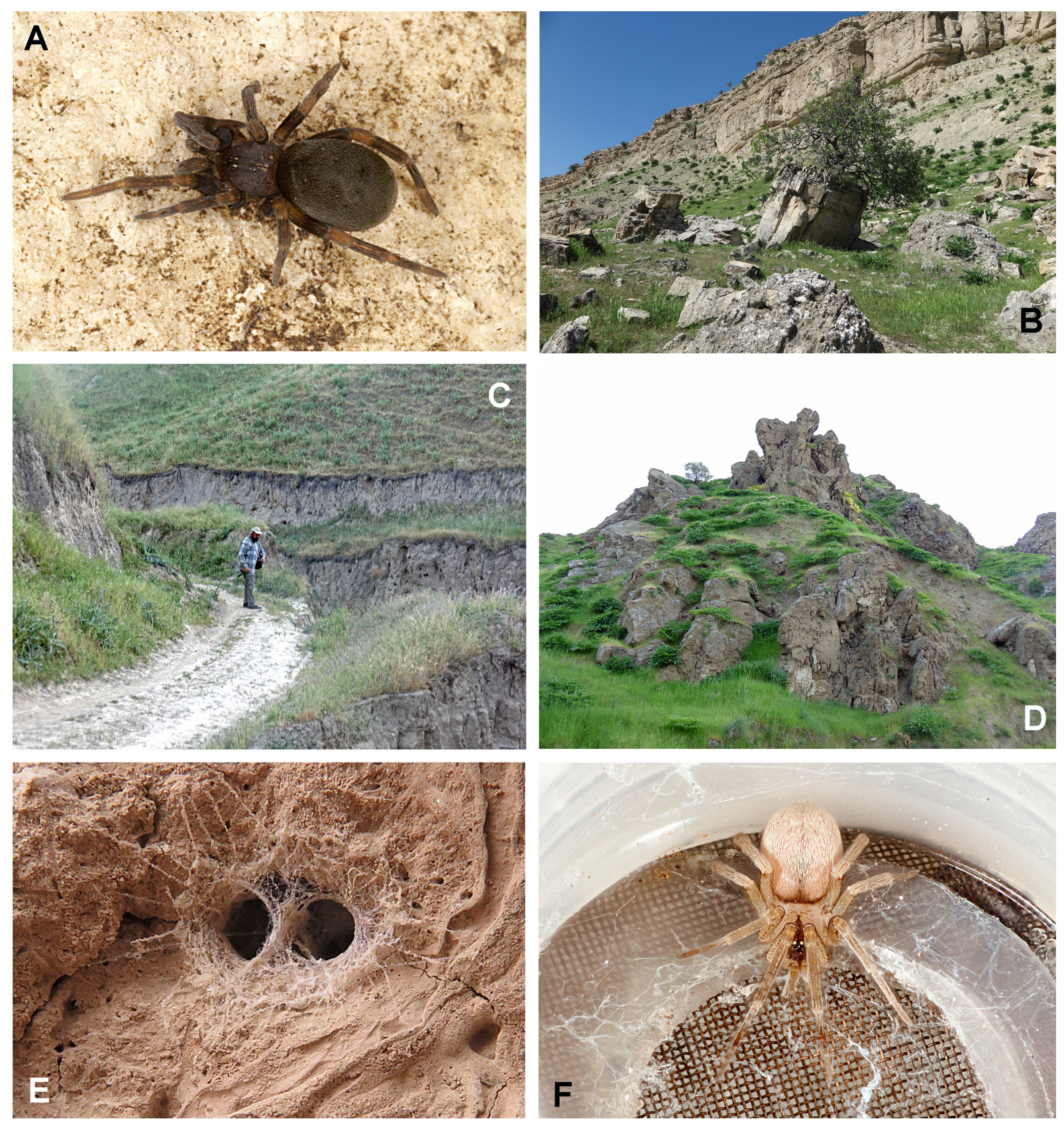

Fig. 50. Live specimens of Zaitunia and habitats of Z. martynovae (Andreeva \& Tyshchenko, 1969) in Southern Tajikistan. A. + of $Z$. schmitzi (Kulczyński, 1911) on the turned stone bottom (Israel, Shoham, image courtesy of Amir Weinstein). B. Surroundings of Gandzhina: the spiders occur under the stones. C. Pyandzh-Karatau Mts, one of the co-authors (YM) near the clay escarps inhabited by filistatids. D. Foothills of the salt dome Khodzha-Mumin: the spiders inhabit crevices and cavities in the rock outcrops. E. One of the figured escarps, a close-up photo showing the twin entrance leading to the inhabited cavity. F. Captured + of Z. martynovae (Andreeva \& Tyshchenko, 1969) weaving a web in the cover of a collecting tube. 
although it is certainly composed of two or even three formerly separate but now fused and juxtaposed rows of 6-7 large and 2-6 tiny setae each (Fig. 2A-E).

Brignoli (1982) was more interested in emphasizing distinctive features of Zaitunia than in finding its affinities. He first provided a figure showing the calamistrum of Zaitunia with a characteristic gap between two groups of setae (Op. cit.: fig. 14) like that in Filistata insidiatrix (Op. cit.: fig. 1). However, regarding $Z$. persica, he presented setae of the calamistrum as having serrate margins and being dilated apically, which has not been confirmed by our examination. We found that the structure of these setae in Z. persica does not differ from that in any other Zaitunia: similarly as with Filistata and Kukulcania, the ribbed and curled lanceolate bristles in Zaitunia are gradually widened in the medial part and then are also gradually narrowed to an acute apex (Fig. 2B-C, E). It is notable that none of Brignoli's figures presenting the calamistra of Filistata, Zaitunia and Sahastata Benoit, 1968 showed them in the correct position on the elevated process (Op. cit.: figs 1, 14 and 17, respectively).

Gray (1995) tentatively assigned Zaitunia to the nominative subfamily which was considered to certainly include Filistata, Kukulcania and Sahastata. However, because of scarce data, Zaitunia was not included in the cladogram. For the same reason, Ramírez \& Grismado (1997) confirmed the provisional placement of Zaitunia among the Filistatinae, but did not include this genus in their phylogenetic reanalysis of the filistatid genera.

Zonstein (2009b) also noted a close similarity between Zaitunia, Filistata and Kukulcania because they "share a relatively broad cribellum and a very short uniseriate calamistrum in the female, as well as curved pseudosegmented tarsi in the male" (Op. cit.: 126). Having re-examined these characters, we found the two latter ones to be significant, whereas the former appears to be confusing. Although Zonstein et al. (2013) and later Marusik \& Zamani (2015) in these regional works listed Zaitunia in the Filistatinae, they have entirely focused on the characters distinguishing Zaitunia from the similarlooking Filistata, without considering the taxonomic position of Zaitunia in detail.

Thus, the above-listed suggestions concerning the taxonomic position of Zaitunia should not be recognized as sufficiently substantiated. An attempt to clarify this question as far as possible has been one of the targets of this study.

During this revision we found that all species assigned to Zaitunia share the following characters (listed according to the description format accepted here):

1) body and legs are covered only with ciliate hairs (Fig. 1D-I); plumose hairs (like those showed by Gray 1995: fig. 10, and Lise et al. 2010: figs 12,20) are absent

2) clypeus short, broad-oval, and steeply inclined

3) clypeus with a comb of long, thick and dense reclined setae (see Fig. 42), more developed in males (Fig. 42A, D, F-G)

4) eye tubercle low or moderately high (probably associated with character 2)

5) thoracic fovea is absent

6) labium usually wider than long (maximum as wide as long); this character is also probably associated with character 2

7) male palpal tibia moderately short and more or less swollen

8) cymbium subcylindrical in shape

9) cymbium relatively short (at least shorter than that in most filistatines; probably associated with character 7)

10) spermophore tightly coiled

11) leg femora, tibiae and metatarsi I-IV spinose

12) calamistrum consists of setae located on a metatarsal crest 
13) calamistral setae form a single row of clearly composite nature

14) this row consists of two groups of juxtaposed (or staggered, after Ramírez 2014) setae with a characteristic gap between them

15) calamistral setae have a ribbed structure

16) these setae lack marginal combing teeth

17) leg tarsi I-IV with small ventral spines

18) male leg tarsi I-IV long and cracked (pseudosegmented), as shown in Fig. $33 \mathrm{G}$

19) tarsal organ with wide opening

20) posterior respiratory system includes two pairs of tracheal branches

21) inner pair of tracheal branches is long, thin, twisted and bent

22) cribellar plate as wide as long, or only slightly wider than long (as in Fig. 4D)

23) cribellar areas are noticeably distant from each other

24) PMS with at least two paracribellar spigots

Characters 1, 10, 11, 12, 15 and 16 are shared with all genera included in Filistatinae (i.e., Filistata, Kukulcania and Sahastata) and also with Microfilistata (Filistatidae inc. sed.). Members of the subfamily Prithinae (12 genera) have plumose hairs, a spermophore that is not tightly coiled, a sessile calamistrum with 2-3 rows of setae possessing marginal combing teeth, almost unarmed leg segments, and completely aspinose leg tarsi (Gray 1995; Ramírez \& Grismado 1997; see also Ramírez 2014: fig. E).

Characters 2 and 4 are shared with Microfilistata and also with Pholcoides, Prithinae (see Zonstein 2009a: figs 1-2, 5; Zonstein et al. 2013: figs 1, 4). By contrast, most Filistatinae and Prithinae have a higher eye tubercle and a forward produced clypeus (Benoit 1968: figs 1, 6; Gray 1994: figs 32, 37, 38, 41, 46, 54, 56, 69, 77, 85, 89, 94, 111-113, 118; Ramírez \& Grismado 1997: figs 30-31, 36, 39, 46, 54, 60, 66, 73, 75, 84, 96; Ubick et al. 2005: fig. 28.1; Zhang et al. 2009: figs 1, 7; Gómez-Rodríguez \& Salazar 2012: fig. 8A; Zonstein et al. 2013: figs 16, 19; Marusik \& Zonstein 2014: figs 7-10; Siyam et al. 2015: figs 7-8).

Characters 3 and 19 appear to be specific for Zaitunia (Figs 1C, 2G, 6E, 8C, 12F, 20D, 23D, 24E, 27B, 28C, 32A, 34E, 37C, 39E). No other filistatid, with a single exception, has been found to possess a similarly long and dense tuft of reclined bristles on the clypeus. In Filistatoides F. O. Pickard-Cambridge, 1899, the presence of similar tufts is evidently convergent (I. Magalhaes, pers. com.). In Filistata and Kukulcania, the tarsal organ is domed with a narrow (Griswold et al. 2005: fig. 152B) and sometimes shallow (Gray 1995: fig. 28) entrance. In Prithinae, this entrance appears to be even narrower (Gray 1994: figs 11-12; 1995: fig. 27).

Character 5 is widely distributed among the genera of the Prithinae that also lack a thoracic fovea or in which it is a very shallow pit (see Gray 1995; Ramírez \& Grismado 1997). This state was also noted for Microfilistata (Zonstein 2009a). By contrast, members of Filistatinae usually possess a well-developed fovea (Gray 1995; Ramírez \& Grismado 1997). However, it should be noted that in small-sized species of Filistata (such as species described from the Canary Islands), the fovea changes from underdeveloped in a moderately small F. canariensis Schmidt, 1972 to almost indistinct in a tiny F. teideensis Wunderlich, 1992 (Zonstein \& Marusik, in prep.). Since it could be connected with spider size (Zaitunia, Microfilistata and the prithine filistatids are small), the taxonomic significance of this character is unclear.

Character 6 is probably associated with states 2 and 4 and is shared with Microfilistata (cf. Zonstein 2009a: figs 3, 6). However, in Pholcoides, which has a similarly short and steeply inclined clypeus, the labium is nevertheless long due to the shortened sternum (see Zonstein et al. 2013: fig. 2). Most Filistatinae and Prithinae have a longer labium, probably due to their produced clypeus (Benoit 1968: 
fig. 2; Gray 1994: figs 34, 40, 45, 71, 86, 91, 110; Zhang et al. 2009: fig. 2; Lise et al. 2010: fig. 4; Marusik \& Zonstein 2014: figs 2, 11, 13; Marusik et al. 2014: figs 24, 31).

Character 7 is known also for some species of the prithine genera Pritha (Ledoux 1977: fig. 3A-C), Tricalamus Wang, 1987 (Song et al. 1999: figs 17W, X, 18E-F) and Wandella Gray, 1994 (Gray 1994: figs 108-109, 114, 117). However, in most Prithinae, the male palpal tibia appears even shorter and incrassate (Gray 1994: figs 65-68, 74-75, 82-84, 92-93; Ramírez \& Grismado 1997: figs 32-34, 41-44, 49-52, 100-102; Song et al. 1999: figs 17N-V, 18A-D, G-J). Among the Filistatinae, only Filistata teideensis Wunderlich, 1992 has a relatively short male palpal tibia (which is generally much longer in other filistatines); but even in F. teideensis this tibia is noticeably longer than in Zaitunia (see Wunderlich 1992: fig. 136).

Characters 8, 17, 18, 23 are shared exclusively with genera of the Filistatinae. In Microfilistata, the cymbium, although subcylindrical, almost completely covers (coats) the embedded bulb (Zonstein 2009a: figs 2, 4). Within the Prithinae, the cymbium is more or less reduced and forms a small horseshoeshaped or collar-like segment (Lehtinen 1967: figs 22-24; Benoit 1968: fig. 7; Ledoux 1977: figs 3A-D; Brignoli 1982: figs 6, 9; Gray 1994: figs 30, 39, 42-43, 57-61, 65-68, 74-75, 82-84, 92, 94, 108-109, 111-115, 117, 119-121; Ramírez \& Grismado 1997: figs 25, 27, 32-34, 42-44, 49-52, 56-58, 62-64, 68-70, 78, 87-89, 91-92, 99-102, 104-106; Song et al. 1999: figs 18O-X, 19A-J). In addition, in Microfilistata and the Prithinae, the leg tarsi are completely aspinose (and the tarsi in males are entire, not curved and pseudosegmented), and the PMS have one probably paracribellar gland spigot (Gray 1995; Ramírez \& Grismado 1997; Zonstein 2009a).

Character 9 distinguishes Zaitunia from Kukulcania (see Chamberlin \& Ivie 1935: figs 23-24, 27-28; Ramírez \& Grismado 1997: fig. 107; Brescovit \& Santos 2013: fig. 1A-F) and Sahastata (Marusik \& Zamani 2015: fig. 3a-d). On the contrary, species of Filistata possess a cymbium of the same relative length or only slightly longer than that in Zaitunia (cf. Wunderlich 1992: figs 132-137; 1995: figs 2-4; Marusik \& Zonstein 2014: figs 15-22).

Character 13 is shared with Filistata, Microfilistata and Kukulcania (cf. Brignoli 1982: fig. 1; Zonstein 2009a: fig. 7; Brescovit \& Santos 2013: fig. 6A, respectively). However, Sahastata differs from those in having the calamistrum plesiomorphically composed of 3 rows of setae (see Gray 1995: fig. 4; Marusik et al. 2014: figs 26-29, 32-33).

Character 14 unites Zaitunia and Filistata (Figs 1C-E, 6F, 10H, 14E-F, 15D, 17E, 18C, 22H, 30F, 31F, 38H, 40E, H; Ramírez 2014: fig. 51F-G), whereas in Kukulcania setae are not grouped, but appear to be spread almost evenly (Griswold et al. 2005: fig. 143B; Brescovit \& Santos 2013: fig. 6A).

Character 20 is shared at least with Filistata and Kukulcania (Ramírez \& Grismado 1997: figs 7-8). Meanwhile, the unusually long, thin and twisted inner tracheal branches of Zaitunia (Character 21) have no known analogs within the subfamily and may represent a possible autapomorphy of this genus (Figs 3B-C and 33E-F). In Prithinae genera, the posterior respiratory system includes only one pair of the tracheal branches (Ramírez \& Grismado 1997: figs 9-13). The structure of the posterior respiratory system in Sahastata and Microfilistata is unknown.

Characters 22 and 23 are probably shared only with Filistata (Ramírez 2014: fig. 111E) and Kukulcania (Platnick et al. 1991: fig. 51; Griswold et al. 2005: fig. 14D; Brescovit \& Santos 2013: fig. 7A-B). In the prithine genera, the cribellar plate is much shorter and distinctly wider than long, and the cribellar areas are close or even touching each other (Ramírez \& Grismado 1997: figs 9-13; Ono 2013: fig. 7). In Sahastata, the wide cribellar areas occupy almost the whole width of the cribellar plate and are not 
distant from each other (see Marusik et al. 2014: fig. 25). The state of these characters in Microfilistata is unclear.

In total, 16 of 24 considered states in Zaitunia are shared with Filistata; 14 with Kukulcania; 11 with Microfilistata; 10 with Sahastata, and only a few, including absence of the thoracic fovea, whose taxonomic significance is not completely evident, with genera of the Prithinae. We thus conclude that Zaitunia should be placed in the nominative subfamily Filistatinae $s$. str. It will be possible to consider further details concerning its allocation within the subfamily and intergeneric relationships when the filistatine genera Filistata and Sahastata are revised (both genera are currently under study; Zonstein \& Marusik, in prep.).

\section{Acknowledgements}

We thank Charlotte Jönsson (NMG), Peter Jäger and Julia Altmann (SMF), Francesco Ballarin (MSNV \& Institute of Zoology, Chinese Academy of Sciences, Beijing, China), Dominika Mierzwa-Szymkowiak (IZW), the late Gershom Levy (HUJ), Kirill Mikhailov (ZMMU), Alireza Zamani (University of Tehran, Tehran, Iran), Seppo Koponen and Pekka T. Lehtinen (ZMTU), Victor Fet (Marshall University, USA), Andrei Feodorov and the late Chingiz Tarabaev (Institute of Zoology, Almaty, Kazakhstan), Alexander Gromov (Bingen-am-Rhein, Germany) and Ivan Luiz Fiorini de Magalhães (Museo Argentino de Ciencias Naturales "Bernardino Rivadavia", Buenos Aires, Argentina) for providing us with Zaitunia types and filistatid specimens for study, including comparative material. Rustam Muratov (Institute of Zoology and Parasitology, Dushanbe, Tajikistan) and Murod Saidov (Dushanbe, Tajikistan) helped us to organise and provide a collecting trip in Tajikistan in April-May 2015. Amir Weinstein, a professional photographer from Israel, kindly provided us with his photo of a live specimen of Z. schmitzi. Special thanks are due to Seppo Koponen for providing us with museum facilities. Jan Bosselaers (Beerse, Belgium) and Ivan Mangalhães revised the initial manuscript and provided us with their valuable comments which helped to improve it considerably. The English of the earlier draft was kindly edited by Victor Fet. The English of the final draft was checked by Sarah Crews (California Academy of Sciences, USA). This study was supported in part by the Ministry of Immigrant Absorption, Israel.

\section{References}

Andreeva E.M. 1976. Spiders of Tajikistan. Donish, Dushanbe. [in Russian]

Andreeva E.M. \& Tyshchenko V.P. 1969. On the fauna of spiders (Araneae) of Tajikistan. Haplogynae, Cribellatae, Ecribellatae Trionychae (Pholcidae, Palpimanidae, Hersiliidae, Oxyopidae). Entomologicheskoe Obozrenie 48: 373-384. [in Russian]

Benoit P.L.G. 1968. Synopsis des Filistatidae africains (Araneae). Annali del Museo Civico di Storia Naturale Giacomo Doria 77: 92-102.

Brescovit A.D. \& Santos A.J. 2013. The spider genus Kukulcania in South America (Araneae: Filistatidae): a redescription of $K$. brevipes (Keyserling) and new records of $K$. hibernalis (Hentz). Zootaxa 3734: 301-316. http://dx.doi.org/10.11646/zootaxa.3734.3.1

Brignoli P.M. 1982. Contribution à la connaissance des Filistatidae paléarctiques (Araneae). Revue arachnologique 4: 65-75.

Brignoli P.M. 1983. A Catalogue of the Araneae Described Between 1940 and 1981. Manchester University Press, Manchester.

Chamberlin R.V. \& Ivie W. 1935. Miscellaneous new American spiders. Bulletin of the University of Utah 26 (4): 1-79. 
Charitonov D.E. 1946. New forms of spiders of the USSR. Izvestiya yestestvenno-nauchnogo Instituta Molotovskogo Universiteta 12: 19-32. [in Russian]

Charitonov D.E. 1969. Materials to the USSR spider fauna. Uchenye zapiski Permskogo Gosudarstvennogo Universiteta 179: 59-133. [in Russian]

Chyzer C. \& Kulczyński W. 1897. Araneae Hungariae: 151-366. Editiones Academiae Scientiarium Hungaricae, Budapest.

Fomichev A.A. \& Marusik Y.M. 2013. New data on spiders (Arachnida: Aranei) of east Kazakhstan. Arthropoda Selecta 22: 83-92.

Gómez-Rodríguez J.F. \& Salazar O.C.A. 2012. Arañas de la región montañosa de Miquihuana, Tamaulipas: listado faunístico y registros nuevos. Dugesiana 19: 1-7.

Gray M.R. 1994. A review of the filistatid spiders (Araneae: Filistatidae) of Australia. Records of the Australian Museum 46: 39-61.

Gray M.R. 1995. Morphology and relationships within the spider family Filistatidae (Araneae: Araneomorphae). Records of the Western Australian Museum. Supplement 52: 79-89.

Griswold C.E., Ramírez M.J., Coddington J.A. \& Platnick N.I. 2005. Atlas of phylogenetic data for entelegyne spiders (Araneae: Araneomorphae: Entelegynae) with comments on their phylogeny. Proceedings of the California Academy of Sciences 56 (Suppl. II): 1-324.

Helsdingen P.J. van. 2015. European Spiders Database, version 2015.1. European Society of Arachnology, available from http://www.european-arachnology.org/ [accessed 24 May 2016]

Huber B.A. 2009. Four new generic and 14 new specific synonymies in Pholcidae, and transfer of Pholcoides Roewer to Filistatidae (Araneae). Zootaxa 1970: 64-68.

Kulczyński W. 1908. Fragmenta Arachnologica, VI. X. Araneae nonnullae in Cypro insula et in Palaestina a Cel. Prof. Dre G. Cecconi lectae. Bulletin de l'Academie des Sciences de Cracovie 1908: 49-86.

Kulczyński W. 1911. Fragmenta Arachnologica, IX. XVI. Aranearum species nonnullae in Syria a Rev. P. Bovier-Lapierre et in Palaestina a Rev. E. Schmitz collectae. Bulletin de l'Academie des Sciences de Cracovie 1911: 12-75.

Ledoux J.C. 1977. Redescription de Pritha nana (Simon) (Araneae, Filistatidae). Revue Arachnologique 1: $65-74$.

Lehtinen P.T. 1967. Classification of the cribellate spiders and some allied families, with notes on the evolution of the suborder Araneomorpha. Annales Zoologici Fennici 4: 199-468.

Lise A.A., Ferreira A.C.K. \& Silva E.L.C. da. 2010. Description of a new species of Pikelinia (Araneae: Filistatidae) from Brazil, with notes on its ecology. Zootaxa 2604: 61-68.

Marusik Y.M. \& Zamani A. 2015. The spider family Filistatidae (Araneae) in Iran. Zookeys 516: 123135. http://dx.doi.org/ 10.3897/zookeys.516.10146

Marusik Y.M., Zamani A. \& Mirshamsi O. 2014. Three new species of mygalomorph and filistatid spiders from Iran (Araneae, Cyrtaucheniidae, Nemesiidae and Filistatidae). ZooKeys 463: 1-10. http:// dx.doi.org/10.3897/zookeys.463.8692

Marusik Y.M. \& Zonstein S.L. 2014. A synopsis of Middle East Filistata (Aranei: Filistatidae), with description of new species from Azerbaijan. Arthropoda Selecta 23 (2): 199-205.

Ono H. 2013. Spiders of the genus Tricalamus (Araneae, Filistatidae) from Japan. Bulletin of the National Museum of Nature and Science Tokyo (A) 39 (1): 15-20. 
Platnick N.I. 1989. Advances in Spider Taxonomy 1981-1987: A Supplement to Brignoli's A Catalogue of the Araneae described between 1940 and 1981. Manchester University Press, Manchester.

Platnick N.I. 1993. Advances in Spider Taxonomy 1988-1991, with Synonymies and Transfers 19401980. New York Entomological Society, New York.

Platnick N.I. 2014. The World Spider Catalog, version 15.0. American Museum of Natural History, available from http://research.amnh.org/iz/spiders/catalog [accessed 15 Jul. 2015]

Platnick N.I., Coddington J.A., Forster R.R. \& Griswold C.E. 1991. Spinneret morphology and the phylogeny of haplogyne spiders (Araneae, Araneomorphae). American Museum Novitates 3016: 1-73.

Ponomarev A.V. 2005. New and interesting finds of spiders (Aranei) in the Southeast of Europe. Vestnik Yuzhnogo Nauchnogo Tsentra RAN 1 (4): 43-50. [in Russian]

Ramírez M.J. \& Grismado C.J. 1997. A review of the spider family Filistatidae in Argentina (Arachnida, Araneae), with a cladistic reanalysis of filistatid genera. Entomologica scandinavica 28 (3): 319-349.

Ramírez M.J. 2014. The morphology and phylogeny of dionychan spiders (Araneae: Araneomorphae). Bulletin of the American Museum of Natural History 390: 1-374.

Roewer C.F. 1962. Araneae Trionycha II und Cribellatae aus Afghanistan. Lunds Universitets årsskrift (Ny följd) 58 (7): 1-15.

Simon E. 1868. Sur quelques aranéides di midi de la France. Revue et Magasin de Zoologie Pure et Appliquée 20 (2) : 449-456.

Siyam M., Dunlop J.A. \& El-Hennawy H.K. 2015. New spider records from the Republic of the Sudan. Arachnology 16 (7): 264-272.

Song D.X., Zhu M.S. \& Chen J. 1999. The Spiders of China. Hebei University of Science and Technology Publishing House, Shijiazhuang.

Spassky S.A. 1941. Araneae palaearcticae novae. VI. Folia Zoologica et Hydrobiologica 11: 12-26.

Spassky S.A. 1952. Spiders of the Turan zoogeographical province. Entomologicheskoe Obozrenie 32: 192-205. [in Russian]

Strand E. 1914. Zweite Mitteilung über Spinnen aus Palästina, gesammelt von Herrn Dr J. Aharoni. Archiv für Naturgeschichte A 80 (3): 173-186. Available from http://biodiversitylibrary.org/page/13260433 [accessed 24 May 2016]

Ubick D., Paquin P., Cushing P.E. \& Roth V. (eds) 2005. Spiders of North America: An Identification Manual. American Arachnological Society.

World Spider Catalog 2015. World Spider Catalog, version 16. Natural History Museum Bern, available from http://wsc.nmbe.ch. [accessed 15 Jul. 2015]

Wunderlich J. 1992. Die Spinnen-Fauna der Makaronesischen Inseln: Taxonomie, Ökologie, Biogeographie und Evolution. Beiträge zur Araneologie 1: 1-619.

Zhang Y.Q., Chen H.M. \& Zhu M.S. 2009. A new cave-dwelling Tricalamus spider from Guizhou, China (Araneae, Filistatidae). Acta Zootaxonomica Sinica 34: 22-24.

Zonstein S.L. 1990. A synopsis of the spider family Filistatidae (Aranei) of the USSR fauna, with description of a new genus and a new species from Western Tien-Shang Mts. Zoologicheskiy Zhurnal 69 (10): 50-53. [in Russian]

Zonstein S.L. 2009a. Taxonomic notes on the genus Microfilistata (Araneae: Filistatidae), with a description of a new species from Turkmenistan. Journal of Arachnology 37: 373-374. http://dx.doi. org/10.1636/A08-65.1 
Zonstein S.L. 2009b. The spider genus Zaitunia Lehtinen, 1967 (Araneae, Filistatidae) in Israel and Egypt. Israel Journal of Entomology 38: 125-131.

Zonstein S.L., Marusik Y.M. \& Koponen S. 2013. Redescription of three species of Filistatidae (Araneae) described by C.F. Roewer from Afghanistan. Zootaxa 3745: 64-72. http://dx.doi.org/10.11646/ zootaxa.3745.1.5

Zyuzin A.A. \& Tarabaev C.K. 1994. The spiders and scorpions inhabiting Ustyurt Plateau and Mangyshlak Peninsula (South-Eastern Kazakhstan). Bollettino dell'Accademia Gioenia di Scienze Naturali di Catania 26 (345): 395-404.

Manuscript received: 19 August 2015

Manuscript accepted: 24 February 2016

Published on: 20 July 2016

Topic editor: Rudy Jocqué

Desk editor: Kristiaan Hoedemakers

Printed versions of all papers are also deposited in the libraries of the institutes that are members of the EJT consortium: Muséum national d'Histoire naturelle, Paris, France; Botanic Garden Meise, Belgium; Royal Museum for Central Africa, Tervuren, Belgium; Natural History Museum, London, United Kingdom; Royal Belgian Institute of Natural Sciences, Brussels, Belgium; Natural History Museum of Denmark, Copenhagen, Denmark; Naturalis Biodiversity Center, Leiden, the Netherlands. 